\title{
Potential Impact of Increasing Ammonia Concentrations upon Microbial Population Dynamics in Anaerobic Meso- and Thermophilic driven Fermenters
}

\author{
Dissertation \\ to obtain the $\mathrm{Ph}$. D. degree \\ in the International Ph. D. Program for Agricultural Sciences in Goettingen (IPAG) \\ at the Faculty of Agricultural Sciences, \\ Georg-August-University Göttingen, Germany
}

presented by

Khulud Alsouleman

born in Syria

Göttingen, May 2019 
D7

Head of the Committee: Prof. Dr. Frank Beneke

Supervisor and Reviewer: Jun.-Prof. Dr. Michaela Dippold

Co-Supervisor and Co-Reviewer: Dr. Michael Klocke 
To my father...

None of my dreams would have been possible without the love you gave me. 


\section{Acknowledgement}

Without question my most significant debt in this project is to my supervisors, Prof. Dr. Dr. Claus-Peter Czerny and Prof. Dr. Bernd Linke. My deep gratitude is due to Prof. Dr. Dr. Claus-Peter Czerny, who sadly passed away before completing this thesis; I will always remember him with affection for his valuable supervision.

I am mostly grateful to Prof. Dr. Linke for his supervision. He gave me the opportunity to work on this very interesting project and to join his team. Without his precious support, it would not have been possible to conduct this research.

I would like to express my sincere gratitude and deepest appreciation to my supervisor Dr. Michael Klocke for the later support of my $\mathrm{Ph} . \mathrm{D}$ study, for his continuous attempts to reach me to last step of my dream and for his patience. He always motivated me when things went wrong or became complicated.

Special thanks go to Jun.-Prof. Dr. Michaela Dippold for kindly agreeing to continue supervising me after the sad departure of Prof. Dr. Dr. Claus-Peter Czerny. I deeply appreciate her valuable supervision of this thesis.

I would like to thank the head of my $\mathrm{PhD}$ advisory committee Prof. Dr. Frank Beneke. I am grateful to Ms. Grete Thinggaard-ter Meulen - Academic advisor of student affairs - for her support and effort to solve all the difficulties I faced during my work on this project.

My thanks go also to all the people of the ATB for the productive working atmosphere they provided, especially the team of the department bioengineering. I thank Kerstin Mundt and Carsten Jost in particular for their wonderful technical support.

Many thanks also to all $\mathrm{PhD}$ students of the ATB for the informative seminars, important discussions, joint work and their friendly interaction.

Throughout the years of my study, my family has contributed to my project by being always loving, caring and supportive.

I am grateful to my mother who was always there for me; to my small family: my husband and my sweet children, Taim and Karam. This work would not have come about without your support. I would particularly thank my sister who was always encouraging me and pushing me to achieve my dreams. Many thanks also to all my brothers who were always caring and loving despite the very far distances. Thank you all from the bottom of my heart! 
The results of the study are published in the following original publications or proceeding in conferences:

Alsouleman, K., Linke, B., Klang, J., Klocke, M., Krakat, N. \& Theuerl, S. (2016): Reorganisation of a mesophilic biogas microbiome as response to a stepwise increase of ammonium nitrogen induced by poultry manure supply. Bioresour. Technol, 208, 200204.

(The main content of this publication was presented as oral presentation in Biogas Science Conference Szeged, Hungary, 21-24. August 2016)

Alsouleman, K. (2019): Effect of increasing amounts of ammonium nitrogen induced by consecutive mixture of poultry manure and cattle slurry on the microbial community within thermophilic anaerobic digestion. J. Microbiol. Biotechnol, 29, 1993-2005.

Theuerl, S., Alsouleman, K., \& Klang, J. (2017): Members of the WWE1 candidate division and the phylum Bacteroidetes as indicators to forecast a subsequent process disturbance.

Proceeding for the 3rd International Conference on Biogas Microbiology - ICBM-3. Wageningen, Netherlands, 01-03. May 2017 - Oral presentation. 


\section{Table of Contents:}

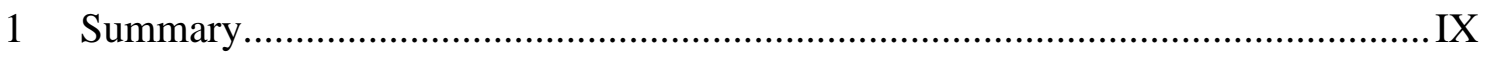

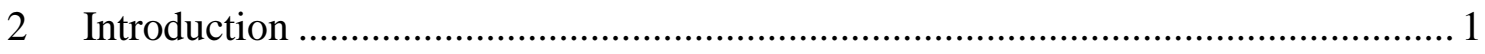

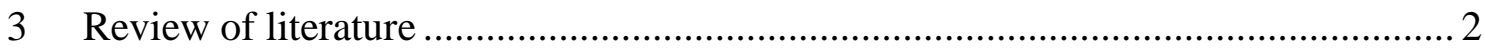

3.1 The challenge of the reduction of global GHG emissions ................................ 2

3.1.1 Global GHG emissions and strategies for renewable energy production...2 2

3.1.2 Biogas production in Europe: Germany as example .................................. 3

3.1.3 Biogas production in the Middle East Region: Syria as example................ 4

3.2 Engineering the biogas production.............................................................. 5

3.2.1 The principles of the anaerobic digestion process ...................................... 5

3.2.2 The anaerobic digestion of nitrogen rich manures..................................... 8

3.3 Characterization of the microbial community .............................................. 4

3.3.1 The importance of investigating the process microbiology ………………. 4

3.3.2 Physico-chemical process analyses ...................................................... 6

3.3.3 DNA-based analysis of the microbial community structures ...................... 8

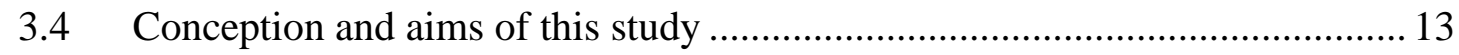

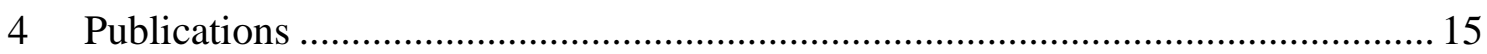

4.1 Reorganisation of a mesophilic biogas microbiome as response to a stepwise increase of ammonium nitrogen induced by poultry manure supply

4.2 Effect of increasing amounts of ammonium nitrogen induced by consecutive mixture of poultry manure and cattle slurry on the microbial community during thermophilic anaerobic digestion

4.3 Members of the WWE1 candidate division and the phylum Bacteroidetes as indicators to forecast a subsequent process disturbance …………………………...... 35

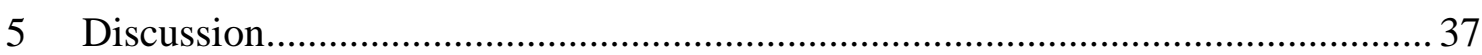

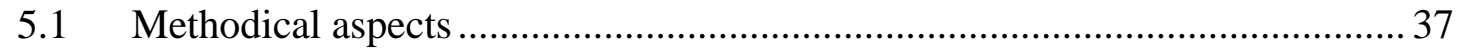

5.1.1 Applicability of CSTRs for anaerobic digestion of nitrogen rich manure 37

5.1.2 Applicability of TRFLP analysis for microbial community analysis in

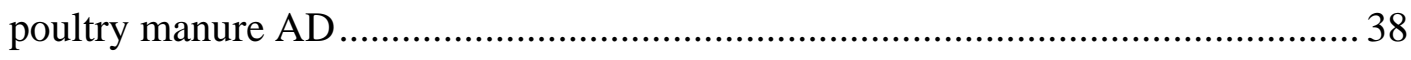

5.2 Performance of the anaerobic digestion process during increasing amounts of

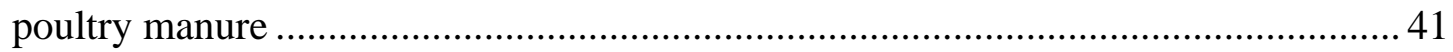

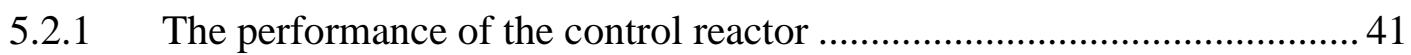

5.2.2 The performance of the experimental reactor at low PM level (25\% PM addition). 
5.2.3 The performance of the experimental reactor at medium PM level (50\% PM addition)

5.2.4 The performance of the experimental reactor at high PM level (75\% PM

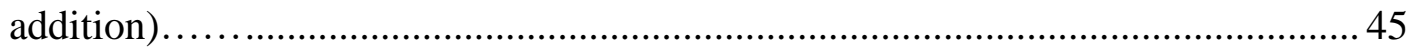

5.3 The response of the microbiome to increased amounts of poultry manure ..... 46

5.3.1 Composition of the microbial community in the control reactor............... 46

5.3.2 Microbial dynamics at low PM level (25\% PM addition) ....................... 48

5.3.3 Microbial dynamics at medium PM level (50\% PM addition) ................. 52

5.3.4 Microbial dynamics at high PM level (75\% PM addition) ......................57

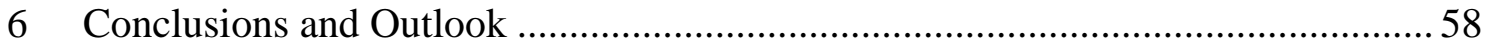

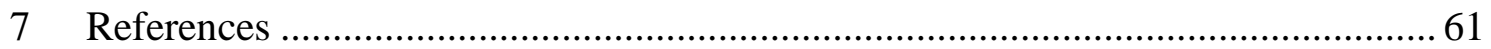

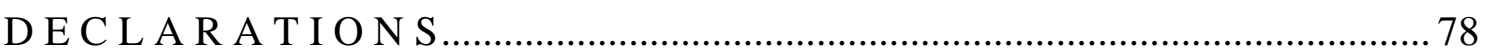

8 Appendix 


\section{Abbreviations}

16S rRNA 16S ribosomal RNA of the prokaryotic 30S small subunit

AD Anaerobic digestion

ATP Adenosine triphosphate

ATB Leibniz-Institut für Agrartechnik und Bioökonomie e.V. (Leibniz Institute for Agricultural Engineering and Bioeconomy)

Bp $\quad$ Base pair

C Conductivity

$\mathrm{CO}_{2} \quad$ Carbon dioxide

CS Cattle slurry

CR Control reactor

CSTR Continuously respectively completely stirred tank reactor

DANN Deoxyribonucleic acid

EEG Renewable Energy Sources Act / Erneuerbare-Energien-Gesetz

EP Experimental phase

EP1 First experimental phase

$25 \%$ poultry manure $+75 \%$ cattle slurry (based on VS)

EP2 Second experimental phase

$50 \%$ poultry manure $+50 \%$ cattle slurry (based on VS)

EP3 Third experimental phase

$75 \%$ poultry manure $+25 \%$ cattle slurry (based on VS)

EP4 Forth experimental phase

$100 \%$ poultry manure (based on VS)

ER Experimental reactor

EU European Union

FIT Feed-in tariff

FM Fresh substrate

FNR Fachagentur nachwachsende Rohstoffe (Agency for Renewable Resources)

GHG Green house gas

HRT Hydraulic retention time

Meso Mesophilic

$\mathrm{NH}_{3} \quad$ Free ammonia 


$\begin{array}{ll}\mathrm{NH}_{4}-\mathrm{N} & \text { Ammonium nitrogen } \\ \text { NMDS } & \text { Non-metric multidimensional scaling } \\ \text { OLR } & \text { Organic loading rate } \\ \text { OTU } & \text { Operational taxonomic unit } \\ \text { PCR } & \text { Polymerase chain reaction } \\ \text { pH } & \text { Pondus hydrogenii } \\ \text { PM } & \text { Poultry manure } \\ \text { rRNA } & \text { Ribosomal ribonucleic acid } \\ \text { SAO } & \text { Syntrophic acetate-oxidizing } \\ \text { Thermo } & \text { Thermophilic } \\ \text { TRF } & \text { Terminal restriction fragment } \\ \text { TRFLP } & \text { Terminal restriction fragmentlength polymorphism } \\ \text { TS } & \text { Total solids } \\ \text { VDI } & \text { Verein Deutscher Ingenieure (The association of German engineers) } \\ \text { VFA } & \text { Volatile fatty acids } \\ \text { VS } & \text { Volatile solids / substances }\end{array}$




\section{Summary}

Anaerobic digestion is the process of decomposition of organic matter by a microbial consortium in an oxygen-free environment. The produced biogas from this process is composed of methane, carbon dioxide, nitrogen, oxygen, hydrogen sulfide and traces of other gases.

Long-term mesophilic and thermophilic anaerobic digestion experiments were investigated to evaluate the reactor performance and the response of the microbial community under consideration of the structure variations due to an increasing content of $\mathrm{NH}_{4}{ }^{+}-\mathrm{N}$ caused by stepwise addition of nitrogen-rich substrates, in this case studies poultry manure (PM).

Therefore, laboratory-scale continuously respectively completely stirred tank reactors (CSTR) with a working volume of eight liter and steady organic loading rate (OLR of $\left.3.0 \mathrm{gVS} \mathrm{L}^{-1} \mathrm{~d}^{-1}\right)$ in mesophilic $\left(37^{\circ} \mathrm{C}\right)$ and thermophilic $\left(55^{\circ} \mathrm{C}\right)$ conditions were operated.

The gradual increasing of $\mathrm{NH}_{4}{ }^{+}-\mathrm{N}$ caused by stepwise addition of nitrogen-rich substrates (poultry manure) will lead to an increase in the free ammonia $\mathrm{NH}_{3}$ concentration. Free ammonia is considered a common inhibitor for the anaerobic digestion process due to its cytotoxic effects, resulting from deprotonation of ammonium $\left(\mathrm{NH}_{4}^{+}\right)$. As the free ammonia $\left(\mathrm{NH}_{3}\right)$ concentration depends on the concentration of $\mathrm{NH}_{4}{ }^{+}-\mathrm{N}$, the $\mathrm{pH}$-value and the reactor temperature, therefore a $\mathrm{NH}_{4}{ }^{+}-\mathrm{N}$ and $\mathrm{NH}_{3}$ values of $>3 \mathrm{~g} \mathrm{~kg}_{\mathrm{FM}}{ }^{-1}$ respectively $>0,4 \mathrm{~g} \mathrm{~kg}_{\mathrm{FM}}{ }^{-1}$ which has no impact on the anaerobic digestion process under mesophilic condition caused a serious disturbance and inhibition under thermophilic condition.

The anaerobic microbiome acclimated to low PM levels in mesophilic and thermophilic conditions which resulted in a stable anaerobic digestion process. After that, with the consecutive application of medium PM level in mesophilic condition, a process disturbance was induced which was characterized by a shift from a Bacteroidetesdominanted to a Clostridiales-dominated bacterial community accompanied by a change from the acetoclastic to the hydrogenotrophic pathway of methane formation. However, the "new" microbial community in mesophilic condition was functionally redundant as the overall process rates in terms of biogas yield methane content and volatile fatty acids VFA content were similar to the former one. A further increase of 
poultry manure (high PM level) resulted in complete process failure due to the ongoing increasing in the total ammonium nitrogen and volatile fatty acid content.

Compared to a mesophilic experiment, the thermophilic anaerobic microbiome was much more sensitive for process disturbances. The application of medium PM level resulted in a process disturbance and a final process failure. The microbial community was able to compensate the high cytotoxic ammonia contents only for a short time. The ongoing increase in the total ammonium nitrogen $\mathrm{NH}_{4}{ }^{+}-\mathrm{N}$ content in combination with an increase of the salt content (quantified as electrical conductivity) are assumed to be the main reasons for the final process failure.

Overall, the microbial community structure in this study might be the key factor explaining the adaption capacity, as it highlighted how an anaerobic microbiome in mesophilic condition was enabled to adapt to changing environmental conditions while the thermophilic ones with less diversity was much more sensitive and failed to overcome the prevalent environmental conditions. Thus, these results serve as a basic to understand and monitor the different microbiome responses to a specific environmental disturbance and to contribute to further optimization of biogas production process based on nitrogen rich substrates. Also, the results of this study may facilitate the application of anaerobic digestion of process-risk feedstock (nitrogen-rich manure) as a management technology and bioenergy resource on the full-scale in the future. 


\section{Introduction}

Reducing greenhouse gas emissions resulting from open storage and uncontrolled spreading of animal slurries and manures are major challenges faced in the agricultural sector (Barret et al., 2015). One of the most important and commonly applied technologies to achieve this goal is the bioconversion of animal wastes into energy-rich biogas by anaerobic digestion (AD). Therefore, the implementation of $\mathrm{AD}$ within the animal waste management is a promising technology as it provides a sustainable, renewable energy resource and reduces the negative environmental impacts. However, the $\mathrm{AD}$ of animal wastes such as cattle, swine and poultry manure, which are usually rich in nitrogen compounds, is related to the risk of process instability.

The accumulation of ammonium nitrogen $\left(\mathrm{NH}_{4}{ }^{+}-\mathrm{N}\right)$ and especially the undissociated form (free ammonia, $\mathrm{NH}_{3}$ ), which are the end-product of anaerobic degradation of nitrogen-rich substrates such as proteins and peptides, is considered to be toxic for the occurring microbial community.

In order to investigate the impact of increasing amounts of $\mathrm{NH}_{4}{ }^{+}-\mathrm{N}$ due to the consecutive poultry manure level addition on the reactor performance and especially on the occurring microbiome, a long-term, mesophilic $\left(37^{\circ} \mathrm{C}\right)$ and thermophilic $\left(55^{\circ} \mathrm{C}\right)$, lab-scale AD experiments were performed and monitored. The characterization of the microbial community structure and its response to changing environmental condition was assessed by a DNA-based community profiling method (terminal restriction fragment length polymorphism, TRFLP) in combination with a cloning/sequencing approach targeting either the bacterial or archaeal 16S rRNA genes. Multivariate statistical analyses were performed to correlate the prevalent environmental conditions with the corresponding microbiome. 


\section{Review of literature}

\subsection{The challenge of the reduction of global GHG emissions}

\subsubsection{Global GHG emissions and strategies for renewable energy production}

In the last decades, the worldwide climatic perturbations have increased due to the continuously increasing population and industrialization (Nelles et al., 2011). This increase in the worldwide population led to a constant growth of the global energy demand and hence greenhouse gas (GHG) emissions from anthropogenic activities especially from the fossil fuels consumption (Shah et al., 2016). Driven by the higher energy demand in 2018, the global energy-related $\mathrm{CO}_{2}$ emissions rose for $1.7 \%$ which was the highest rate of increase since 2013, and $70 \%$ higher than the average increase since 2010 (IEA, 2019).

The primary sources of global GHG emissions are the increasing consumption of fossil fuels (coal, oil, and gas) which reach to $76 \%$ of the total GHG emission while the AFOLU (agriculture, forestry and other land use) contribute the remaining 24\% of the total GHG emission with $12 \%$ from the agricultural sector alone (WRI, 2012; UBA, 2013; Bruckner et al., 2014; Smith et al., 2014; Scheftelowitz and Thrän, 2016).

Consequently, the GHG emission reduction was considered a major challenge faced not only by the energy sector but also by the agricultural sector worldwide.

To achieve the predict reduction target of worldwide GHG emissions, an alteration of the energy system towards the use of renewable energy such as wind power, hydropower, solar energy and bioenergy, is one of the most important recommendation (Scarlat et al., 2015; Scheftelowitz and Thrän, 2016). In the European Union the share of renewable energy in the gross final energy consumption has increased from $8.5 \%$ in 2005 to almost 14\% in 2016 (IEA, 2018; Scarlat et al., 2018).

Biogas is considered as one of the indispensable sources in the energy transition system towards renewable energy production (Martinot et al., 2002; Szarka et al., 2013). Methane, which is the main component of the biogas, can be used as alternative to the fossil fuel to generate heat, electricity (Weiland, 2010). The production of biogas prevents an emission of $549 \mathrm{~g} \mathrm{CO}_{2}$ equivalent per $\mathrm{kWh}$ in electricity generation and 171 g CO2 equivalent per $\mathrm{kWh}$ in heating supply (BMU, 2012). Also, the biogas can also be upgraded to biomethane which could be injected directly in the natural gas grid after a specific purification steps or used as gaseous vehicle fuel (Theuerl et al., 2019). 
The biogas production can be categorized depending on the source of biogas in three main categories; biogas produced from $\mathrm{AD}$ using agricultural waste, manure, and energy crops, with about $74 \%$ of the primary biogas energy output, a biogas derived from landfill gas recovery with about $17 \%$ of the primary biogas energy output and, as smaller extent, from sewage sludge treatment plants and other sources, with $9 \%$ of the primary biogas energy output (Scarlat et al., 2018).

\subsubsection{Biogas production in Europe: Germany as example}

Germany, as example of the most developed countries in biogas energy production, is considered nowadays the European leader of biogas production. In Germany, approximately $81 \%$ of the energy produced in 2017 being based on fossil fuels (BMU, 2018; FNR based on ZSW/AGEB, 2018). The gross consumption of the fossil fuels for energy supplies (provision) amount to $83 \%$ of total GHG emissions (Bruckner et al., 2014). While the agricultural sector contribution accounted for $7.7 \%$ of the total GHG emissions (UBA, 2013), and more than $10 \%$ of the later GHG emissions were caused by the open storage and uncontrolled spreading of animal residues (Scheftelowitz and Thrän, 2016). In regard to these data, Germany has set its targets to increase the quota of the renewable energy up to $14 \%$ in the heating sector, up to $30 \%$ in the electricity sector and about 10\% in the transport sector by 2020 (BMU, 2009; FNR, 2013). As a consequence, the share of the renewable energy sources in the primary energy consumption reached in 2017 up to $13.1 \%$ whereby the use of the biomass alone covered $7.1 \%$ (FNR, 2019).

During the last years, and due to the EEG law (Erneuerbare-Energien-Gesetz/ Renewable Energy Sources Act) which provides guaranteed feed-in tariffs (FIT) program for renewable energy sector, the biogas sector faced clear development. Therefore, an increase in the number of the biogas plants from 7215 plants in 2011 to 9494 in 2018 was recorded (FNR, 2012; FNR, 2019). The German contribution of total biogas production in the EU reached to 50\% in 2015 (Scarlat et al., 2018). More than $50 \%$ of the biogas potential in Germany results from AD of energy crops. Together with animal manure and harvesting residues, more than $80 \%$ of the potential feedstocks were produced by the agricultural sector (FNR, 2008; Weiland, 2010).

Due to the estimated continuous increase in the human population from 6.9 billion people in 2010 to 9.15 billion people in 2050 (Alexandratos and Bruinsma, 2012), the 
livestock industries are growing rapidly worldwide. This trend yields in large amounts of animal waste products, especially in developing countries (Sakar et al. 2009). The EU ranks third in world's poultry meat production after USA and Brazil, but more than $70 \%$ of the EU's poultry meat is produced in six countries: Poland, UK, France, Germany, Spain, and Italy (Eurostat, 2014). In 2016, the animal excrements (slurry, manure) in Germany formed $44.5 \%$ of the total substrate input in biogas plants (mass related) with $72 \%$ of cattle slurry and $3 \%$ of poultry manure (FNR, 2019).

\subsubsection{Biogas production in the Middle East Region: Syria as example}

Syria is one of the developing and Middle East countries which characterized by long hot summer and mild wet winter. Middle East countries have enormous potential for renewable energy resources; wind, solar in addition to the biomass. But at the same time the renewable energy applications in these countries have not been widely promoted yet. The main objective of choosing Germany (EU leader in biogas production) and Syria (a developing country with immature experience in biogas production) as key countries, is to transfer the current state of knowledge, policies, facilitates from Germany to Syria. This in turn will help to elaborate recommendations and future plans for efficient application of the biogas production in Syria. The total primary energy supply in Syria was dominated by $71.3 \%$ of crude oil/petroleum products, $21.8 \%$ of natural gas, $4.1 \%$ of hydro energy and $2.8 \%$ of biomass energy (Country Report Syria, 2009). During the last years, the Syrian government has also been setting new legislation and regulations for renewable energy development, which aims to encourage the use of renewable energy. Therefore, the Syrian government has set its target to provide $4.3 \%$ of primary energy demand from renewable energies by 2030 (RCREEE, 2019).

Different (AD) units and small biogas plants were established in cooperation with other countries in Syria to support biogas production from the most available and cheap organic wastes. So that, Syria has now several pilot projects which use biogas to produce electricity, including biogas production from the animal wastes and treatment of wastewater in Damascus (Al-Mohamad, 2001).

In regard to Al-Mohamad (2001), the daily municipal and agricultural wastes are higher than 300 million cubic meters per year, which in turn forms a continuous source for biogas production. 
In Syria as one of developing and agricultural countries, the livestock industry including the poultry industry - increases obliviously to meet the food needs of growing population (FAO, 2008). The demand on poultry is high in Syria as it is considered the cheapest source of meat protein; in addition to its relatively short production cycle time which make it profitable under the industrialized production system.

\subsection{Engineering the biogas production}

\subsubsection{The principles of the anaerobic digestion process}

The AD process is a highly complex chemical microbial-mediated process in terms of functionality and community diversity (Vanwonterghem et al. 2014). This process is achieved by the interaction between different microbial taxa within the superkingdom Bacteria and Archaea, involving several consequent degradation phases, typically hydrolysis/cellolysis, acidogenesis, acetogenesis, and methanogenesis as shown in Fig. 1 (Angenent et al. 2004; Vanwonterghem et al., 2014; Hassa et al., 2018). The efficiency and stability of this process is entirely dependent on the concerted and syntrophic activity of microorganisms belonging to different functional guilds (Li et al., 2009).

The first step of the AD process is the hydrolysis. In this step, the hydrolytic bacteria break down the polymeric substances such as carbohydrates, proteins, and lipids into oligo-, di-, and monosaccharides, amino acids, as well as fatty acids by the excretion of hydrolytic extracellular enzymes such as proteases, amylases, cellulases, or lipases (Boone and Mah, 1987; Bergmann, 2010; Weiland, 2010).

In the second subsequent acidogenesis step, the obtained metabolic products from the first stage are degraded by a large variety of fermentative bacteria into volatile fatty acids, alcohols, formate, carbon dioxide $\left(\mathrm{CO}_{2}\right)$, some organic nitrogen compounds, some organic-sulfur compounds, and molecular hydrogen $\left(\mathrm{H}_{2}\right)$ (Gerardi, 2003; Bergmann, 2010; Cabezes, 2015).

The third step in the AD process is the acetogenesis. The acetate-forming bacteria or acetogenic bacteria convert mainly volatile fatty acids and alcohols into acetate and $\mathrm{H}_{2}$. The oxidation of intermediate fermentation products to acetate is performed by hydrogen producing acetogenic bacteria.

Most of the representatives of these bacteria grow in a syntrophic relationship with hydrogen utilizing methanogens under low hydrogen concentration which results in 
energetically favorable metabolic pathway of methane production (Gerardi, 2003; Talbot et al., 2008). The Syntrophic acetate oxidation involves the conversion of acetate to hydrogen and carbon dioxide by syntrophic acetate-oxidizing bacteria (SAO) which is energetically unfavorable. This unfavorable reaction can proceed if hydrogenutilizing methanogens eliminate the hydrogen keeping the hydrogen partial pressure low enough to make the reaction sufficiently exergonic.

Otherwise, Siriwongrungson and colleagues (2007) have indicated under thermophilic conditions that the $\mathrm{H}_{2}$ produced after butyrate oxidation was directly used together with $\mathrm{CO}_{2}$ by homoacetogenic bacteria for the production of acetate. It was found that such homoacetogenic bacteria have a competitive advantage over hydrogen-utilizing methanogens due to their ability to use a wide range of substrate in unfavorable conditions for example in slightly acidic and low temperature (Phelps and Zeikus, 1984; Conrad and Wetter, 1990). On the other hand, other studies showed that homoacetogenic bacteria have also a competitive advantage over aceticlastic methanogens (which converts acetate to methane and $\mathrm{CO}_{2}$ ) under thermophilic conditions (Schink, 1997) and mesophilic conditions with high ammonia concentrations (Angenent et al., 2002; Schnurer and Nordberg, 2008).

The last phase of the $\mathrm{AD}$ process is the methanogenesis which is considered to be the rate-limiting step of the biogas process due to the very slow growth rates of methane producers and their sensitivity to inhibitory substances (Chen et al., 2008; Liu and Withman, 2008). In this step, $\mathrm{CO}_{2}$ and $\mathrm{H}_{2}$, acetate, or methyl-group containing compounds can directly be converted into methane $\left(\mathrm{CH}_{4}\right)$ by methanogenic archaea. All methanogens belonged to the archaeal phylum Euryarchaeota and until now were classified into seven orders: Methanobacteriales, Methanococcales, Methanomicrobiales, Methanosarcinales, Methanocellales, Methanopyrales and Methanomassiliicoccales (Thauer et al., 2008; Thauer et al., 2010; Lang et al., 2015).

Methane can be produced by three principal groups of methane-forming archaea:

- The acetolastic methanogens converts acetate to methane and $\mathrm{CO}_{2}$. This pathway is the predominant source of atmospheric methane and only members of the Methanosarcinales are capable of acetoclastic methanogenesis (Fournier and Gogarten, 2008; Lang et al., 2015).

- The hydrogenotrophic methanogens which use $\mathrm{H}_{2}$ or formate as electron donor to convert $\mathrm{CO}_{2}$ to $\mathrm{CH}_{4}$. This hydrogenotrophic methanogenesis is the most widespread and is considered the most favorable methanogenesis pathway in 
terms of energy gains even it is slower than the acetoclastic pathway. The known groups of methanogens that use $\mathrm{H}_{2}$ are all members belonging to the previous orders with the exception of Methanomassiliicoccales.

- Methylotrophic methanogens which utilize methyl-group containing compounds such as methanol, methylated amines and methylated sulfides to produce methane. These methanogens are found in the orders Methanosarcinales, Methanobacteriales and Methanomassiliicoccales (Vanwonterghem et al., 2016).

The classic hypothesis that methane metabolism originated early in the evolution of the Euryarchaeota (Gribaldo and Brochier-Armanet, 2006) has recently been changed. It has been proposed depending on the metagenomic reconstruction of environmental samples that certain microbial species of phyla Bathyarchaeota and Verstraetearchaeota phyla are also capable to conduct methanogenesis (Evans et al., 2015; Borrel et al., 2016; Vanwonterghem et al., 2016). The recently proposed Bathyarchaeota phylum represented an evolutionarily diverse group of microorganisms (Kubo et al., 2012; Gagen et al., 2013; Lazar et al., 2014; Meng et al., 2014) which found in a wide range of environments. In addition, He and colleagues (He et al., 2016) indicated that Bathyarchaeota also have the potential to fix inorganic carbon in the form of $\mathrm{CO}_{2}$ to produce acetate. Otherwise Maus and colleagues (2018) found in their work that the Bathyarchaeota in the analyzed biogas reactor biofilms are not able to produce methane via the hitherto known methanogenesis pathway (Maus et al., 2018), which in turn indicates a diverse metabolism within this phylum. In contrast, (Berghuisa et al., 2019) found that these non-euryarchaeal methanogens have been found to be exclusively methylotrophic.

It could be assumed depending on the previous contradictory results that the member of the phylum Bathyarchaeota has genetic potential diverse metabolic activities. Also, the accurate role or function of the members of this phylum in anaerobic digestion remains until now unclear. 


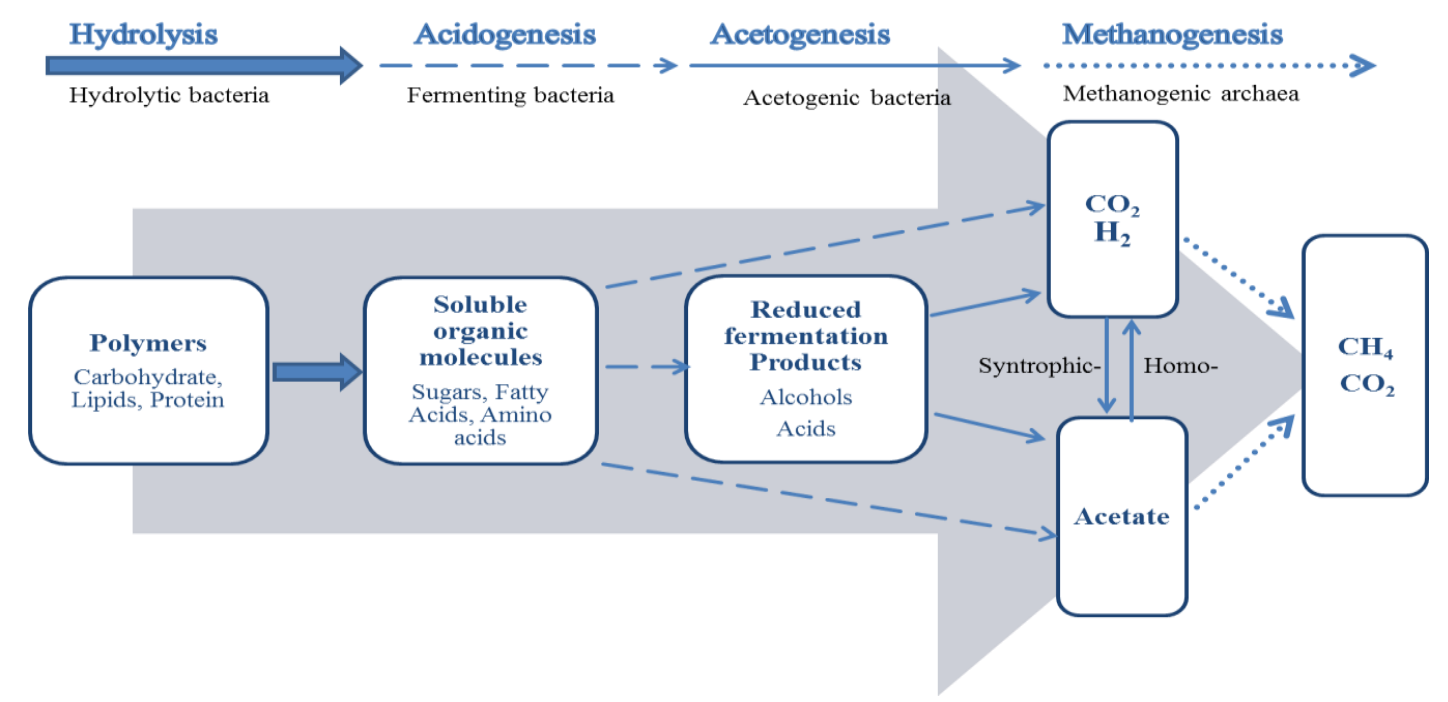

Figure 1: The four-stages of the anaerobic digestion process to produce biogas (modified after Weiland, 2010).

\subsubsection{The anaerobic digestion of nitrogen rich manures}

\subsubsection{The importance of anaerobic digestion of nitrogen rich manures}

As known, liquid and solid manures are usually considered and used as very important fertilizers (Scheftelowitz and Thrän, 2016) as they contribute to the closing of the nutrient cycles and hence substitutes mineral fertilizer (Arthurson, 2009; Weiland, 2010). But at the same time, the application of pure manure as fertilizer forms a big challenge to the sustainable development as can lead to eutrophication of water bodies due to the large amounts of pathogens and excess organic matter, as well as the release of climate relevant gases in terms of methane, ammonia, $\mathrm{CO}_{2}$ or $\mathrm{N}_{2} \mathrm{O}$, and odorants from the natural degradation during storage (Jongbloed and Lenis, 1998; Dagnall et al., 2000; Kelleher et al., 2002; Moeller et al., 2004 ; Sakar et al., 2009 ; Thompson et al., 2013).

As the main risk of nitrate leaching in water bodies represents the main limitation to the direct application of not pre-treated livestock manure to soil. The anaerobic degradation of the organic matter (animal manure) ensures the formation of high amount of ammonium (the $\mathrm{N}$-form which is more rapidly assimilated by the crops) without incurring in the subsequent oxidation into nitrate (Arthurson, 2009).

Therefore, the implementation of the $\mathrm{AD}$ of animal manure has become a promising alternative treatment technology for animal waste management as it considered a sustainable waste disposal system (Weiland, 2010). Also the AD of the animal manure 
contributes to the GHG emission reductions as the produced biogas displaces the use of the fossil fuel (Dämmgen and Webb, 2006; Sakar et al., 2009; Bekkering et al., 2010; Rademacher et al., 2013, Lv et al. 2014; Scheftelowitz and Thrän, 2016), and can also reduce the GHG emissions from the natural decomposition of the manure during the storage. In addition to the previously mentioned environmental benefits, the produced digestate can be used as fertilizer as it has higher extent nutrients in inorganic plantavailable forms (more easily leachable) compared to untreated waste due to the large input of organic nutrients that are mineralized during the digestion process (Field et al., 1984; Larsen et al., 1986; Plaixats et al., 1988Möller et al., 2008; Kirchmann and Witter, 1992). This in turn brings additional economic and environmental benefits by reducing the use of chemical fertilizers (Dagnall et al., 2000; Moeller et al., 2004; Thompson et al., 2013; Scarlat et al.,2018).

\subsubsection{Limitations of anaerobic digestion of nitrogen rich manures}

Animal wastes, a widely used substrate for biogas production, are rich in organic nitrogen (proteins and urea-uric acid in birds) (Krylova et al., 1996; Bujoczek et al., 2000: Kelleher et al., 2002; Sakar et al., 2009; Abouelenien et al., 2010; Singh et al., 2010; Zhang et al., 2011). Proteins are complex, high molecular-weight compounds. Proteins are long chains of amino acids (such as alanine, arginine, glycine, lysine etc.) which joined by peptide bonds. All amino acids contain an amino group $\left(-\mathrm{NH}_{2}\right)$ and a carboxyl group $(-\mathrm{COOH})$. The peptide bonds joint the hydroxyl group $(-\mathrm{OH})$ in the carboxyl group $(-\mathrm{COOH})$ of one amino acid with the amino group $\left(-\mathrm{NH}_{2}\right)$ of other amino acid. The exoenzymes proteases and peptidases hydrolyze the peptide bond between amino acids. These amino acids can be taken up into bacterial cells by transporters and can be converted by the intra-cellular endoenzymes to a variety of organic acids depending on the converted amino acid (Kirchmann and Witter, 1992; Möller et al., 2008).

The conversion of the amino acids to organic acid is showed in the later equation:

$$
4 \mathrm{H}_{2} \mathrm{NCH}_{2} \mathrm{COOH}+2 \mathrm{H}_{2} \mathrm{O} \rightarrow 4 \mathrm{NH}_{3}+2 \mathrm{CO}_{2}+3 \mathrm{CH}_{3} \mathrm{COOH} \quad \text { (Equation I) }
$$

In this study the ammonium nitrogen $\mathrm{NH}_{4}{ }^{+}-\mathrm{N}$ and the total ammonium nitrogen TAN referred to the same compound to be able to compare the results of this study with other studies (Niu et al., 2013; 2014). The reduced nitrogen is thereafter present as 
ammonium nitrogen $\mathrm{NH}_{4}{ }^{+}-\mathrm{N}$ and exits in two forms in the anaerobic digester, the ammonium ion $\mathrm{NH}_{4}{ }^{+}$and free or undissociated ammonia $\mathrm{NH}_{3}$. The two forms are in equilibrium, and the relative concentration of each form is dependent on the digester $\mathrm{pH}$ as illustrated in (Equation II) (Gerardi, 2003).

$$
\mathrm{NH}_{4} \leftrightarrow \mathrm{NH}_{3}+\mathrm{H}^{+} \quad \text { (Equation II) }
$$

The free ammonia $\left(\mathrm{NH}_{3}\right)$ concentration can be calculated based on the concentration of $\mathrm{NH}_{4}{ }^{+}-\mathrm{N}$, the $\mathrm{pH}$-value and the reactor temperature using the formula (Equation III) (Hansen et al., 1998).

$\frac{\mathrm{NH}_{3}}{\mathrm{NH}_{4}{ }^{+}-\mathrm{N}}=\left(1+\frac{10^{-p H}}{10^{-\left(0.09018+\frac{2729.92}{T(K)}\right)}}\right)^{-1} \quad$ (Equation III)

Whereby: $\mathrm{NH}_{3}=$ Free ammonia concentration

$\mathrm{NH}_{4}{ }^{+}-\mathrm{N}=$ Ammonium nitrogen

$\mathrm{T}=$ Temperature (kelvin)

Free ammonia or the undissociated ammonia $\left(\mathrm{NH}_{3}\right)$ has a positive impact on the anaerobic digestion process as it provides the alkalinity to the system. Due to (Gehardi, 2003), the released ammonia $\mathrm{NH}_{3}$ reacts with the carbon dioxide and water to form ammonium carbonate which maintains the system's alkalinity as follow:

$$
\mathrm{NH}_{3}+\mathrm{CO}_{2}+\mathrm{H}_{2} \mathrm{O} \rightarrow \mathrm{NH}_{4} \mathrm{HCO}_{3} \quad \text { (Equation IV) }
$$

At the same time free ammonia is considered a common inhibitor for methanogens especially for the acetoclastic methanogens due to its passive diffusion ability through the cell membranes into the cells (Kroeker et al., 1979; de Baere et al., 1984; Sung and Liu 2003; Chen et al., 2008; Rajagopal et al., 2013; Yenigün \& Demirel, 2013; Lv et al., 2014). The most widely accepted mechanisms explaining the inhibition of methanogenesis by free ammonia is the direct inhibition of the methane synthesizing enzymes by free ammonia. The second mechanism is related to the ability of hydrophobic free ammonia molecules to diffuse passively into the cell and convert there to ammonium which alters the intracellular $\mathrm{pH}$ of the cell, or can effect on the concentration of other cations (proton imbalance) such as $\mathrm{K}^{+}$(important ion to maintain the $\mathrm{pH}$ balance) or $\mathrm{Mg}^{2+}$ (important ion in the action of many enzymes that catalyze 
ATP-dependent reactions) (Sprott et al., 1984; Henrichs et al., 1990; Kadam and Boone, 1996).

Numerous studies had been conducted to evaluate the potential of several animal residues such as cow respectively cattle, swine and poultry manure as feedstock to produce biogas (Yenigun and Demirel, 2009; for review: Nasir, 2012; Niu et al., 2013, 2014; Regueiro et al., 2015; Toumi et al., 2015; Akyol et al., 2016; Usack and Angenent, 2016).

Anaerobic digestion of cattle slurry (CS) has been assessed over the last 25-30 years and is now an established waste management technique

The cattle slurry was used in this study as considered an excellent "carrier" substrate for the anaerobic digestion of concentrated waste such as poultry manure, which would be difficult to treat separately. The reasons for choosing the cattle slurry as co-digestion substrate in this study are:

- The high moisture content of this substrate which acts as solvent for wastes of high dry content (poultry manure).

- The high buffering capacity of this substrate which in turn prevents the process disturbances arising from the $\mathrm{pH}$ fluctuations due to the temporary accumulation of the volatile fatty acids (VFA).

- The richness of this substrate with the necessary nutrients for an optimal bacterial growth.

- The wide availability of this substrate (Angelidaki and Ellegaard, 2003; Callaghan et al., 2002).

The high solid content of poultry manure (Kelleher et al., 2002), and thus the corresponding higher biogas yields (Zhang et al., 2011; Niu et al., 2013) make poultry manure a very valuable co-feedstock for anaerobic digestion.

Table 1 showed the chemical and physiochemical characterization of the used poultry manure and cattle slurries in this study. 
Tab. 1: The chemical and physiochemical characterization of the used poultry manure and cattle slurry

\begin{tabular}{ccc}
\hline Chemical and physiochemical characterisation & Poultry manure & Cattle slurry \\
\hline Dry matter content (TS\% FM) & 60 & $7-10$ \\
Organic matter content (TS\% FM) & 63 & 80 \\
$\mathrm{pH}$ & 7 & 7 \\
Conductivity $\left(\mathrm{mS} \mathrm{cm}^{-1}\right)$ & 4 & $11-15$ \\
TAN $\left(\mathrm{g} \mathrm{Kg}^{-1} \mathrm{FM}\right)$ & 3 & $1-2$ \\
TKN $\left(\mathrm{g} \mathrm{Kg}^{-1} \mathrm{FM}\right)$ & 34 & $3-5$ \\
Total VFA $\left(\mathrm{g} \mathrm{Kg}^{-1} \mathrm{FM}\right)$ & 6 & $5-8$ \\
\hline
\end{tabular}

FM: Fresh material; TAN: Total ammonium nitrogen; TKN: Total Kjeldahl nitrogen; VFA: Volatile fatty acids; FM: Fresh material; TS: Total solid

However, the major concern of applying the AD technology on animal manure, especially on poultry manure, is related to the risk of accumulation of ammonium nitrogen $\left(\mathrm{NH}_{4}{ }^{+}-\mathrm{N}\right)$, the end-product of anaerobic degradation of nitrogen-rich substrates (Kayhanian, 1999; Liu et al., 2012; Yenigün and Demirel, 2013; Niu et al., 2014). Several studies investigated the effect of $\mathrm{NH}_{4}{ }^{+}-\mathrm{N}$ accumulation on the reactor performance. They reported that process inhibition threshold varies widely, from 1.7 to $14 \mathrm{~g} \mathrm{NH}_{4}{ }^{+}-\mathrm{N} \mathrm{L}^{-1}$ (Niu et al., 2013; Rajagopal et al., 2013; Shi et al., 2013; Yenigün et al., 2013; Westerholm et al., 2016).

In addition, further studies have investigated the use of poultry manure or poultry litter as feedstock for AD with different technical procedures. Some of these studies investigated the process stability with respect to process parameters such as organic loading rate OLR, hydraulic retention time HRT, total solid content TS, temperature, reactor design and another operational parameters (Webb and Hawkes, 1985; Kalyuzhnyi et al., 1998; Bujoczek et al., 2000; Atuanya and Aigbirior, 2002; Chamy et al., 2011; Dalkilic and Ugurlu, 2015; Latifi et al., 2019; Zahan and Othman, 2019). Other studies focused on the anaerobic digestion of poultry manure as co-substrate and various mixtures were investigated (Gungor-Demirci and Demirer, 2004; Anozie et al., 2005; Zhang et al., 2011; Carlini et al., 2015; Bayrakdar et al., 2017; Chao et al., 2017). Also, some studies were published focusing on the microbiological aspects of the anaerobic digestion process of poultry manure (Zhang et al., 2011; Niu et al., 2013; Niu et al., 2014; Alsouleman et al., 2016: Alsouleman, 2019). These studies illustrated clear 
shifts in the microbial community structure as a response to the elevated ammonium nitrogen content and the prevalent operational parameters. In all previous studies, the recovered and inhibited microbial community was dominant with members of the phylum Firmicutes on the bacterial level and with hydrogenotrophic methanogens on the archaeal level.

\subsubsection{Technical solutions for anaerobic digestion of nitrogen rich manures}

During the last years, several studies have been done to reduce the impact of the ammonia accumulation during the anaerobic digestion of nitrogen rich substrate. The most applied methods are: the anaerobic digestion in semi-solid form (Bujoczek et al., 2000) or in wet form (Bujoczek et al., 2000; Gangagni Rao et al., 2008; Yetilmezsoy and Sakar, 2008); the co-digestion with other substrate (Carlini et al., 2015, Zhang et al., 2011); the acclimation of the microbial community to the high concentration of the ammonia (for review: Rajagopal et al., 2013; Güngör-Demirci and Demirer, 2004; Abouelenien et al., 2009b); additives with adsorptive capacity such as zeolites (Milán et al., 2001; Tada et al., 2005); the application of activated carbon (Cuetos et al., 2017) or biochar (Mumme et al., 2014); and bioaugmentation which is the addition of specific microbial cultures to improve the operational performance (Fotidis et al., 2013; Li et al., 2017).

Other efforts were focused on the ammonia removal techniques in combination with AD such as: ammonia stripping in which a fluid is percolated with gas (Bousek, 2016; Walker et al., 2011; Abouelenien et al; 2010 ); membrane extraction (Fuchs et $a l ., 2018$ ); struvite precipitation by magnesium phosphate compounds (RomeroGüiza et al., 2014); biological removal through Anammox (for review: Magrí et al., 2013); ultrasonication (Chao et al., 2014); and microwave irradiation which depends as was proposed by Lin et al. (2009) on the formation of molecular ammonia $\left(\mathrm{NH}_{3}\right)$ and the subsequent evaporation of $\mathrm{NH}_{3}$ by $\mathrm{MW}$ radiation. Both thermal effect of microwave irradiation which is related to the heat generated by the absorption of microwave energy by water and other polar molecules and non-thermal effect which is claimed to change the chemical, biochemical, or physical behaviors of systems were responsible of this removal (Lin et al., 2009). In addition to the previous methods, there are still other nitrogen removal techniques which are applied on the side streams of municipal effluent and could be used also in AD processes (for review: Fuchs et al., 2018). 


\subsection{Characterization of the microbial community}

\subsubsection{The importance of investigating the process microbiology}

As was described previously, a diverse and complex interacting microbial community respectively network comprising hydrolytic, acidogenic and acetogenic bacteria as well as methanogenic archaea convert biomasses into energy-rich biogas through consequent degradation phases. It is well known that the performance of an anaerobic digestion system is primarily linked to the structure and functionality of this diverse and complex interacting microbial network. Therefore, the management and engineering of this microbial community enhanced the development of the optimization strategies of the anaerobic digestion process (Carballa et al., 2015; Koch et al., 2014).

During the last years, the understanding of the factors that determine the anaerobic digestion process stability, as an example of ecosystem, has been one of the main challenges. Hence, the knowledge of the conditions that affect the process stability is needed to determine the effects of external parameters on the microbial community structure. For example, the abundance of the bacterial phyla Firmicutes and Bacteroidetes varying in the biogas community depending on the prevalent process conditions. While the diversity of the methanogenic archaea affected mainly by the substrate composition and hence by the availability of nutrients and ammonium/ammonia contents (Alsouleman et al., 2016, Alsouleman, 2019)

It was proved previously that, the disturbances in the microbial populations or the change in the prevalent microbial community structure from one trophic level affect the entire community and might cause a change in the functionality of this microbial community. Alsouleman and colleagues (Alsouleman et al., 2016) recorded that, the addition of $50 \%$ poultry manure led to a reconstruction of the prevalent BacteroidetesMethanosaetaceae microbiome. The resulted microbiome -which was functional redundant- was Clostridiales-Methanobacteriaceae-dominated. This disturbance in the microbial community structure and hence in the functionality of the microbial community might be reflected in the reactor performance by accumulation of intermediates, pH changes, or reduced efficiency (Schink, 1988).

Therefore, detailed and accurate information on the diversity and identity of the key microorganisms capable of carrying out specific metabolic processes in anaerobic digestion are very important to understand bioreactor functioning especially when concerning new metabolic processes. For example, the discovery of microorganisms 
involved in the anaerobic oxidation of ammonium (Anammox process) (Jetten et al., 1999; Ni and Zhang, 2013), and in the syntrophic oxidation of organic acids (McInerney et al., 2008). Also the operational and chemical parameters of the process itself such as the substrate composition, applied organic loading rate, hydraulic retention time and the operating temperature affect the structural composition, the organization, the functionality as well as the ecological behavior of the microbial community (Demirel and Scherer, 2008; Carballa et al., 2011). Different environment pressure levels on the entire microbial community of the $\mathrm{AD}$ process may affect the efficiency of the whole process and may lead to a process imbalance or disturbance (Fernandez et al., 1999). On the other hand, these disturbances which caused by the physico-chemical factors may also be a feasible development strategy in shaping the profile of microbial community of the anaerobic digestion process and improve the efficiency of this process, since it could inhibit certain species and promote the growth of others that are resistant to the disturbance (for review: Theuerl et al., 2019; Alsouleman et al., 2016). Shaw and colleagues (Shaw et al., 2019) proved that an increase in COD and TS removal efficiency and methane content was recorded after a long-term temperature shock. This result agreed with the results of the previous studies that recorded an increase in COD removal rate or a decrease of total volatile fatty acids15 after temperature shock (Ahn and Forster, 2002).

Hence, the resulted microbial community structure from the artificial disturbance arising from the stepwise increasing in PM content (increasing in the ammonia concentration) might be also a feasible strategy to shape the structure and functionality of the prevalent microbial community and hence to improve the efficiency of the anaerobic digestion process of nitrogen-rich substrate.

There are four ways in which the microbial community in term of structure and functionality responses to the changing in the environmental parameters or to the process imbalances or disturbances. Firstly, the microbial community might be resistant to the disturbance on the engineering level and maintains its original composition after a disturbance. Secondly, the microbial community composition can be resilient by meaning that the microbial community changes due to the changing in the environmental conditions, but still has the ability to recover quickly and return to the original one. Thirdly, the microbial community composition changes and differs from the original one but has the ability to perform as the original one; in this case the functional redundancy in the microbial community structure is the applied mechanism 
to maintain the functional stability during the disturbance. And lastly, the microbial community composition changes and performs completely different (Allison et al., 2008; Spirito et al., 2018).

The whole anaerobic digestion process can be disturbed when a single degradation step of the consequent degradation steps is out of balance (Gerardi, 2003). This disturbance can occur due to one (Shaw et al., 2019) or mix of physio-chemical factors (for review: Theuerl et al., 2019). For example, a process disturbance resulting from medium content of ammonium nitrogen $\left(\mathrm{NH}_{4}{ }^{+}-\mathrm{N}\right)$ led to change in the structure and functionality of the microbial community. The prevalent microbial community structure after this disturbance was able to maintain the stability of the anaerobic digestion process and perform efficiently under the new conditions (Alsouleman et al., 2016).

On the other hand, a process disturbance, resulting from high content of ammonium nitrogen $\left(\mathrm{NH}_{4}{ }^{+}-\mathrm{N}\right)$ and volatile fatty acids, was characterized by a big decline in the activity of the hydrogentrophic methanogens and acetogenic bacteria causing a process failure (Westerholm et al., 2016; Alsouleman et al., 2016).

The deeper understanding of the fundamental structure and metabolic interactions within biogas microbial consortia in different environmental conditions is very essential in order to control the whole process and at the end to determine the optimal operation conditions (Zakrzewski et al., 2012; Niu et al., 2014; Cabezas et al., 2015). Hence several studies have assumed that biomonitoring of the microbial community characteristics and the identification of key organisms related to specific process conditions could lead to an early detection of operational problems, making preventive action possible which could be used at the end as basis for microbiological monitoring, control and management (Verstraete et al., 2007; Lee et al., 2008; Malin and Illmer, 2008; Talbot et al., 2008; Theuerl et al., 2015).

\subsubsection{Physico-chemical process analyses}

There is a variety of the anaerobic digestion systems and configurations. The proper design of the reactor is dependent on the feedstock characteristics (content, quality), the investment costs, and the principle functioning of the anaerobic digestion process (Ward et al., 2008). Different reactor designs are commonly used for the $\mathrm{AD}$ of livestock manure waste such as: continuously respectively completely stirred tank reactors (CSTR) with continuous or periodic influent feeding (Ahring et al., 2001; Omar et al., 
2008; Zhang et al., 2011, Niue et al., 2013; Niu et al., 2014; Alsouleman et al., 2016), upflow anaerobic sludge blanket (UASB) reactors (Marañón et al., 2001; Castrillon et al., 2002 ), anaerobic batch reactors (Kalia and Singh, 2001; Adebayo et al., 2015), and plug flow reactors (PFR) (Ramaswamy and Vemareddy, 2015). Out of these, the most commonly used reactor types to investigate the biogas production from poultry manure are: the batch system (e.g. Dahunsi et al., 2019; Carlini et al., 2015), the continuously respectively completely stirred tank reactor (CSTR) (Niu et al., 2014; Niu et al., 2013; Zhang et al., 2011), and the upflow anaerobic sludge blanket (UASB) reactors (Yetilmezsoy and Sakar, 2008). In this study, laboratory-scales continuously respectively completely stirred tank reactors (CSTRs) with a working volume of 8 Liter were operated in mesophilic and thermophilic conditions as shown in Fig. 2. To ensure a high diversity of a well-performing starter. The start-up phase was carried out based on the VDI 4630 (The association of German engineers, 2006). To avoid process inhibition through a lack of micronutrient, $10 \mu \mathrm{l}$ per g volatile substances (VS) trace element solution DSMZ 144 was added during the whole experimental period (German collection of microorganisms and cell cultures, Braunschweig, Germany) as recommended by Schattauer et al. (2011). Schattauer and his colleagues (2011) found in their investigation of 10 biogas plants that, the biogas plant which was fed with manure and energy crops recorded a depletion of the content of these trace elements over a longer time span.

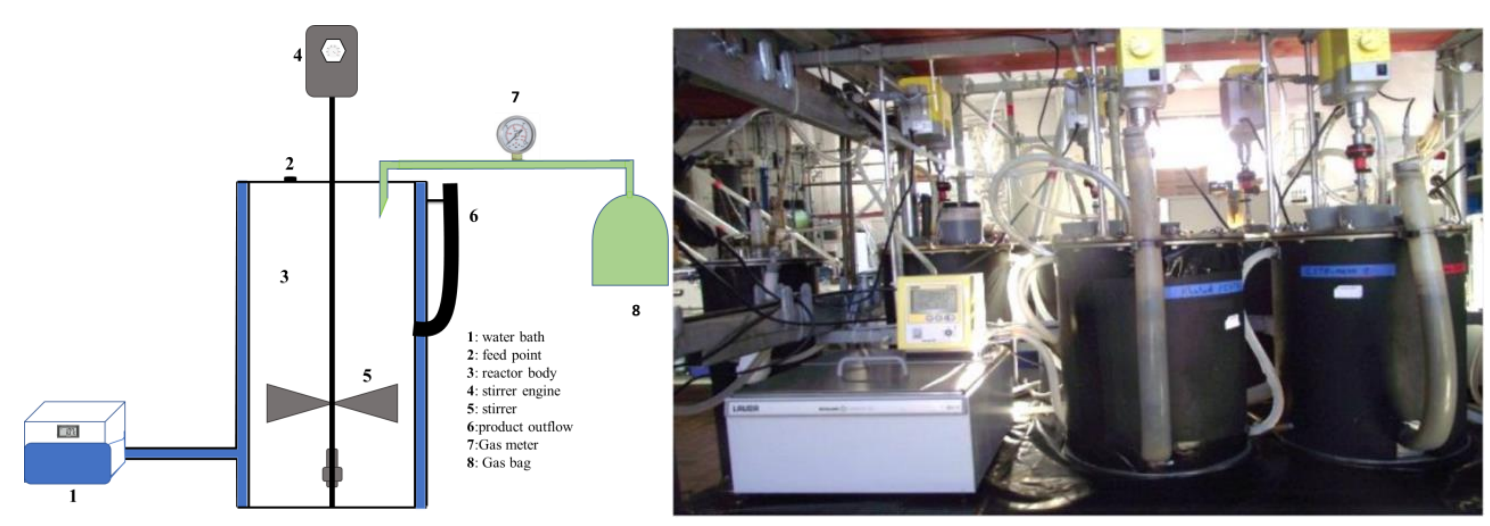

Figure 2: Construction of the CSTR biogas reactor 
Afterwards, the OLR was maintained at $3.0 \mathrm{~g} \mathrm{vs} \mathrm{L}^{-1} \mathrm{~d}^{-1}$ for further 65 days and both reactors were operated at stable conditions indicated by $\mathrm{pH}$, VFA as well as biogas yield and methane content. During the experimental phase (EP), the experimental reactors (ER) in two temperature condition were fed with an increasing amount (based on VS) of poultry manure, whereby the OLR was kept at $3.0 \mathrm{gvs} \mathrm{L}^{-1} \mathrm{~d}^{-1}$ : low PM level $=75 \% \mathrm{CS}$ and 25\% PM, medium PM level $=50 \% \mathrm{CS}$ and 50\% PM and high PM level $=25 \% \mathrm{CS}$ and $75 \%$ PM. While over the entire EP, the parallel operated control reactor (CR) was fed with cattle slurry as sole substrate (OLR of $3.0 \mathrm{~g} \mathrm{vs}^{-1} \mathrm{~d}^{-1}$ ).

Biogas production from the anaerobic digesters was daily monitored and the biogas content was analyzed detecting the content of carbon dioxide $\left(\mathrm{CO}_{2}\right)$, methane $\left(\mathrm{CH}_{4}\right)$, hydrogen sulphide $\left(\mathrm{H}_{2} \mathrm{~S}\right)$ and oxygen $\left(\mathrm{O}_{2}\right)$.

During the anaerobic digestion process, various process parameters were determined: $\mathrm{pH}$, total solids (TS), volatile solids (VS), total ammonium nitrogen $\left(\mathrm{NH}_{4}{ }^{+}-\mathrm{N}\right)$, soluble volatile fatty acids (VFA) in terms of acetate, propionate, iso- and n-butyrate, iso- and $\mathrm{n}$-valerate, and capronate in addition to the conductivity, according to the Association of the German Agricultural Investigation and Research Institutes VDLUFA (1997). The free ammonia nitrogen $\left(\mathrm{NH}_{3}\right)$ content was calculated by using the formula previously described by Hansen et al. (1998) (Equation III).

\subsubsection{DNA-based analysis of the microbial community structures}

Different approaches are available now to investigate the process microbiology of the anaerobic digestion process (for review: Hassa et al., 2018; for review: Cabezas et al., 2015; Vanwonterghem et al., 2014; Su et al., 2012; for review: Talbot et al., 2008). Mainly, these approaches can be divided into culture-dependent and cultureindependent methods, whereby each method has its advantages and disadvantages.

As generally known, most of our knowledge about microorganisms nowadays, their physiological capacities and the possibilities to use them in biotechnological applications has derived from the traditional isolation, cultivation and characterization of pure strains and species (Stewart, 2012). Classically, the application of culturedependent techniques is required to identify microorganisms which are responsible for specific metabolic processes and to deeply understand their physiological potential of these microorganisms (Su et al., 2012; Amann et al., 1995). 
But on the other side, these techniques are restricted by the use of the chosen cultivation media, which favor the growth of a limited number of community members and therefore limit the validity of the obtained results (Marzorati et al., 2008; Wagner et al., 1993). Wagner et al. (1993) reported that only $1-15 \%$ of the total microbial community could be detected in activated sludge samples by using culture-dependent methods. Therefore a "microbial dark matter" (uncultured microbial majority) is identified as the most important priority for biologist. This term refers to the sum of the taxonomically and functionally unassigned sequences in environmental genomics data sets, in addition to the uncultured microbes (for review: Brian et al., 2014).

Moreover, our knowledge and understanding of the anaerobic digestion process, a very complex microbial process in terms of functionality and community diversity, would be insufficient depicted due to the fact that the environmental factors which influence the microbial community structure, activity and interactions would not be taken into consideration (Kleerebezem and van Loosdrecht, 2007; Yoshiguchi et al., 2012; Zarraonaindia et al., 2013; Vanwonterghem et al., 2014). Thus, a combination of cultivation-independent methods is essential to investigate and study the complex anaerobic microbiome.

A commonly used cultivation-independent approach to investigate and profile the microbial community depends on the analysis of the $16 \mathrm{~S}$ respectively small subunit ribosomal-RNA (rRNA) gene. The $16 \mathrm{~S}$ rRNA gene is the most widely used marker gene because this gene is present in all bacteria and archaea, its function over time has not changed, the 16S rRNA gene is with $1500 \mathrm{bp}$ long which is enough for informatics purposes, has the most extensive reference databases, and the presence of variable regions in this gene allows sufficient diversification while the presence of conserved regions enabled the design of suitable PCR primers (Godon et al., 1997; Sekiguchi et al., 1998; Patel, 2001; Talbot et al., 2008; Su et al., 2012; Sundberg et al., 2013; Ve`trovsky' and Baldrian, 2013; Cabezas et al., 2015; Theuerl et al., 2015). Hence, a 16S rRNA (gene)-based approach can provide a broad overview of community presence, activity in form of fluorescence in situ hybridization FISH and potential performance (depending on the prevalent microbiome), which could serve as a valuable overview and basis for several molecular techniques. 


\subsubsection{The terminal restriction fragment length polymorphism (TRFLP)}

The terminal restriction fragment length polymorphism (TRFLP) is a fingerprinting technique to monitor the main spatial and temporal changes in the microbial community composition in response to the environmental perturbations (Lukow et al., 2000; Marsh, 2005; Talbot et al., 2008; Enwall und Hallin, 2009; Sboner et al., 2011; van Dorst et al., 2014; Cabezas et al., 2015; Alsouleman et al., 2016; Weise et al., 2016; De Vrieze et al., 2018). This method has been introduced firstly by Liu et al. in 1997. After that, huge efforts were done to optimize this technique in order to limit the drawbacks in applying this technique in the investigation of the microbial communities even in anaerobic digestion processes (Osborn et al., 2000; Engebretson and Moyer, 2003; Abdo et al., 2006; Osborne et al., 2006; Schütte et al., 2008 ; Rademacher et al., 2012).

During the last years, the TRFLP analysis has been widely applied in microbial community investigation of biogas production process (e.g., Feng et al., 2010 ; Wang et al., 2010; Carballa et al., 2011; Pycke et al., 2011; Ziganshin et al., 2011; Rademacher et al., 2012; Klang et al., 2015; Alsouleman et al., 2016; De Vrieze et al., 2018; Alsouleman, 2019). The Traditional T-RFLP technique relies on the use of at least one fluorescently labelled PCR primer to amplify the 16S rRNA gene. After the DNA amplification, the fluorescently labeled PCR product was digested by a restriction enzyme (endonuclease). Afterwards, the fluorescently labeled fragments were separated together with an internal length standard - allowing a size calculation of the terminal restriction fragments (TRFs) - by an automated capillary gel electrophoresis system Fig. 3.

Further analysis and comparison of the TRFLP profiles can be conducted by using appropriate software solutions, e.g., BioNumerics (Applied Maths, Belgium). The TRFLP profiles of each sampling point were evaluated separately in the fingerprint curve-processing window. The identification of "true" terminal restriction fragments (TRFs) by distinguishing background and baseline "noise" or false positives (bleed through peaks) from signals of correctly fluorescent-labelled fragments as well as the alignment (band matching) of detected terminal restriction fragments (TRFs) was done. Finally, TRFs were visualized by their relative distribution within tables (Appendix 1; Alsouleman, 2019). 

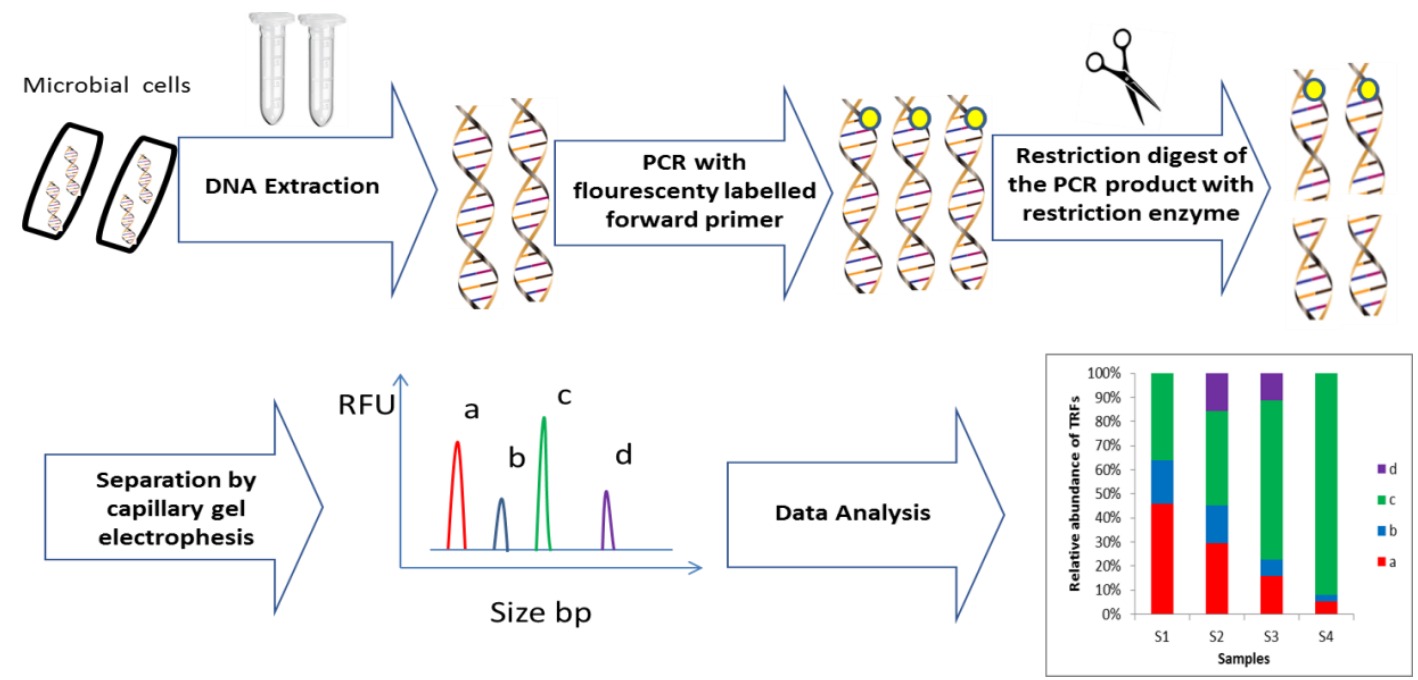

Figure 3: Short workflow of the TRFLP analysis

Different studies in different environments have compared the TRFLP with next generation amplicon sequencing based on the 16S rRNA gene, e.g., by using the Illumina sequencing platforms. These studies proved the potential of the TRFLP as robust and reliable technique for fast community screening (for review: De Vrieze et al., 2018; Witzig et al., 2015) and the capability of this technique to be used as pre-analysis before the application of the next generation sequencing (Brugger et al., 2012). Recently, De Vrieze et al. (2018) revealed with a comparison of the Illumina amplicon sequencing (next generation sequencing technique) and bacterial TRFLP and archaeal TRFLP profiles of 25 full-scale AD plants a high degree of similarity in the $\beta$-diversity profiles. The $\beta$-diversity index gives the value of the dissimilarity between communities between samples. While they found a clear dissimilarity between the Illumina archaeal profile and TRFLP archaeal profile at $\alpha$-diversity levels which give information about the number of the species and their relative abundance in each sample. Also, they concluded that the TRFLP technique may be easier and cheaper and alternative to $16 \mathrm{~S}$ rRNA gene amplicon sequencing to monitor the overall structure of the microbial communities.

In this study, as the major aim is to investigate the microbial structure, its dynamics over time and how the prevalent operational and environmental conditions could affect the microbial community structure, the terminal restriction fragment length polymorphism (TRFLP) was used. The TRFLP analyses were carried out following the optimized protocol published by Rademacher et al. (2012). Bioinformatic evaluation of 
the obtained microbiological data was performed according to Klang et al. (2015) using the software package BioNumerics 7.1 (Applied Maths, Belgium).

\subsubsection{Identification of detected TRFs by construction and screening of 16S rRNA gene sequence libraries}

The 16S rRNA gene sequence libraries were constructed to identify and characterize the detected TRFs and hence the microbial community structure during the course of fermentation. The PCR amplification of the 16S rRNA gene was conducted using the same primer set of the TRFLP approach but in this case without fluorescent labeling. Cloning of $16 \mathrm{~S}$ rRNA gene amplicons was performed according to Rademacher and colleagues (2012).

The sequences of the selected clones as determined by GATC Biotech AG (Germany) were then clustered into operational taxonomic units (OTUs) at 97\% (Bacteria) and 99\% (Archaea) sequence similarity required for the identification at the species level (Kim et al., 2011). Then the taxonomic position of the representative sequences and the identification of the detected TRFs were determined according to the Klang et al., (2015). This cloning and sequencing approach was firstly reported by Giovannoni et al. (1990) in an analysis of the diversity of bacterioplankton in Sargasso Sea. After that a huge number of studies applying this approach to identify and characterize the complex microbial community composition of the anaerobic microbial community were conducted (Godon et al., 1997; Sekiguchi et al., 1998; Roest et al., 2005; Nettmann et al., 2008; Goberna et al., 2009; Nelson et al., 2011; Rademacher et al., 2012; Klang et al., 2015; Alsouleman et al., 2016; Alsouleman, 2019). 


\subsection{Conception and aims of this study}

The main aim of this study was to evaluate the impact of a stepwise increase of ammonium nitrogen due to the addition of different poultry manure levels on the mesophilic and thermophilic anaerobic reactors performance and especially the structure and dynamic variations of the occurring microbial community. In other words, this study aimed to investigate how much poultry manure, and respectively how much ammonium nitrogen, can be tolerated by the $\mathrm{AD}$ microbial community without any negative effects on the overall process performance in two different temperature ranges, and to follow the response of the occurring microbial community to the environmental disturbance arising from the changing in the feedstock supply and nutrient availability in terms of stability, functional redundancy and resilience.

The composition and dynamics of microbial communities during long term bioreactors operation were investigated by molecular methods targeting 16S rRNA genes. T-RFLP fingerprinting in combination with $16 \mathrm{~S}$ rRNA gene sequence libraries were performed covering the whole experimental period and all putative community changes correspond to the increasing amount of poultry manure.

In detail, the main aim of this study was achieved by:

- $\quad$ The evaluation of the effect of the consecutive addition of three poultry manure levels on the long-term mesophilic and thermophilic reactors performance; three experimental phases were defined depending on the added PM level: EP1 with low PM level $=75 \% \mathrm{CS}$ and 25\% PM, EP2 with medium PM level $=50 \% \mathrm{CS}$ and 50\% PM, EP3 with high $\mathrm{PM}$ level $=25 \% \mathrm{CS}$ and $75 \% \mathrm{PM}$.

- The characterization of the bacterial and archaeal community of the control reactors (feeding with cattle slurry as sole feedstock) in mesophilic and thermophilic conditions.

- The investigation of the changes in the microbial community structure as a consequence to poultry manure addition. Therefore, the bacterial and archaeal community structure was analyzed using TRFLP technique at different time points during the experimental phases depending on the reactor performance. 
- $\quad$ The correlation between the microbial community structure and the prevalent process parameters $\left(\mathrm{NH}_{4}{ }^{+}-\mathrm{N}, \mathrm{NH}_{3}, \mathrm{VFA}, \mathrm{VS}\right.$ and conductivity).

Out of these parameters it will be possible to draw conclusions on: how much poultry manure can be applied without any disturbance of the overall AD process performance on the experimental level; the efficiency of the thermophilic AD of the added PM levels, which is a preferable option from the economical point of view in the countries with long and hot summer like Syria, and the efficiency of the microbial community structure which is robust against the disturbances arising from the added PM level. The previous aspects will help to run the $\mathrm{AD}$ of nitrogen-rich manure as efficient as possible and to apply this technology in future on full scale as an animal waste treatment technology and bioenergy resource. 


\section{Publications}

4.1 Reorganisation of a mesophilic biogas microbiome as response to a stepwise increase of ammonium nitrogen induced by poultry manure supply

Bioresource Technology 208: 200-204 (2016)

http://dx.doi.org/10.1016/j.biortech.2016.02.104

(The majority of this publication was presented as oral presentation in Biogas Science

Conference- Szeged, Hungary, 21-24. August 2016)

Khulud Alsouleman, Bernd Linke, Johanna Klang, Michael Klocke, Niclas Krakat, Susanne Theuerl 
Short Communication

\title{
Reorganisation of a mesophilic biogas microbiome as response to a stepwise increase of ammonium nitrogen induced by poultry manure supply
}

\author{
Khulud Alsouleman ${ }^{\mathrm{a}, \mathrm{b}}$, Bernd Linke ${ }^{\mathrm{a}}$, Johanna Klang ${ }^{\mathrm{a}}$, Michael Klocke ${ }^{\mathrm{a}}$, Niclas Krakat ${ }^{\mathrm{a}}$,
} Susanne Theuerl ${ }^{\mathrm{a}, *}$

${ }^{2}$ Leibniz Institute for Agricultural Engineering Potsdam-Bornim (ATB), Department Bioengineering, Max-Eyth-Allee 100, D-14469 Potsdam, Germany ${ }^{\mathrm{b}}$ Faculty of Agricultural Science, Georg-August-University Göttingen, Büsgenweg 5, D-37077 Göttingen, Germany

H I G H L I G H T S

- Process-risk feedstocks such as poultry manure have to be used with caution.

- Low amounts of $\mathrm{NH}_{4}{ }^{+}-\mathrm{N}$ and VFA favour a Bacteroidetes-Methanosaetaceae microbiome.

- The addition of $50 \%$ poultry manure led to a reconstruction of the microbiome.

- The functional redundant microbiome was Clostridiales-Methanobacteriaceae-dominated.

- A natural-regulated microbial diversity management was recorded.

\section{A R T I C L E I N F O}

\section{Article history:}

Received 19 December 2015

Received in revised form 22 February 2016

Accepted 23 February 2016

Available online 7 March 2016

\section{Keywords:}

Anaerobic digestion

Poultry manure

Disturbance

Mit community reconstruction

\begin{abstract}
A B S T R A C T
An anaerobic digestion experiment was investigated to evaluate the impact of increasing amounts of ammonium nitrogen due to poultry manure addition on the reactor performance, especially on the microbiome response. The microbial community structure was assessed by using a 16S rRNA gene approach, which was further correlated with the prevalent environmental conditions by using statistical analyses. The addition of $50 \%$ poultry manure led to a process disturbance indicated by a high VFA content (almost $10 \mathrm{~g}_{\mathrm{HAc}-\mathrm{Eq}} \mathrm{L}^{1}$ ) in combination with elevated concentrations of ammonium nitrogen $\left(5.9 \mathrm{~g} \mathrm{NH}_{4}^{+}-\mathrm{N} \mathrm{kg}_{\mathrm{FM}}^{1}\right)$ and free ammonia $\left(0.5 \mathrm{~g} \mathrm{NH}_{3} \mathrm{~kg}_{\mathrm{FM}}^{1}\right)$. Simultaneously the microbiome, changed from a Bacteroidetes-dominated to a Clostridiales-dominated community accompanied by a shift from the acetoclastic to the hydrogenotrophic pathway. The "new" microbial community was functional redundant as the overall process rates were similar to the former one. A further increase of poultry manure resulted in a complete process failure.
\end{abstract}

(c) 2016 Elsevier Ltd. All rights reserved.

\section{Introduction}

The implementation of anaerobic digestion (AD) on animal waste has become a promising alternative treatment technology as it reduces the negative environmental impacts and offers a sustainable renewable energy resource. However, applying AD on animal manure is related to the risk of ammonium nitrogen $\left(\mathrm{NH}_{4}^{+}-\mathrm{N}\right)$ accumulation, whereby the undissociated form (free ammonia, $\mathrm{NH}_{3}$ ), is considered to be toxic for the microbial community, especially for the acetoclastic methanogens, which may lead to process disturbances/failures (Chen et al., 2008; Lv et al., 2014). It has also

\footnotetext{
* Corresponding author. Tel.: +49 3315699 900; fax: +49 3315699849 .
} E-mail address: susanne.theuerl@googlemail.com (S. Theuerl). been shown that a process imbalance can naturally be prevented by a shift from acetoclastic to hydrogenotrophic methanogenesis in combination with syntrophic acetate oxidation (Schnürer and Nordberg, 2008). Hence one of the most important factors to ensure a stable biogas production is a highly efficient microbiome which is resilient against process disturbances (Theuerl et al., 2015). Consequently, the scientific challenge is to expand the knowledge of the complex ecological network within the biogas reactor.

In order to investigate the process microbiology, a broad range of methods is available, whereby it is recommended to use a combination of different methods and link the community structure information to its role in its respective habitat (Cabezas et al., 2015; Carballa et al., 2011; Verstraete et al., 2007). So far only a 
few long-term studies are available dealing with the effects of a gradual increase of $\mathrm{NH}_{4}^{+}-\mathrm{N}$ due to the addition of poultry manure on the reactor performance, especially under consideration of the structure and dynamic variations of the microbiome. Therefore, the aim of the present study was to investigate how much poultry manure, respectively how much $\mathrm{NH}_{4}^{+}-\mathrm{N}$ can be tolerated by the $\mathrm{AD}$ microbiome without any negative effects on the overall process performance.

\section{Methods}

2.1. Experimental setup, biogas reactor operation and chemical analyses

To investigate the response of the microbial community due to an increasing concentration of $\mathrm{NH}_{4}^{+}-\mathrm{N}$ caused by addition of poultry manure (PM), two mesophilic $\left(37^{\circ} \mathrm{C}\right)$ laboratory-scale (eight litre working volume) continuously stirred tank reactors (CSTRs) were operated at an organic loading rate (OLR) of $3.0 \mathrm{gvS}_{\mathrm{VS}} \mathrm{L}^{-1} \mathrm{~d}^{-1}$. Over the experimental phase (EP), the control reactor (CR) was operated with cattle slurry (CS) as sole feedstock, whilst the experimental reactor (ER) was fed with an increasing amount of PM (based on volatile solids, VS) as followed: $\mathrm{EP} 1=75 \% \mathrm{CS}$ and $25 \% \mathrm{PM}$ for 143 days with a hydraulic retention time (HRT) of 30 days $\mathrm{EP} 2=50 \% \mathrm{CS}$ and 50\% PM for 165 days (HRT $=37$ days) $\mathrm{EP} 3=25 \% \mathrm{CS}$ and $75 \% \mathrm{PM}$ for 171 days $($ HRT $=52$ days $)$; and finally $\mathrm{EP} 4=100 \%$ PM for 22 days (HRT $=134$ days $)$. Over the entire trai period, the produced amount of biogas was measured continuously, whilst the gas composition was analysed twice a week Digestate samples were analysed regarding their main chemica characteristics (total Kjeldahl nitrogen (TKN), $\mathrm{NH}_{4}^{+}-\mathrm{N}$ content volatile fatty acids (VFA) in terms of acetate, propionate, iso- and $n$-butyrate, iso- and $n$-valerate, and capronate) according to Schönberg and Linke, (2012).

\subsection{Microbial community analyses}

To investigate the process microbiology 14 different time points (depending on the reactor performance) were chosen from the $\mathrm{ER}$ (day $98,137,155,185,207,230,274,305,319,337,372,479,490$, 514 ) and three from the CR (day 98, 207, 479). Genomic DNA was extracted using the FastDNA ${ }^{\circledR}$ SPIN Kit for soil (MP Biomedicals, Heidelberg, Germany) according to the manufacturer's guidelines.

To characterise the microbial community structure and its dynamic variation the genomic fingerprinting method terminal restriction fragment length polymorphism (TRFLP) targeting eithe the bacterial or the archaeal 16S rRNA gene was used as described by Rademacher et al. (2012) and Klang et al. (2015). Bioinformatic evaluation of the obtained data was performed as published by Klang et al. (2015) using the software package BioNumerics 7.1 (Applied Maths, Belgium).

Additionally, 165 rRNA gene sequence libraries were constructed from samples ER-98, ER-137, ER-185, ER-305, ER-372, ER-514, and CR-98, covering all putative community changes Cloning of PCR products was performed according to Rademache et al. (2012), followed by DNA sequencing (GATC Biotech AG, Kon$\operatorname{stanz}$, Germany). The obtained sequences were processed, grouped into operational taxonomic units (OTUs) and virtually cut according to Klang et al. (2015) using the software package BioNumerics 7.1 (Applied Maths, Belgium). Subsequently, OTUs were taxonomically assigned using the Ribosomal Database Project RDP Version 2.6 (Wang et al., 2007). All new sequences obtained in this study have been deposited in the European Molecular Biology Laboratory (EMBL) database under accession numbers LN849462-LN849688 (Bacteria) and LN874153-LN874209 (Archaea).
In order to get information about the microbial system ecology the community organisation expressed by the Gini coefficients was calculated (Carballa et al., 2011; Klang et al., 2015; Theuerl et al. 2015; Verstraete et al., 2007). Additionally, the software package of PC Ord Version 6 (McCune and Mefford, 2011) was used to perform a non-metric multidimensional scaling (NMS) (Clarke, 1993) to conduct a correlation amongst and between the operational and microbiological parameters.

\section{Results and discussion}

3.1. Performance of anaerobic co-digestion of cattle slurry with stepwise increased addition of poultry manure

During the experimental period, the control reactor (CR) showed no significant changes neither in the produced biogas (376 $\pm 72 \mathrm{~L}_{\mathrm{N}} \mathrm{kg}^{-1}$ with a $\mathrm{CH}_{4}$ content of $62 \pm 2 \%$; Fig. 1A) nor in the main chemical parameters $\left(\mathrm{NH}_{4}^{+}-\mathrm{N}=1.8 \pm 0.2 \mathrm{~g} \mathrm{~kg}_{\mathrm{FM}}^{-1}\right.$ $\mathrm{NH}_{3}=0.07 \pm 0.02 \mathrm{~g} \mathrm{~kg}_{\mathrm{FM}}^{-1}$ and VFA concentration $\leqslant 0.5 \mathrm{~g} \mathrm{~L}^{-1}$ ).

The increasing $\mathrm{NH}_{4}^{+}-\mathrm{N}$ concentration caused by the addition of PM showed no significant effects on the process parameters until $4.2 \mathrm{~g} \mathrm{~kg}_{\mathrm{EM}}^{-1}$ were reached in EP2; a values which exceeded the reported inhibition levels of the $\mathrm{AD}$, especially of the acetoclastic methanogenesis (Drosg, 2013; Schnürer and Nordberg, 2008). Subsequently, a serious process imbalance occurred as indicated by a VFA accumulation of almost $10 \mathrm{~g}_{\mathrm{HAC}-\mathrm{Eq}} \mathrm{L}^{-1}$ (mainly acetic acid) and a drop in the biogas production (Fig. 1). After a certain time (without active counteracting) the system recovered symbolized by a decrease in the VFA concentration and a subsequent increase of the biogas, respectively methane contents. Hence, it can be supposed, that an adaption from the acetoclastic to hydrogenotrophic pathway of methane formation took place.

A further increase of PM (75\% in EP3, respectively $100 \%$ in EP4) and, hence, a continuous increase of $\mathrm{NH}_{4}^{+} \mathrm{N}$ of up to $9.6 \mathrm{~g} \mathrm{~kg}-1$ resulted in a complete process failure indicated by a constant increase in the VFA concentration accompanied by a strong decrease of the biogas amount and methane content (Fig. 1).

3.2. The response of the microbiome to increased amounts of poultry manure

The microbiome of the three samples from the CR consisted mainly of members from the phylum Bacteroidetes (35\%) followed by Firmicutes (17\%), and the WWE1 candidate division (10\%) at the bacterial level and members of the genus Methanosaeta (phylum Euryarchaeota) with an abundance of around $60 \%$ at the archaeal level. The Gini coefficients in the CR were 0.41 (Bacteria), respectively 0.69 (Archaea), values which are reported to symbolise well-established communities (Theuerl et al., 2015). Hence, it can be assumed that the methane formation was mainly carried out by the acetoclastic pathway which in turn indicated a good performing reactor system as previously reported by Regueiro et al. (2012).

Although no significant changes in the reactor performance were observed during EP1 (see Section 3.1), the microbial community, especially the archaeal community was affected by changes in the feedstock supply and, therefor, the nutrient availability as the abundance of members belonging to the family Methanobacteriaceae increased slightly. This led to a more even distributed community organisation combined with an increasing importance of the hydrogenotrophic pathway of methane formation.

Compared to EP1, the sample ER-155 taken 11 days after increasing the PM amount to 50\% (EP2), showed significant differences in the bacterial community structure whereby members from the family Porphyromonadaceae (phylum Bacteroidetes) 


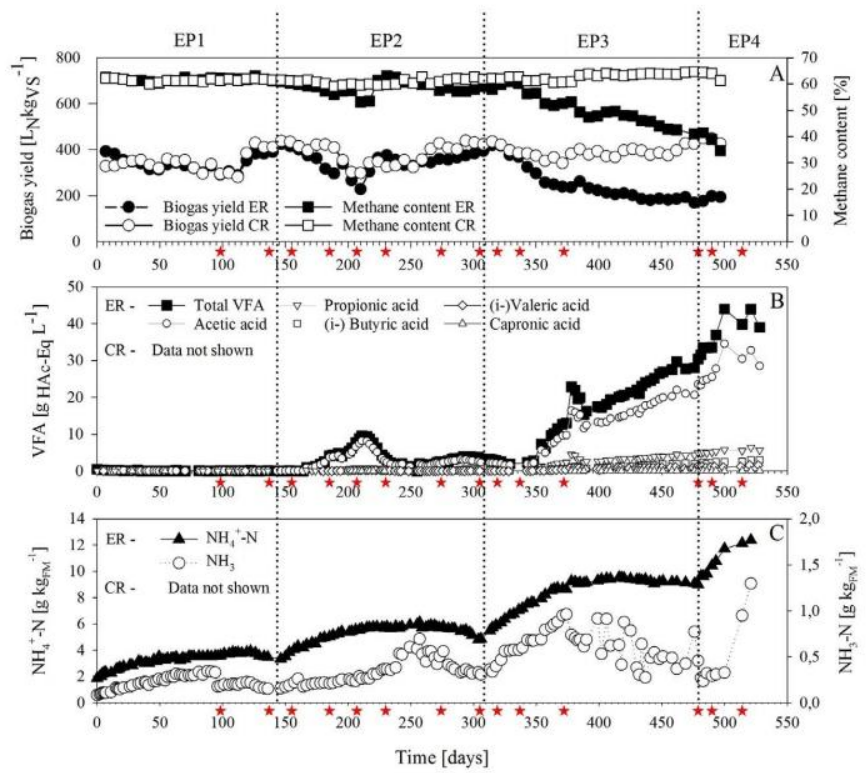

Fig. 1. Process performance in terms of the biogas yield and methane content for the control and experimental reactor (A), the volatile fatty acids (VFA) produced in the experimental reactor (B) as well as the ammonium nitrogen $\left(\mathrm{NH}_{4}^{+}-\mathrm{N}\right)$ and the free ammonia $\left(\mathrm{NH}_{3}\right)$ nitrogen content of the experimental reactor (C) over the entire experimental period. $\mathrm{Stars}$ at $\mathrm{X}$-axis indicate the sampling points for the molecular biological analyses. $\mathrm{EP}=$ experimental phase, $\mathrm{ER}=$ experimental reactor, $\mathrm{CR}=\mathrm{control}$ reactor.

accounted for around $44 \%$ of the entire community (calculated as a sum of all group-related TRFs). This increased abundance may explain the subsequent VFA accumulation as several members from the order Bacteroidales are reported as acid producers with acetic acid as main end product (e.g., Hahnke et al., 2016). Over the course of the process disturbance a reorganisation of the bacterial community occurred as the Bacteroidetes-dominated microbiome was gradually replaced by members of the order Clostridiales (phylum Firmicutes) as they reached about $47 \%$ of the entire bacterial community at day 274 (Fig. 2A). This finding is in accordance with De Vrieze et al. (2015) who reported a negative correlation between the order Bacteroidales and the orders belonging to the phylum Firmicutes, with higher abundances of the Bacteroidales order at low $\mathrm{NH}_{4}^{+}-\mathrm{N}$ and VFA concentrations. At this point it is questionable whether the VFAs produced by Bacteroidales led to self-inhibition or whether the increasing $\mathrm{NH}_{4}^{+}-\mathrm{N}$ concentrations suppressed their growth. Moreover, De Vrieze et al. (2015) further pointed out that Bacteroidales-dominated AD microbiomes are also dominated by the archaeal family Methanosaetaceae which was also found in this study. As it is well-known that Methanosaetaceae are significantly negative correlated with the both mentioned parameters $\mathrm{NH}_{4}^{+}-\mathrm{N}$ and VFA, it can be assumed that the increased amount of acetic acids in combination with rising $\mathrm{NH}_{4}^{+}-\mathrm{N}$ concentration led to an inhibition of the acetoclastic pathway of methane formation which in turn forced the community reorganisation.

The order Clostridiales consists not only of several species which possess hydrolytic and acido-/acetogenic capacities (substrate degradation and acid production) but also of species which are able to perform syntrophic acetate oxidation (Schnürer and Nordberg, 2008). In case of a syntrophic relationship a close contact between hydrogen producers and consumers is necessary which means that the reorganisation at the bacterial level should be accompanied by a shift to hydrogenotrophic methanogens which was recorded by the TRFLP results (Fig, 2B). In the beginning of EP2 a high abundance of TRF-107 bp was detected; a TRF which was assigned to the genus Methanosaeta based on the conducted sequence libraries of ER-98 and ER-137. However, the sequence libraries of ER-185 revealed a different picture as sequences from the family Methanobacteriaceae (symbolized inter alia also by TRF-107 bp and further by TRF- $340 \mathrm{bp}$ ) became more abundant. Consequently, the prevalent chemical conditions arising from the increasing amount of $\mathrm{NH}_{4}^{+}-\mathrm{N}$ and $\mathrm{NH}_{3}$ resulted in a shift from the acetoclastic pathway of methane formation to the hydrogenotrophic pathway (Fig. 2B) which is well known to be the more stable/robust metabolic pathway considering the risk of ammonia toxicity (Chen et al. 2008: Fotidis et al., 2014). Concluding, the addition of $50 \%$ PM resulted in a reorganisation of the occurring microbial community. According to the reported ecological theories by Allison and Martiny (2008) it can be assumed that the "new" microbial community is functional redundant compared to the former one as the overall process rates were similar after the disturbance phase. This is a very good example for a natural-regulated, highly efficient microbial diversity management system.

According to the ongoing increase of the $\mathrm{NH}_{4}^{+}-\mathrm{N}$ conten during EP3 (75\% PM) the trend of EP2 (Fig. 2A) was moving on towards a Clostridiales-Methanobacteriaceae-dominated microbiome. Although EP3 lasted for 170 days, the induced process disturbance could not be compensated by the occurring microbial community. Regarding that the biogas yield and the methane content showed a significant decrease resulting in a complete process failure (Fig. 1), it has to be concluded that the methanogenic activity was seriously inhibited. Hence, it is reasonable to assume that the molecular hydrogen $\left(\mathrm{H}_{2}\right)$ level increased which further inhibited the growth of acid converting bacteria that can only grow if the $\mathrm{H}_{2}$, (which is produced by themselves), is consumed by their syntrophic 


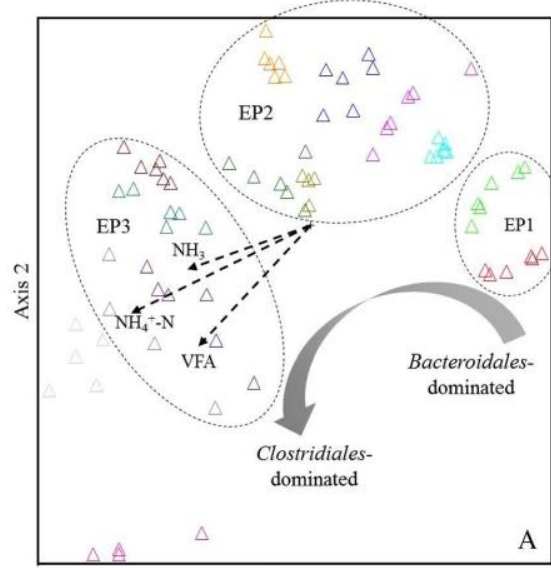

Axis 1

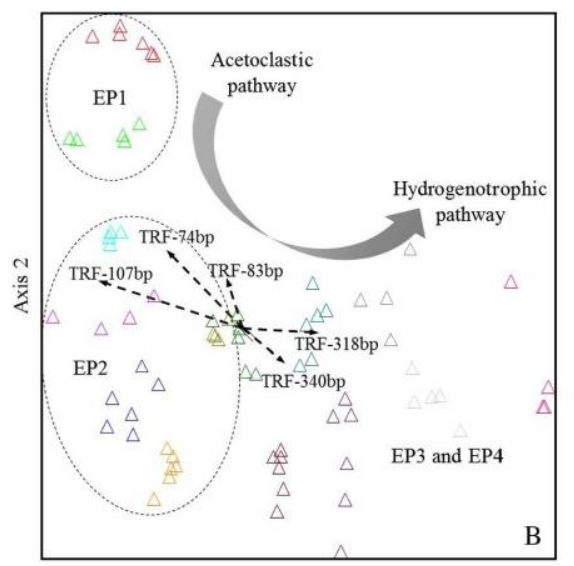

Axis 1
$\left.\triangle_{\mathrm{ER}-137}^{\mathrm{ER}-98}\right\} \mathrm{EP}$

$\triangle$ ER-155

$\triangle$ ER-185

$\triangle$ ER-207

$\triangle$ ER-230

$\triangle$ ER-274

$\triangle$ ER-305

$\triangle$ ER-319

$\triangle$ ER-337

$\triangle$ ER-372 $\}$ EP3

$\triangle$ ER-479

$\triangle$ ER-490

Fig. 2. Non-metric multidimensional scaling (NMS) regarding three selected prevalent process parameters in terms of ammonium nitrogen ( $\mathrm{NH}_{4}^{+}-\mathrm{N}$ ), free ammonia nitrogen $\left(\mathrm{NH}_{3}\right)$, and total volatile fatty acids (VFA) and their effects on the bacterial community structure (A), respectively regarding the bacterial community structure and the corresponding archaeal community with special emphasis on the major pathway of methane formation (B).

archaeal partners. Consequently, the hydrolytic and acidogenic bacterial community members of the microbiome still converted the supplied feedstock/substrates into acids but the successive steps of conversion were completely inhibited which explains the VFA accumulation (see Section 3.1).

\section{Conclusion}

This study revealed that the present $\mathrm{AD}$ microbiome was able to tolerate a certain amount of poultry manure. The addition of $50 \%$ $\mathrm{PM}$ induced a process disturbance which was characterised by a shift from a Bacteroidetes-dominated to a Clostridiales-dominated bacterial community accompanied by a change from the acetoclastic to the hydrogenotrophic pathway of methane formation. This study is a good example for a natural-regulated microbial diversity management system, as it highlighted how an anaerobic microbiome was enabled to adapt to changing environmental conditions. In regard to configure the biogas process as efficiently as possible, it can be assumed that the use of process-risk feedstocks is possible but it has to be used with cautions and especially with respect to the demands of the microbiome.

\section{Additional information}

The relative distribution of the detected bacterial and archaeal terminal restrictions fragments (TRFs) highlighted by colours according to an increasing abundance and their phylogenetic assignment is given as supplement.

\section{Acknowledgements}

K.A. was supported by the Erasmus Mundus Joseleen Programm which was financed by the European Commission, Brussels, Belgium (grant number FIIR 2010/34) as well as by the Leibniz Institute for Agricultural Engineering Potsdam-Bornim. The authors would like to thank Kerstin Mundt and Carsten Jost for their excellent technical support.

\section{Appendix A. Supplementary data}

Supplementary data associated with this article can be found, in the online version, at http://dx.doi.org/10.1016/j.biortech.2016.02. 104.

\section{References}

Allison, S.D., Martiny, J.B., 2008. Resistance, resilience, and redundancy in microbial communities. Proc. Natl. Acad. Sci. 105, 11512-11519.

Cabezas, A. Calabria de Araujo, J., Callejas, C., Galè, A., Hamelin, J., Marone, A., Sousa, D. Z., Trably, E., Etchebehere, C., 2015. How to use molecular biology tools for the study of the anaerobic digestion process? Rev. Environ. Sci. Biotechnol. 14, 555593.

Carballa, M., Smits, M., Etchebehere, C., Boon, N., Verstraete, W., 2011. Correlations between molecular and operational parameters in continuous lab-scale anaerobic reactors. Appl. Mircobiol. Biotechnol. 89, 303-314.

Chen, Y., Cheng, J..., Creamer, K.S., 2008. Inhibition of anaerobic digestion process: review. Bioresour. Technol. 99, 4044-4064.

arke, K.R., 1993. Non-parametric multivariate analyses of changes in community structure. Aust. J. Ecol. 18, 117-117.

De Vrieze, J., Saunders, A.M., He, Y., Fang, J., Nielsen, P.H., Verstraete, W., Boon, N. 2015. Ammonia and temperature determine potential clustering in the

Drosg, B., 2013. Process monitoring in biogas plants. In: IEA Bioenergy Task 37 -

Energy from Biogas.
Fotidis, I., Karakashev, D., Angelidaki, I., 2014. The dominant acetate degradation pathway/methanogenic composition in full-scale anaerobic digesters operating Hahnke, S, Langer, T, Koeck, D. F, Klocke, M. 2016. Description of Proteiniphilum saccharofermentans sp. nov, Petrimonas mucosa sp. nov, and Fermentimone saccharofermentans sp. nov., Petrimonas mucosa sp. nov. and Fermentimona and emended description of the genus Proteiniphilum. Int. J. Syst. Evol Microbiol. http://dx.doi.org/10.1099/ijsem.0.000902 (online available since 15 January 2016).

Klang, J., Theuerl, S., Szewzyk, U., Huth, M., Tölle, R., Klocke, M., 2015. Dynamic variation of the microbial community structure during the long-time monofermentation of maize and sugar beet silage. Microb. Biotechnol. 8, 764-775.

Lv, Z., Hu, M., Harms, H., Richnow, H.H., Liebetrau, J., Nikolausz, M., 2014. Stable isotope composition of biogas allows early warning of complete process failure as a result of ammonia inhibition in anaerobic digesters. Bioresour. Techno.

McCune, B., Mefford, M.J. 2011. PC-ORD - Multivariate analysis of ecological data Version 6.08

Rademacher, A., Nolte, C., Schönberg, M., Klocke, M., 2012. Temperature increases from 55 to $75^{\circ} \mathrm{C}$ in a two-phase biogas reactor result in fundamental alteration Biotechnol. 96, 565-576. 
Regueiro, L., Veiga, P., Figueroa, M., Alonso-Gutierrez, J., Stams, A.J., Lema, J.M. Carballa, M., 2012. Relationship between microbial activity and microbia community structure in six full-scale anaerobic digesters. Microbiol. Res. 167 581-589.

Schnürer, A., Nordberg, A., 2008. Ammonia, a selective agent for methane production by syntrophic acetate oxidation at mesophilic temperature. Wate Sci. Technol. 57, 735-740.

Schonberg, M., Linke, B., 2012. The influence of the temperature regime on the formation of methane in a two-phase anaerobic digestion process. Eng. Life Sc $12,279-286$
Theuerl, S., Kohrs, F., Benndorf, D., Maus, I., Wibberg, D., Schlüter, A., Kausmann, R., Heiermann, M., Rapp, E., Reichl, U., 2015. Community shifts in a well-operating agricultural biogas plant: how process variations are handled by the microbiome. Appl. Microbiol. Biotechnol. 99, 7791-7803.

Verstraete, W., Wittebolle, L., Heylen, K., Vanparys, B., De Vos, P, Van de Wiele, T. Boon, N., 2007. Microbial resource management: the road to go for environmental biotechnology. Eng. Life Sci. 7, 117-126.

Wang, Q. Garrity, G.M., Tiedje, J.M., Cole, J.R., 2007. Naive Bayesian classiffer fo rapid assignment of rRNA sequences into the new bacterial taxonomy. App. 
4.2 Effect of increasing amounts of ammonium nitrogen induced by consecutive mixture of poultry manure and cattle slurry on the microbial community during thermophilic anaerobic digestion

Journal of Microbiology and Biotechnology 29: 1993-2005 (2019)

https://doi.org/10.4014/jmb.1909.09023

Khulud Alsouleman 


\title{
Effect of Increasing Amounts of Ammonium Nitrogen Induced by Consecutive Mixture of Poultry Manure and Cattle Slurry on the Microbial Community during Thermophilic Anaerobic Digestion
}

\author{
Khulud Alsouleman ${ }^{1,2 *}$ \\ ${ }^{1}$ Department Bioengineering, Leibniz Institute for Agricultural Engineering and Bioeconomy (ATB), Potsdam, Germany \\ ${ }^{2}$ Faculty of Agricultural Sciences, Georg-August-Universität Göttingen, Göttingen, Germany
}

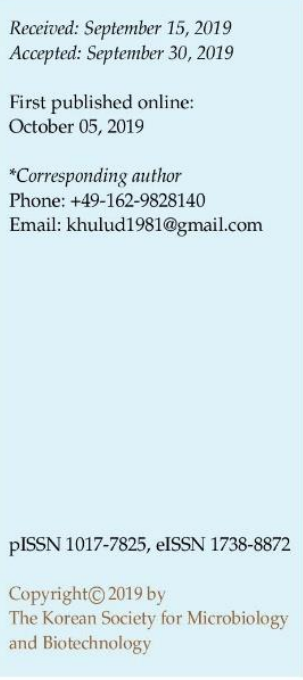

Received: September 15, 2019

First published online

October 05,2019

"Corresponding author

Phone: +49-162-9828140

Email: khulud1981@gmail.con

Introduction

Reducing greenhouse gas emissions resulting from open storage and uncontrolled spreading of animal slurries and manures is a major challenge faced by the agricultural sector [1]. One of the most important and commonly applied technologies to achieve this goal is the bioconversion of animal wastes into energy-rich biogas by anaerobic digestion (AD) $[2,3]$.

The thermophilic $\mathrm{AD}\left(\mathrm{TAD}, 50-60^{\circ} \mathrm{C}\right)$ has generally higher metabolic rates and hence higher overall process efficiency than mesophilic $\mathrm{AD}$ performed at $37^{\circ} \mathrm{C}$ [4-7]. On the other hand, TAD is very sensitive to changes in operating factors such as total solids (TS), mixing rate, organic loading rate (OLR), $\mathrm{pH}$, volatile fatty acid (VFA) content, and total ammonium nitrogen content (TAN) which in turn reduce the process stability [8-11].

Due to the cytotoxic effects of ammonia $\left(\mathrm{NH}_{3}\right)$, resulting from deprotonation of ammonium $\left(\mathrm{NH}_{4}{ }^{+}\right)$, many efforts have been previously made to determine the TAN thresholds in mesophilic and thermophilic AD processes which ranged between 1.8 and $5.0 \mathrm{~g} \mathrm{NH}_{4}^{+}-\mathrm{N} / \mathrm{L}$. These inhibition thresholds varied widely due to the direct or indirect effect of many other factors such as the substrate composition, the initial nitrogen concentrations, the temperature, the $\mathrm{pH}$, the OLR, the acclimation period, and the acclimation of the inoculum [12-20].

The efficiency and stability of the AD process are entirely dependent on the concerted and syntrophic activity of the involved microorganisms. Several studies investigated basically the effect of increasing TAN on the thermophilic microbial community structure [11, 21-25]. For example, 
Hao et al. [21] showed in batch thermophilic acetate fed experiments at two TAN (low, i.e., $0.26 \mathrm{~g} / \mathrm{l}$, and high, i.e., $7.00 \mathrm{~g} / \mathrm{l})$ - that the microbial communities were similar for both TAN conditions. While in a previous work the syntrophic acetate oxidation coupled with hydrogenotrophic methanogenesis was shown as the dominant pathway in both mesophilic and thermophilic full-scale anaerobic digesters with high ammonia levels $\left(2.8-4.57 \mathrm{~g} \mathrm{NH}_{4}{ }^{+} \mathrm{N} / \mathrm{L}\right)$, whereas the acetoclastic methanogenic pathway dominated at low ammonia content $\left(<1.21 \mathrm{~g} \mathrm{NH}_{4}^{+}-\mathrm{N} / \mathrm{L}\right)$ [22]. Other studies showed that the mesophilic microbial community shifted significantly as members belonging to the Bacteroidetes and Methanosaeta were gradually disappeared with elevated TAN and hence elevated $\mathrm{NH}_{3}$ contents [20, 26, 27].

However, with main focus on the reactor performance and the microbial community structure of the TAD of nitrogen-rich substrate, only a few is known about the relationship between TAD microbial community shifts and performance variation resp. disturbances due to the accumulation of TAN.

We hypothesized that the potential impact of the stepwise increase of the TAN, as a consequence of the application of nitrogen-rich fermentation substrates, and hence the consequent prevalent operational process conditions will lead to more serious disturbances in the TAD process compared to mesophilic ones as previously published by Alsouleman et al. [20]. So that, this study focused mainly on the (in-) stability of the long-term TAD process in terms of biogas and methane yield, VFA content and accumulation of TAN as a response to the environmental perturbations arising from increasing amounts of poultry manure (PM). Also the response of the thermophilic microbial community was determined by $16 \mathrm{Sr}$ RNA gene targeted terminal restriction fragment length polymorphism (TRFLP) fingerprinting which allows the direct screening and comparison of microbial communities' dynamics in different samples [28-36]. Subsequent determination of respective nucleotide sequences enables the identification of representatives for the most abundant taxa [37-39].

\section{Materials and Methods}

Experimental Setup and Biogas Reactor Operation

Two thermophilic $\left(55^{\circ} \mathrm{C}\right)$ continuously resp. completely stirred tank reactors (CSTRs) with a working volume of $8 \mathrm{~L}$ were operated in parallel for ( 385 days), allowing the adaptation of the microbial community to the apparent process conditions. The start-up of the CSTRs was conducted according to [40]. To ensure a high diversity of a well-performing starter community, both reactors were initiated with anaerobic inoculum from previous experimental reactors which were fed with cattle and pig slurry as well as maize silage. This inoculum was diluted 1:2 with tap water before inoculation. During the first 75 days, both reactors were fed with CS starting with an organic loading rate (OLR) of $0.5 \mathrm{~g}_{\mathrm{vS}} / \mathrm{l} / \mathrm{d}$ and gradually increased (using $0.5 \mathrm{~g}_{\mathrm{vs}} / \mathrm{l} / \mathrm{d}$ steps) until the final OLR of $3.0 \mathrm{~g}_{\mathrm{vs}} / 1 / \mathrm{d}$ was achieved. Afterwards, the OLR was maintained at $3.0 \mathrm{~g}_{\mathrm{vs}} / 1 / \mathrm{d}$ for the further 65 days.

To avoid process inhibition through a lack of micronutrient, $10 \mu \mathrm{l}$ of the trace element solution DSMZ 144 was added per $g$ volatile solids (VS) (German collection of microorganisms and cell cultures, Germany) as recommended by [41]. Both reactors were operated at stable conditions indicated by $\mathrm{pH}$, VFA as well as biogas yield and methane content.

The experimental CSTR (= ER) was fed with an increasing amount (based on VS) of PM as followed whereby the OLR was kept constantly at $3.0 \mathrm{~g}_{\mathrm{vs}} / \mathrm{l} / \mathrm{d}$ : first experimental period (= EP1) with $75 \%$ CS and 25\% PM for 176 days and hydraulic retention time (HRT) of 26 days; second experimental period (= EP2) with $50 \%$ CS and 50\% PM for 165 days and HRT of 39 days. Over the entire EP, the control reactor (CR) was operated with CS as sole substrate with a constant OLR of $3.0 \mathrm{~g}_{\mathrm{vs}} / 1 / \mathrm{d}$ equal to the OLR of the ER.

Biogas production was monitored daily using a drum-type gas meter (Meter TG 05, Ritter Apparatebau, Germany). The biogas composition was analysed three times per week using the gas analyser SSM 6000 (Pronova Analysentechnik, Germany).

\section{Chemical Characterization of the Used Feedstocks and Digestate} Samples

The used feedstocks as well as the digestate samples (sampling twice a week), were analysed as follows: Total solids (TS), volatile solids (VS), total Kjeldahl nitrogen (TKN), the $\mathrm{NH}_{4}{ }^{+}-\mathrm{N}$ content, the amounts of VFA in terms of acetate, propionate, iso- and nbutyrate, iso- and n-valerate, and capronate were analysed according to [42]. The $\mathrm{pH}$-value was measured three times a week using $\mathrm{pH} /$ cond $340 \mathrm{i}$ with the $\mathrm{pH}$-Electrode SenTix41 (WTW, Germany).

The free ammonia $\left(\mathrm{NH}_{3}\right)$ content was calculated based on the $\mathrm{NH}_{4}{ }^{+} \mathrm{N}$ content, the $\mathrm{pH}$-value and the reactor temperature using the formula previously described by Hansen [17].

\section{Microbial Community Analysis}

To investigate the process microbiology, samples were taken from the ER at following process-relevant time points; day 81 , and 162 , i.e., the beginning and the end of EP1; day 199, i.e., the beginning of the EP2: day 250, i.e., the beginning of short-termed stable biogas yield period; day 300, i.e., the beginning of the biogas yield decrease period; day 340 , i.e., the end of EP2. From the CR, samples were analysed for days 81 and 340 , i.e., the beginning and the end of ER, as the CR showed an almost stable anaerobic digestion process during the whole ER as indicated by VFA content, biogas yield, and methane content. From two sub- 
samples of each sample (i.e., technical replicates), the microbial genomic DNA was extracted using the FastDNA SPIN Kit for soil (MP Biomedicals, Germany) according to the manufacturer's guidelines.

To characterize the microbial community structure, terminal restriction fragment length polymorphism (TRFLP) analysis targeting the bacterial or the archaeal 16Sr RNA gene was applied as described in [23].

16Sr RNA gene sequence analysis was conducted as described before [23]. The obtained sequences were processed, grouped into operational taxonomic units (OTUs) and virtually cut according to [43] using the software package BioNumerics 7.6 (Applied Maths, Belgium).

All sequences obtained in this study have been deposited in the European Molecular Biology Laboratory (EMBL) database under accession numbers LT718731 - LT718850 (Bacteria) and LT718710 LT718730 (Archaea)

\section{Statistical and Ecological Analysis}

Correlation coefficients among and between the operational and microbiological parameters, an indicator species analysis (ISA) [44], a non-metric multidimensional scaling (NMS) [45, 46], Gini coefficients $[47,48]$ in addition to Shannon [49] and Richness [47] diversity indices were estimated to show the correlation amongst and between the operational and microbiological parameters and to get more information about the microbial system ecology and the diversity of the microbial community. Detailed information on the whole materials and methods section is provided as supplemental material appendix 1 .

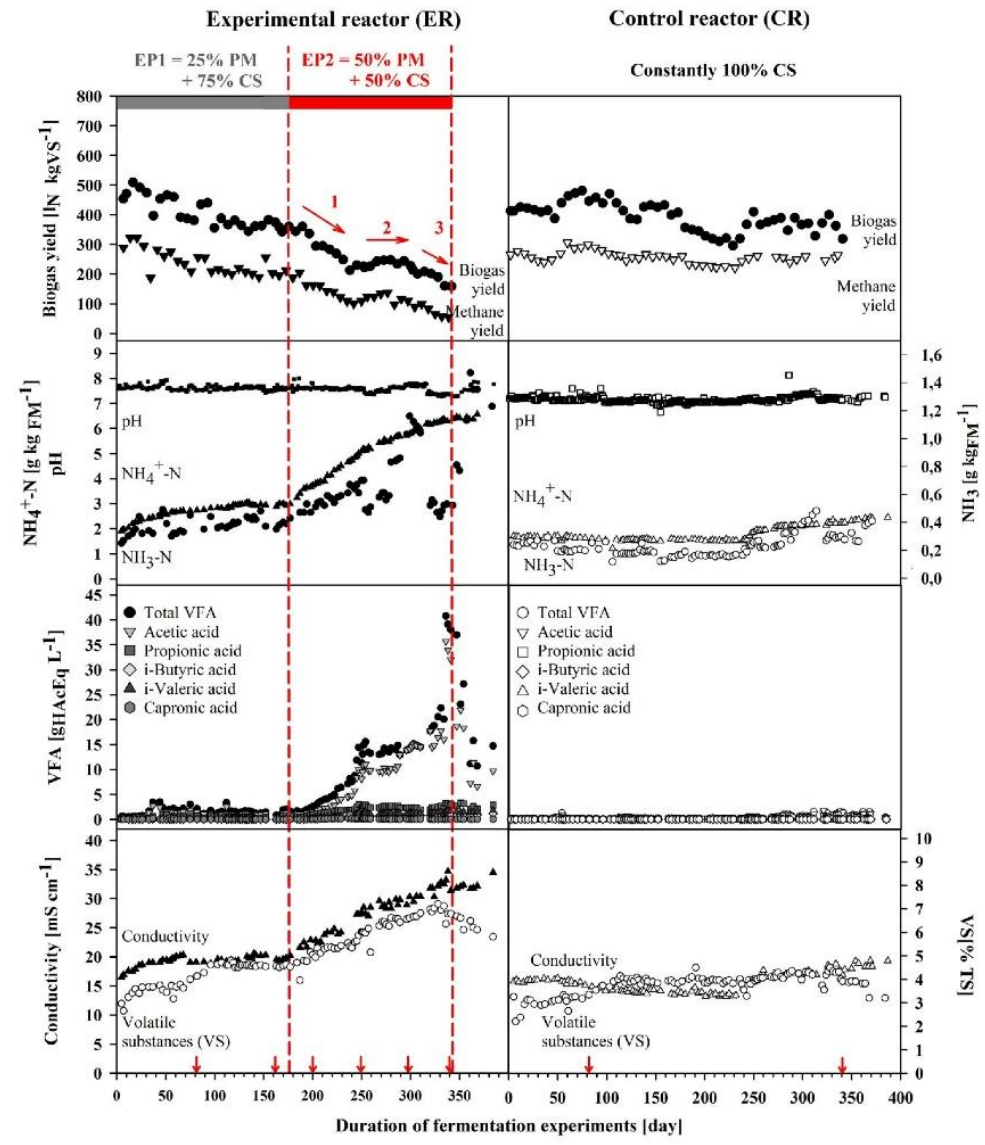

Fig. 1. Process performance parameters for the experimental (ER) and control reactor (CR) during experimental phases1 (EP1) and 2 (EP2).

The arrows on the $\mathrm{X}$-axis indicate sampling points for molecular analyses. The arrows 1, 2, 3 indicate three-stage process disturbance. 


\section{Results}

\section{Operation of CSTRs}

Changes in control and experimental TAD performance during the entire experimental period are shown in (Fig. 1). During both experimental periods (EP1 and EP2), the control reactor $(\mathrm{CR})$ supplied exclusively with cattle slurry showed no significant changes in the produced biogas yield $\left(\mathrm{R} 2=0.27 ; p<3.7 \times 10^{-25}\right)$ (Fig. 1$)$. Thus, the almost stable chemical parameters in the CR indicated a more or less stable and metabolically active microbial biocoenosis.

In the experimental reactor (ER), as expected, the change of the feedstock composition during EP1 resulted in an increased TAN content up to $3.0 \mathrm{~g} \mathrm{NH}_{4}{ }^{+}-\mathrm{N} / \mathrm{kg}_{\mathrm{FM}}$ at the end of this experimental phase with a corresponding increase in $\mathrm{NH}_{3}$ content up to $0.4 \mathrm{~g} / \mathrm{kg}_{\mathrm{FM}}$ respectively (Fig. 1). The total VFA content which consisted mainly of acetic acid showed a minor increase in this experimental phase. The content of the other volatile fatty acids in terms of propionate, iso- and n-butyrate, iso- and n-valerate and capronate was found in minor amount and was more or less constant. The relative alteration of the VFA concentration (as acetic acid) during EP1 was $1.46 \mathrm{~g} / 1$ compared with $1.13 \mathrm{~g} / 1$ in control reactor. The $\mathrm{pH}$ value was almost stable with $7.62 \pm 0.09$ on average. However, the change of feedstock composition had no significant effect on the overall process performance indicated by a constant biogas content $\left(\mathrm{R}^{2}=0.31 ; p=8.8 \times 10^{-16}\right)$.

In EP2, a gradual ongoing increase in the TAN was recorded and reached highest values of $6.3 \mathrm{~g} \mathrm{NH}_{4}{ }^{+}-\mathrm{N} / \mathrm{kg}_{\mathrm{FM}}$ with a corresponding $\mathrm{NH}_{3}$ content of $0.5 \mathrm{~g} / \mathrm{kg}_{\mathrm{FM}}$ at the end of this experimental phase. No evident alteration in the $\mathrm{pH}$ value was recorded during the EP2 which recorded an averaged value of $7.56 \pm 0.14$. Also, a gradual increase in the VFA content was recorded, which reached up to $15.5 \mathrm{~g} / 1$ at day 253. Presumably the increased VFA content and also the increased TAN/ $\mathrm{NH}_{3}$ content led to a decrease in the biogas yield as well as in the methane content (Fig. 1, first phase showing process disturbance resp. microbiome inhibition). Afterwards (from day 254 to day 309), a gradual increase in the TAN and a constant and stable VFA content of approximately $14.0 \pm 0.7 \mathrm{~g} / \mathrm{l}$ were recorded. So that, a short-termed stable biogas yield- indicated by comparatively constant biogas yield of $235.1 \pm 44.57 \mathrm{~L}_{\mathrm{N}} / \mathrm{kg}_{\mathrm{vs}}$ over 55 days- was recorded indicating a stabilisation of the process performance and microbial activity (Fig. 1, second phase showing short-termed stable biogas yield). After that and with continuous applying of $50 \%$ PM, an ongoing accumulation of the VFA was recorded resulting in VFA content of $38.1 \mathrm{~g} / 1$ accompanied with a decreasing in the biogas yield to $158.8 \mathrm{~L}_{\mathrm{N}} / \mathrm{kg}_{\mathrm{vs}}$ with a methane content of $35.8 \%$ at the end of EP2. The previous conditions symbolized a critical resp. significant process disturbance (Fig. 1, third phase showing process disturbance resp. microbiome inhibition).

\section{Alteration of the Microbial Community Structure in the Response of TAN Increase}

The dynamic variation of the microbial community was investigated by the fingerprinting method TRFLP targeting either the bacterial or the archaeal 16SrRNA genes based on the samples ER-81, ER-162, ER-199, ER-250, ER-300, and ER-340 from the ER, and CR- 81 and CR-340 of the CR, followed by taxonomic profiling of the microbial community by $16 \mathrm{~S}$ rRNA gene nucleotide sequence analysis of the samples ER-81, ER-250, ER-340, and CR-81.

The Shannon and the Richness indices for microbial diversity were calculated and presented in (Table 1). Both

Table 1. Statistical parameters of bacterial and archaeal 16S RNA gene libraries and TRFLP analysis for reactor effluent samples.

\begin{tabular}{|c|c|c|c|c|c|c|c|}
\hline \multirow{2}{*}{$\begin{array}{l}\text { Reactor resp. } \\
\text { AD experiment }\end{array}$} & \multirow{2}{*}{ AD substrate ${ }^{a}$} & \multirow{2}{*}{$\begin{array}{l}\text { Day of sampling } \\
\text { (day) }\end{array}$} & \multirow{2}{*}{$\begin{array}{c}\text { Sample } \\
\text { denomination }\end{array}$} & \multicolumn{2}{|c|}{ Shannon diversity } & \multicolumn{2}{|c|}{ Richness resp. no. of TRFs } \\
\hline & & & & Bacteria & Archaea & Bacteria & Archaea \\
\hline Control & $100 \%$ CS (vol/volVS $)$ & 81 & CR-81 & 3.12 & 0.977 & 21 & 8 \\
\hline \multirow{2}{*}{$\begin{array}{l}\text { Experimental } \\
\text { phase } 1(\mathrm{EP} 1)\end{array}$} & \multirow{2}{*}{$\begin{array}{l}25 \% \mathrm{PM}+75 \% \mathrm{CS} \\
\text { (vol/vol VS) }\end{array}$} & 81 & ER-81 & 3.24 & 0.806 & 22 & 8 \\
\hline & & 162 & ER-162 & - & - & 20 & 6 \\
\hline \multirow{4}{*}{$\begin{array}{l}\text { Experimental } \\
\text { phase } 2 \text { (EP2) }\end{array}$} & \multirow{4}{*}{$\begin{array}{l}50 \% \mathrm{PM}+50 \% \mathrm{CS} \\
\text { (vol/vol VS) }\end{array}$} & 199 & ER- 199 & - & - & 17 & 6 \\
\hline & & 250 & ER-250 & 2.87 & 0.223 & 13 & 7 \\
\hline & & 300 & ER-300 & - & - & 15 & 5 \\
\hline & & 340 & ER-340 & 3.10 & 0.532 & 13 & 6 \\
\hline Control & $100 \%$ CS (vol/volvS $)$ & 340 & CR-340 & 3.11 & 1.32 & 16 & 9 \\
\hline
\end{tabular}

aCS, cattle slurry; PM, poultry manure.

${ }^{b} \mathrm{VS}$, volatile substances. 
Table 2. Relative distribution of the terminal restriction fragments (TRFs) detected for Bacteria as the relative abundance of particular TRFs divided on the sum of relative abundance of all TRFs in the sample ( 0 , light green; 1 to 4 , green; 5 to 9 , yellow; 10 to 14 , orange; $\geq 15$, red).

\begin{tabular}{|c|c|c|c|c|c|c|c|c|c|}
\hline \multirow{4}{*}{$\begin{array}{l}\text { AD substrate } \\
\text { Day of sampling (day) } \\
\text { Sample } \\
\text { denomination }\end{array}$} & \multirow{3}{*}{$\begin{array}{c}\text { Control } \\
100 \% \text { CS } \\
\frac{(\text { vol/vol VS })}{81}\end{array}$} & \multirow{2}{*}{\multicolumn{2}{|c|}{$\begin{array}{c}\text { Experimental phase } 1 \\
\text { (EP1) } \\
25 \% \text { PM + 75\% CS } \\
\text { (vol/vol VS) }\end{array}$}} & \multirow{2}{*}{\multicolumn{4}{|c|}{$\begin{array}{c}\text { Experimental phase } 2 \\
\text { (EP2) } \\
50 \% \mathrm{PM}+50 \% \mathrm{CS} \\
\text { (vol/vol VS) }\end{array}$}} & \multirow{3}{*}{$\begin{array}{c}\begin{array}{c}\text { Control } \\
100 \% \text { CS } \\
\text { (vol/vol VS) }\end{array} \\
340\end{array}$} & \\
\hline & & & & & & & & & \\
\hline & & 81 & 162 & 199 & 250 & 300 & 340 & & \\
\hline & CR-81 & ER- 81 & ER-162 & $\begin{array}{l}\text { ER- } \\
199\end{array}$ & $\begin{array}{l}\text { ER- } \\
250\end{array}$ & $\begin{array}{l}\text { ER- } \\
300\end{array}$ & $\begin{array}{l}\text { ER- } \\
340\end{array}$ & CR-340 & \\
\hline $\begin{array}{l}\text { Gini } \\
\text { coefficient }\end{array}$ & 0.43 & 0.35 & 0.40 & 0.39 & 0.40 & 0.40 & 0.43 & 0.40 & \\
\hline TRF $[\mathrm{bp}]$ & \multicolumn{8}{|c|}{ Relative abundance (\%) } & Phylogenetic assignment of detected $\mathrm{TRFs}^{\mathrm{c}}$ \\
\hline 75 & 2 & 2 & 3 & 2 & 0 & 0 & 4 & 3 & $\begin{array}{l}\text { Firmicutes, Bacilli, Lactobacillales } \\
\text { (Firmicutes, Clostridia) }\end{array}$ \\
\hline 94 & 7 & 7 & 3 & 2 & 0 & 0 & 0 & 6 & Firmicutes, Bacilli, Bacillales (Bacteroidetes) \\
\hline 99 & 5 & 5 & 5 & 6 & 8 & 3 & 8 & 0 & Firmicutes, Clostridia, Natranaerobiales \\
\hline 141 & 5 & 5 & 8 & 7 & 0 & 0 & 0 & 0 & $\begin{array}{l}\text { Firmicutes, Clostridia (Actinobacteria, } \\
\text { Actinobacteria, Actinomycetales) }\end{array}$ \\
\hline 150 & 14 & 14 & 27 & 23 & 26 & 21 & 21 & 22 & $\begin{array}{l}\text { Firmicutes, Bacilli, Bacillales } \\
\text { (Firmicutes, Clostridia) }\end{array}$ \\
\hline 154 & 0 & 0 & 4 & 7 & 8 & 10 & 9 & 0 & Firmicutes, Bacilli, Lactobacillales \\
\hline 159 & 4 & 4 & 0 & 0 & 0 & 0 & 0 & 0 & Firmicutes, Clostridia, Thermoanaerobacterales \\
\hline 161 & 2 & 2 & 3 & 0 & 2 & 3 & 3 & 0 & $\begin{array}{l}\text { Firmicutes, Clostridia (Actinobacteria, } \\
\text { Actinobacteria, Actinomycetales) }\end{array}$ \\
\hline 166 & 3 & 3 & 4 & 6 & 6 & 7 & 6 & 0 & $\begin{array}{l}\text { Firmicutes, Erysipelotrichia, Erysipelotrichales } \\
\text { (Firmicutes, Clostridia, Clostridiales) }\end{array}$ \\
\hline 169 & 2 & 2 & 2 & 3 & 4 & 4 & 4 & 0 & Firmicutes, Clostridia, Clostridiales \\
\hline 177 & 3 & 3 & 6 & 4 & 3 & 0 & 3 & 5 & Firmicutes, Bacilli, Bacillales \\
\hline 180 & 8 & 8 & 10 & 10 & 9 & 8 & 10 & 9 & Firmicutes $^{\mathrm{d}}$ \\
\hline 190 & 5 & 5 & 0 & 6 & 7 & 8 & 0 & 10 & Firmicutes, Clostridia, Clostridiales \\
\hline 194 & 3 & 3 & 3 & 3 & 3 & 3 & 0 & 5 & Firmicutes, Clostridia, Clostridiales \\
\hline 198 & 0 & 0 & 0 & 2 & 3 & 3 & 2 & 0 & $\mathrm{nd}^{\mathrm{e}}$ \\
\hline 205 & 2 & 2 & 2 & 2 & 0 & 2 & 0 & 4 & Firmicutes, Clostridia, Clostridiales \\
\hline 213 & 0 & 0 & 0 & 3 & 11 & 2 & 4 & 3 & $\begin{array}{l}\text { Proteobacteria, Gammaproteobacteria, } \\
\text { Pseudomonadales (Xanthomonadales) }\end{array}$ \\
\hline 216 & 5 & 5 & 8 & 7 & 3 & 3 & 0 & 6 & $\begin{array}{l}\text { Firmicutes, Bacilli, Lactobacillales } \\
\text { (Clostridia, Clostridiales) }\end{array}$ \\
\hline 228 & 0 & 0 & 2 & 0 & 0 & 2 & 0 & 5 & Bacteria $^{3}$ \\
\hline 288 & 2 & 2 & 4 & 3 & 0 & 0 & 0 & 3 & Firmicutes, Clostridia, Clostridiales \\
\hline 294 & 3 & 2 & 2 & 0 & 0 & 0 & 0 & 2 & Firmicutes, Clostridia, Clostridiales \\
\hline 367 & 2 & 2 & 2 & 0 & 0 & 0 & 0 & 2 & Firmicutes, Clostridia, Halanaerobiales \\
\hline 376 & 2 & 2 & 0 & 0 & 0 & 0 & 0 & 0 & Firmicutes, Clostridia, Halanaerobiales \\
\hline 453 & 3 & 3 & 0 & 0 & 0 & 0 & 0 & 2 & Firmicutes, Clostridia, Clostridiales \\
\hline 466 & 0 & 0 & 0 & 0 & 0 & 0 & 2 & 0 & nd \\
\hline 502 & 3 & 3 & 2 & 0 & 0 & 0 & 0 & 3 & nd \\
\hline 558 & 0 & 0 & 0 & 0 & 0 & 3 & 2 & 0 & Firmicutes, Bacilli, Lactobacillales \\
\hline 571 & 0 & 3 & 2 & 0 & 0 & 0 & 0 & 0 & nd \\
\hline
\end{tabular}

TRFs with relative abundance $>=2 \%$ were shown.

${ }^{\mathrm{a} C S}$, cattle slurry; PM, poultry manure.

bV, volatile substances.

'In case of alternative sequencing or taxonomic identification results, corresponing taxonomic affiliation is given in brackets.

${ }^{\mathrm{d}}$ Lowest taxonomic rank.

'nd, not determined. 
indices were considerably higher for bacterial than for archaeal communities in both control and experimental reactors. Also the bacterial community organisation in all samples was more even than the archaeal one. At the same time, the Richness indices for both bacterial and archaeal communities were lower in thermophilic condition compared to mesophilic ones as was previously shown by Alsouleman et al. (Data not show) [20] and also was in accordance with [50], reporting that the thermophilic microbiome has lower diversity than the mesophilic one.

In the CR, the highest diversity was recorded for the bacterial and archaeal communities compared to the experimental reactor (Table 1). The bacterial community of the CR reactor at both sample points (CR-81 and CR-340) consisted mainly of members belonging to the phylum Firmicutes from orders Clostridiales, Bacillales, and Halanaerobiales (Table 2). The methanogenic community included members belonging to genera Methanosarcina, Methanobrevibacter, Methanothermobacter, and Methanoculleus (Table 3).

In the ER, during EP1, no significant changes were detected in the overall reactor performance. Interestingly, between sampling day 81 (sample ER-81) and 162 (sample

Table 3. Relative distribution of the terminal restriction fragments (TRFs) detected for Archaea as the relative abundance of particular TRFs divided on the sum of relative abundance of all TRFs in the sample ( 0 , light green; 1 to 4 , green; 5 to 9 , yellow; 10 to 14 , orange; $\geq 15$, red).

\begin{tabular}{|c|c|c|c|c|c|c|c|c|c|}
\hline $\begin{array}{l}\text { Reactor resp. } \\
\text { AD experiment }\end{array}$ & Control & \multirow{2}{*}{\multicolumn{2}{|c|}{$\begin{array}{c}\text { Experimental phase } 1 \\
\text { (EP1) } \\
25 \% \text { PM }+75 \% \text { CS } \\
\text { (vol/vol VS) } \\
\end{array}$}} & \multirow{2}{*}{\multicolumn{4}{|c|}{$\begin{array}{l}\text { Experimental phase } 2 \\
\text { (EP2) } \\
50 \% \mathrm{PM}+50 \% \mathrm{CS} \\
\text { (vol/vol VS) }\end{array}$}} & \multirow{3}{*}{$\begin{array}{c}\begin{array}{c}\text { Control } \\
100 \% \mathrm{CS} \\
\text { (vol/vol VS) } \\
340\end{array}\end{array}$} & \\
\hline AD substrate $^{\mathrm{a}}$ & $\begin{array}{c}100 \% \mathrm{CS} \\
(\mathrm{vol} / \mathrm{vol} \mathrm{VS})\end{array}$ & & & & & & & & \\
\hline $\begin{array}{l}\text { Day of } \\
\text { sampling (day) }\end{array}$ & 81 & 81 & 162 & 199 & 250 & 300 & 340 & & \\
\hline $\begin{array}{l}\text { Sample } \\
\text { denomination }\end{array}$ & CR-81 & ER-81 & ER-162 & $\begin{array}{l}\text { ER- } \\
199\end{array}$ & $\begin{array}{l}\text { ER- } \\
250\end{array}$ & $\begin{array}{l}\text { ER- } \\
300\end{array}$ & $\begin{array}{l}\text { ER- } \\
340\end{array}$ & CR-340 & \\
\hline $\begin{array}{l}\text { Gini } \\
\text { coefficient }\end{array}$ & 0.47 & 0.5 & 0.56 & 0.59 & 0.51 & 0.64 & 0.61 & 0.54 & \\
\hline TRF [bp] & & & Relative ab & undan & ce $(\%)$ & & & & $\begin{array}{l}\text { Phylogenetic assignment of detected TRFs } \\
\text { within phylum Euryarchaeota }\end{array}$ \\
\hline 68 & 0 & 4 & 5 & 4 & 3 & 0 & 0 & 0 & $\mathrm{nd}^{c}$ \\
\hline 73 & 2 & 6 & 6 & 7 & 9 & 5 & 5 & 3 & $\begin{array}{l}\text { Methanomicrobia, Methanosarcinales, } \\
\text { Methanosarcinaceae, Methanosarcina }\end{array}$ \\
\hline 84 & 0 & 0 & 0 & 0 & 3 & 0 & 0 & 2 & $\begin{array}{l}\text { Methanomicrobia, Methanosarcinales, } \\
\text { Methanosarcinaceae, Methanosarcina }\end{array}$ \\
\hline 108 & 9 & 22 & 3 & 4 & 5 & 3 & 3 & 1 & $\begin{array}{l}\text { Methanomicrobia, Methanomicrobiales, } \\
\text { Methanomicrobiaceae, Methanoculleus }\end{array}$ \\
\hline 173 & 4 & 7 & 7 & 7 & 7 & 5 & 5 & 5 & nd \\
\hline 317 & 1 & 5 & 6 & 3 & 4 & 3 & 4 & 2 & $\begin{array}{l}\text { Methanobacteria, Methanobacteriales, } \\
\text { Methanobacteriaceae, Methanothermobacter }\end{array}$ \\
\hline 342 & 6 & 5 & 3 & 0 & 0 & 0 & 3 & 3 & $\begin{array}{l}\text { Methanobacteria, Methanobacteriales, } \\
\text { Methanobacteriaceae, Methanothermobacter }\end{array}$ \\
\hline 336 & 26 & 33 & 52 & 59 & 48 & 68 & 68 & 29 & $\begin{array}{l}\text { Methanobacteria, Methanobacteriales, } \\
\text { Methanobacteriaceae, Methanobrevibacter }\end{array}$ \\
\hline 471 & 3 & 0 & 0 & 0 & 0 & 0 & 0 & 3 & $\begin{array}{l}\text { Methanomicrobia, Methanosarcinales, } \\
\text { Methanosarcinaceae, Methanosarcina }\end{array}$ \\
\hline 627 & 28 & 4 & 0 & 0 & 0 & 0 & 0 & 29 & $\begin{array}{l}\text { Methanomicrobia, Methanosarcinales, } \\
\text { Methanosarcinaceae, Methanosarcina }\end{array}$ \\
\hline
\end{tabular}



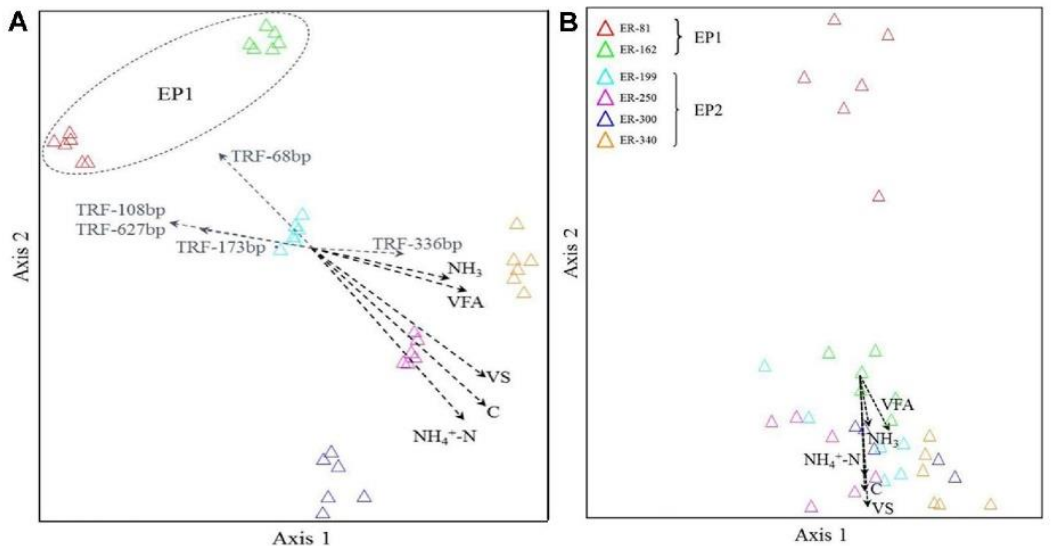

Fig. 2. Non-metric multidimensional scaling (NMS) of the effects of the prevalent process parameters in the experimental reactor (ER) in terms of ammonium nitrogen $\left(\mathrm{NH}_{4}^{+}\right)$, free ammonia nitrogen $\left(\mathrm{NH}_{3}\right)$, total volatile fatty acids (VFA), volatile solids (VS) and conductivity $(\mathrm{C})$ on the bacterial and archaeal community structure.

The $\mathrm{x}$-axis symbolizes the distance in ordinations space while the y-axis symbolizes the dissimilarity of the investigated objects. EP1, EP2 indicate exprimental phases. Sampling points are indicated by triangles. TRFs indicate detected methanogenic archaea.

ER-162), a definite shift in both the fermentative bacteria community and the methanogenic archaea community was observed (Fig. 2). The Gini coefficients of the bacterial community and the archaeal communities of ER-81 were 0.35 resp. 0.50 , and for ER-162 were 0.40 resp. 0.56 which indicate a well-balanced community composition at both process stages as they were in the medium range of the community organisation.

Similar to the CR, in the ER the most abundant member of the bacterial community were also belonged to the order Clostridiales followed by members of the order Bacillales (Table 2). This result was supported by the performed indicator species analysis where the highest significant indicator values (IV $=100 ; p \leq 0.05)$ in this phase were found for the TRFs related to the order Clostridiales independent from the tested process factors (data not shown). The calculated pairwise distance between the bacterial communities of CR-81 and ER-81 resp. ER-162 showed a change in the bacterial community composition in the ER of up to $17 \%$ (Table 4 ).

In the ER, the archaeal community during the EP1 showed more distinct changes in their composition as the relative abundance of members belonging to the genus Methanobrevibacterreached increased to $52 \%$ of the entire archaeal community in the ER-162 comparing by $26 \%$ in control reactor (Table 3). This increase through the whole experimental phase was accompanied with a apparent decrease in the relative abundance of members belonging to the family Methanosarcinaceae TRF-627. While other members of this genus did not affect (e.g., TRF-73) similar to members of genus Methanothermobacter (TRF-317). The calculated pairwise distance between the archaeal communities of CR-81 and ER-81 resp. ER-162 showed a change in the archaeal community composition in the ER of up to $32 \%$ (Table 5).In the ER and during the EP2 (which was divided into three phases depending on the reactor performance (Fig. 1), Shannon's diversity index for the bacterial community of the sample ER-250 reflected the lowest diversity of the microbial community during the entire experimental phase (Table 1 ).

A slight alteration in the structure of the bacterial community in sample ER-199, the first disturbance phases (Fig. 1), was detected (Table 2). This slight alteration was also supported by the calculated pairwise distance between the bacterial communities of ER-162 and ER-199, which reached up to $9 \%$ (Table 4 ).

For members of class Euryarchaeota, a clear decrease in the relative abundance of the genus Methanothermobacter accompanied with a continuous increase in the relative abundance of the genus Methanobrevibacter was detected (Table 3).

Between day 250 and day 300 (Fig. 1, second phase 
Table 4. Similarity matrix in comparison of the bacterial communities.

\begin{tabular}{|c|c|c|c|c|c|c|c|c|}
\hline \multirow{3}{*}{$\begin{array}{l}\text { Reactor resp. AD experiment } \\
\text { AD substrate }^{\mathrm{a}} \\
\text { Day of sampling (day) }\end{array}$} & \multirow{3}{*}{$\begin{array}{c}\begin{array}{c}\text { Control } \\
100 \% \mathrm{CS} \\
\left(\mathrm{vol} / \mathrm{vol} \mathrm{VS}^{b}\right)\end{array} \\
81\end{array}$} & \multirow{2}{*}{\multicolumn{2}{|c|}{$\begin{array}{c}\text { Experimental phase } 1 \text { (EP1) } \\
25 \% \mathrm{PM}+75 \% \mathrm{CS} \\
\text { (vol/vol VS) }\end{array}$}} & \multirow{2}{*}{\multicolumn{4}{|c|}{$\begin{array}{c}\text { Experimental phase } 2 \text { (EP2) } \\
50 \% \mathrm{PM}+50 \% \mathrm{CS} \\
\text { (vol/vol VS) }\end{array}$}} & \multirow{3}{*}{$\begin{array}{c}\begin{array}{c}\text { Control } \\
100 \% \text { CS } \\
\text { (vol/vol VS) }\end{array} \\
340\end{array}$} \\
\hline & & & & & & & & \\
\hline & & 81 & 162 & 199 & 250 & 300 & 340 & \\
\hline Sample & CR-81 & ER-81 & ER-162 & ER-199 & ER-250 & ER-300 & ER-340 & CR-340 \\
\hline CR-81 & 100 & 99 & 83 & 81 & 65 & 62 & 60 & 81 \\
\hline ER-81 & & 100 & 84 & 81 & 65 & 62 & 60 & 81 \\
\hline ER-162 & & & 100 & 91 & 77 & 75 & 80 & 78 \\
\hline ER-199 & & & & 100 & 89 & 88 & 84 & 79 \\
\hline ER-250 & & & & & 100 & 91 & 91 & 71 \\
\hline ER-300 & & & & & & 100 & 86 & 71 \\
\hline ER-340 & & & & & & & 100 & 57 \\
\hline CR-340 & & & & & & & & 100 \\
\hline
\end{tabular}

showing short-termed stable biogas yield), the calculated pairwise distance between the bacterial communities of ER-250 and ER-300 showed a change in the bacterial community composition of up to $9 \%$ (Table 4 ).

Regarding the archaeal community, an increase in the relative abundance of the genus Methanobrevibacter was recorded which formed $68 \%$ of the entire archaeal community structure, whereby members belonging to the genus Methanosarcina completely disappeared (Table 3).
At the end of the fermentation experiment, in sample ER340 , the most abundant members of the bacterial community were also belonged to the phylum Firmicutes mainly from the orders Bacillales, followed by members of the order Lactobacillales and Clostridiales (Table 2).

In the course of the experiment, the trend of the archaeal community organization moved in the same way as ER199 , and the most abundant members were belonged to the genus Methanobrevibacter, whereby members belonging to

Table 5. Similarity matrix in comparison of the archaeal communities.

\begin{tabular}{|c|c|c|c|c|c|c|c|c|}
\hline \multirow{3}{*}{$\begin{array}{l}\text { Reactor resp. AD experiment } \\
\text { AD substrate }^{\mathrm{a}} \\
\text { Day of sampling (day) }\end{array}$} & \multirow{3}{*}{$\begin{array}{c}\text { Control } \\
100 \% \text { CS } \\
(\text { vol/vol VS }) \\
81\end{array}$} & \multirow{2}{*}{\multicolumn{2}{|c|}{$\begin{array}{l}\text { Experimental phase } 1 \text { (EP1) } \\
25 \% \mathrm{PM}+75 \% \mathrm{CS} \\
\text { (vol/vol VS) }\end{array}$}} & \multirow{2}{*}{\multicolumn{4}{|c|}{$\begin{array}{c}\text { Experimental phase } 2 \text { (EP2) } \\
50 \% \mathrm{PM}+50 \% \mathrm{CS} \\
\text { (vol/vol VS) }\end{array}$}} & \multirow{3}{*}{$\begin{array}{c}\begin{array}{c}\text { Control } \\
100 \% \mathrm{CS}\end{array} \\
\text { (vol/vol VS } \\
340\end{array}$} \\
\hline & & & & & & & & \\
\hline & & 81 & 162 & 199 & 250 & 300 & 340 & \\
\hline Sample & CR-81 & ER-81 & ER-162 & ER-199 & ER-250 & ER-300 & ER-340 & CR-340 \\
\hline CR-81 & 100 & 93 & 68 & 63 & 65 & 61 & 60 & 90 \\
\hline ER-81 & & 100 & 66 & 77 & 67 & 65 & 63 & 79 \\
\hline ER-162 & & & 100 & 79 & 83 & 82 & 80 & 72 \\
\hline ER-199 & & & & 100 & 86 & 85 & 84 & 70 \\
\hline ER-250 & & & & & 100 & 88 & 86 & 56 \\
\hline ER-300 & & & & & & 100 & 90 & 53 \\
\hline ER-340 & & & & & & & 100 & 52 \\
\hline CR-340 & & & & & & & & 100 \\
\hline
\end{tabular}

The calculated pairwise similarity considered both, changes in the number and the relative abundance of each detected terminal restriction fragment within and between two samples depending on Pearson algorithm.

${ }^{a} \mathrm{CS}$, cattle slurry; PM, poultry manure.

${ }^{b} \mathrm{VS}$, volatile substances. 
the genus Methanosarcina completely disappeared (Table 3) After this inhibited steady state phase, a severe perturbation in the process performance was recorded.

\section{Discussion}

In the $\mathrm{CR}, \mathrm{AD}$ was performed by members of the bacterial phylum Firmicutes in combination with obligate or facultative hydrogenotrophic methanogens, namely of genera Methanosarcina, Methanobrevibacter, Methanothermobacter, and Methanoculleus. The predominance of the Firmicutes phylum is mostly explained by its capability to produce diverse enzymes performing celluloylsis, hydrolysis, acidogenesis, and acetogenesis. This microbial structure under thermophilic conditions was in accordance with previously published results and supported the assumption of more or less stable microbial biocenoses and metabolic activity in the CR [11, 23, 51-53]. The moderate alteration in the microbial community structure in the CR between sampling days 81 and 340 with constant biogas yields can be assumed to be more related to the natural development of the microbial community itself (Table 4)

In the ER, during EP1, no significant effects on the reactor performance were recorded. The TAN reached a maximum of $3 \mathrm{~g} / \mathrm{kg}_{\mathrm{FM}}$ with a corresponding $\mathrm{NH}_{3}$ content of $0.4 \mathrm{~g} / \mathrm{kg}_{\mathrm{FM}}$, values which are lower than the published thresholds for process inhibition [11, 14, 54]. Even a slight increase in the VFA concentrations was recorded in this experimental phase, the degradation process run stably. It is assumed that the increase in the TAN concentration led to an increase in the buffer capacity, which supports a stable process. The recorded VFAs concentrations were lower than the recorded inhibition thresholds [55, 56].

Nevertheless, it is known that the used feedstock can affect the microbial community structure [57-60]. Hence, in this study, a definite shift in the microbiome structure was observed between ER-81 and ER-162 in the EP1, according to $25 \% \mathrm{PM}$ addition as well as the consequent abiotic parameters. In the first sample ER- 81 of the EP1 a minor change in the microbial community structure was recorded as was indicated by the changes of the relative abundance of the detected archaeal and bacterial TRFs. While in the second sample ER-162 of EP1, a clear shift was detected as indicated by the similarity values (Tables 4 and $5)$, the relative abundance of the detected archaeal and bacterial TRFs (Tables 2 and 3) in addition to the NMS analysis. The NMS revealed no significant correlation between the investigated process parameters and the related arrangement of the bacterial community in the EP1.
So that the bacterial community of EP1 (ER-81 and ER-162) formed a separate cluster (Fig. 2), while the archaeal community structure already showed a clear shift during EP1 as the archaeal community of the first sample of EP1 (ER-81) formed a separate cluster (Fig. 2).

It can be assumed that functional redundancy was the primary microbial strategy in EP1, ensuring an ongoing and stable biogas production as the compositional shifts did not affect significantly the reactor performance [61, 62]. The results of this study showed that the phylum Firmicutes was the most abundant phylum during the whole experimental phase which was shown previously $[63,64]$

The archaeal community in EP1 seemed to have lower tolerance values for the elevated TAN. The more sensitive response of the archaeal community was related to a clear decrease in the abundance of some obligate (Methanoculleus) or facultative (Methanosarcina) hydrogenotrophic methanogens which accompanied with a substantial increase in the abundance of other and exclusively hydrogenotrophic genus Methanobrevibacter (Table 2). These results are in accordance with $[22,50]$ reporting that the obligate or facultative acetoclastic methanogens dominate the archaeal community preferentially at medium TAN, VFA, and/or salt concentrations. High concentrations of these parameters in combination with thermophilic conditions were positively correlated with a predominance of obligate hydrogenotrophic methanogens.

Hydrogenotrophic methanogens utilize carbon dioxide $\left(\mathrm{CO}_{2}\right)$ and molecular hydrogen $\left(\mathrm{H}_{2}\right)$ for methane production. Thus, the acetate produced by fermentative bacteria has to be converted via the acetate oxidation pathway performed by syntrophic bacteria $[65,66]$. This fact could explain the previous slight recorded changes within the bacterial community composition of the EP1. To conclude, the shift within the microbial community was the result of a synergetic effect of physical (temperature) and chemical (partial feedstock change) factors which had no effects on the overall process performance.

In the second experimental phase (EP2; day 177- 341) the amount of PM was doubled to $50 \%$ (vol/vol based on VS). As expected, shortly after starting EP2, the reactor performance was distinctly negatively influenced symbolized by a decrease in both the biogas yield and the methane content which was significantly related to a gradual increase in the $\mathrm{NH}_{4}^{+}-\mathrm{N}$ and $\mathrm{NH}_{3}$ as well as the VFA concentrations (Fig. 1).

The high VFA and TAN concentrations led to the presence of them in their un-dissociated forms, which are more toxic for microorganisms $[67,68]$. 
As is known, in a highly buffered system like this system, the VFA is the best indicator for indicating process imbalance and reactor failure [69]). The relative alteration of the VFA concentration in EP2 reached to $36 \mathrm{~g} / 1$ compared with $1.13 \mathrm{~g} / \mathrm{l}$ in the control reactor.
During EP2, a three-stage process disturbance was recorded: an initial disturbance (as mentioned above), a short-termed stable biogas yield stage, and a final complete process disturbance resulting in complete process failure. The initial accumulation in a VFA led to a drop in the $\mathrm{pH}$

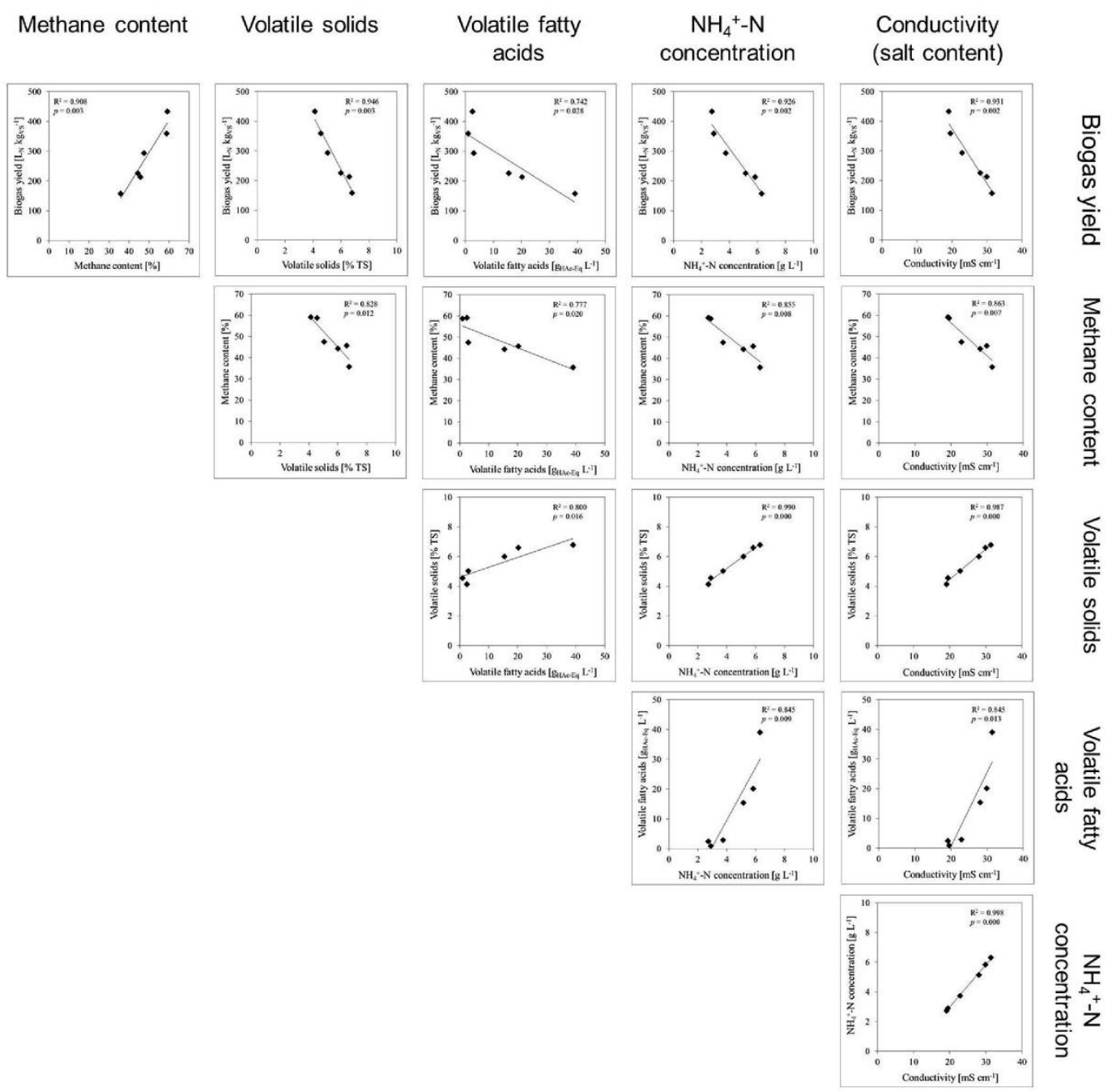

Fig. 3. Correlation matrix indicated by linear regression among and between the operational parameters.

The operational parameter values were determined for 6 sampling points of the experimental reactor. Statistical significance was established at the $p<0.05$ level. 
value and hence, a decrease in the $\mathrm{NH}_{3}$ content (between day 250 and 270, Fig. 1). It can be assumed that these conditions encouraged the microbial communities especially the archaeal community to adapt and recover again which could be interpreted the subsequent process stability at elevated TAN but with a lower biogas yield and methane content [14].

The reason for the final reactor performance deterioration could not be related to one, but rather to different prevalent environmental factors (Fig. 3).This is reflected in the NMS analyses results which showed that the variation within the bacterial and the archaeal community structure community in EP2 could be related to different parameters; VFA, $\mathrm{NH}_{4}{ }^{+} \mathrm{N}$, $\mathrm{NH}_{3}$, salt content, and/or VS (Fig. 2). The salt content was symbolized in our study by the conductivity which reached to the reported threshold value of $30 \mathrm{mS} / \mathrm{cm}[57$, 70]. Here, it could be assumed depending on our finding that, the alteration in the microbial community structure in the ER was more related to the strong impact of the PM addition (Table 4). As the methanogenic activity is seriously inhibited, it can be assumed that the growth of acid converting bacteria is restricted as they can only grow if the $\mathrm{H}_{2}$ is consumed by their syntrophic archaeal partners which subsequently led to a VFA accumulation of more than $38 \mathrm{~g} / 1$ at the end of this experimental phase. Based on these findings and in comparison with an $\mathrm{AD}$ experiment performed under the same but mesophilic conditions [20], an anaerobic microbiome adapted to thermophilic conditions can be assumed as much more sensitive for process disturbances in consequence of biomass load with high contents of organic nitrogen.

\section{Acknowledgments}

This study was supported by the Erasmus Mundus Joseleen Programm provided by the European Commission (grant number FIIR 2010/34) as well as by the Leibniz Institute for Agricultural Engineering and Bioeconomy Potsdam-Bornim. I would like to thank Prof. Bernd Linke for his support in developing this project. I would like also to thank Dr. Michael Klocke for his valuable participation in the discussions of results and data interpretation. Kerstin Mundt and Carsten Jost are thanked for their excellent technical support.

\section{Conflict of Interest}

The authors have no financial conflicts of interest to declare.

\section{References}

1. Barret M, Gagnon N, Morissette B, Kalmokoff ML, Topp E, Brooks SPJ, et al. 2015. Phylogenetic identification of methanogens assimilating acetate-derived carbon in dairy and swine manures. Syst. Appl. Microbiol. 38: 56-66.

2. Börjesson P, Berglund M. 2007. Environmental systems analysis of biogas systems - Part II: Environmental impact of replacing various reference systems. Biomass Bioenergy 31: 326-344.

3. Arthurson V. 2009. Closing the global energy and nutrient cycles through application of biogas residues to agricultural land - potential benefits and drawbacks. Energies 2: 226-242.

4. Abbassi-Guendouz A, Brockmann D, Trably E, Dumas C, Delgenès JP, Steyer JP, et al. 2012. Total solids content drives high solid anaerobic digestion via mass transfer limitation. Bioresour. Technol. 111: 55-61.

5. Ahring BK. 1993. Perspectives for anaerobic digestion. Adv. Biochem. Eng. Biotechnol. 81: 1-30.

6. Shi J, Wang Z, Stiverson JA, Yu Z, Li Y. 2013. Reactor performance and microbial community dynamics during solid-state anaerobic digestion of corn stover at mesophilic and thermophilic conditions. Bioresour. Technol. 136: 574-581.

7. Wilson CA, Murthy SM, Fang Y, Novak JT. 2008. The effect of temperature on the performance and stability of thermophilic anaerobic digestion. Water Sci. Technol. 57: 297-304.

8. Akyol Ç, Turker G, Ince O, Ertekin E, Üstünerc O, Incea B. 2016. Performance and microbial community variations in thermophilic anaerobic digesters treating OTC medicated cow manure under different operational conditions. Bioresour. Technol. 205: 191-198.

9. Guo X, Wang C, Sun F, Zhu W, Wu W. 2014. A comparison of microbial characteristics between the thermophilic and mesophilic anaerobic digesters exposed to elevated food waste loadings. Bioresour. Technol. 152: 420-428.

10. Hori T, Haruta S, Sasaki D, Hanajima D, Ueno Y, Ogata A, et al. 2015. Reorganization of the bacterial and archaeal populations associated with organic loading conditions in a thermophilic anaerobic digester. J. Biosci. Bioeng. 19: 337-344.

11. Niu QG, Qiao W, Qiang H, Li YY. 2013. Microbial community shifts and biogas conversion computation during steady, inhibited and recovered stages of thermophilic methane fermentation on chicken manure with a wide variation of ammonia. Bioresour. Technol. 146: 223-233.

12. Hashimoto AG. 1986. Ammonia inhibition of methanogenesis from cattle wastes. Agricultural Wastes. 17: 241-261.

13. Koster IW, Lettinga G. 1988. Anaerobic digestion at extreme ammonia concentrations. Biological Wastes. 25:51-59.

14. Angelidaki I, Ahring BK. 1993. Thermophilic anaerobic digestion of livestock waste: the effect of ammonia. Appl. Biochem. Biotechnol. 38: 560-564.

15. Poggi-Varaldo HM, Rodriguez-Vazquez R, FernandezVillagomez G, Esparza-Garcia F. 1997. Inhibition of mesophilic 
solid substrate anaerobic digestion by ammonia nitrogen Appl. Microbiol. Biotechnol. 47: 284-291.

16. Gallert C, Winter J. 1997. Mesophilic and thermophilic anaerobic digestion of source-sorted organic wastes: effect of ammonia on glucose degradation and methane production. Appl. Microbiol. Biotechnol. 48: 405-410.

17. Hansen KH, Angelidaki I, Ahring BK.1998. Anaerobic digestion of swine manure: inhibition by ammonia. Water Res. 32: 5-12.

18. Sung S, Liu T. 2003. Ammonia inhibition on thermophilic anaerobic digestion. Chemosphere 53: 43-52.

19. Nakakubo R, Moller HB, Nielsen AM, Matsuda J. 2008. Ammonia inhibition ofmethanogenesis and identification of process indicators during anaerobic digestion. Environ. Eng. Sci. 25: 1487-1496.

20. Alsouleman $K$, Linke B, Klang J, Klocke M, Krakat N Theuerl S. 2016. Reorganisation of a mesophilic biogas microbiome as response to a stepwise increase of ammonium nitrogen induced by poultry manure supply. Bioresour. Technol. 208: 200-204.

21. Hao L, Lü F, Mazéas L, Quémnér ED, Madigou C, Guenne A, et al. 2015. Stable isotope probing of acetate fed anaerobic batch incubations shows a partial resistance of acetoclastic methanogenesis catalyzed by Methanosarcina to sudden increase of ammonia level. Water Res. 69: 90-99.

22. Fotidis I, Karakashev D, Angelidaki I. 2014. The dominant acetate degradation pathway/methanogenic composition in full-scale anaerobic digesters operating under different ammonia levels. Int. J. Environ. SciTe. 11: 2087-2094.

23. Rademacher A, Nolte C, Schönberg M, Klocke M. 2012. Temperature increases from 55 to $75^{\circ} \mathrm{C}$ in a two-phase biogas reactor result in fundamental alterations within the bacterial andarchaeal community structure. Appl. Microbiol. Biotechnol. 96: 565-576.

24. Yabu H, Sakai C, Fujiwara T, Nishio N, Nakashimada Y. 2011. Thermophilic two-stage dryanaerobic digestion of model garbage with ammonia stripping. J. Biosci. Bioeng. 111: 312319.

25. Weiss A, Jérôme V, Freitag R, Mayer HK. 2008. Diversity of the resident microbiota in a thermophilic municipal biogas plant. Appl. Microbiol. Biotechnol. 81: 163-173.

26. Niu Q, Kubota K, Qiao W, Jing Z, Zhang Y, Yu-You L. 2014 Effect of ammonia inhibition on microbial community dynamic and process functional resilience in mesophilic methane fermentation of chicken manure. J. Chem. Technol. Biotechnol. 90: 2161-2169.

27. Yenigün O, Demirel B. 2013. Ammonia inhibition in anaerobic digestion: a review. Process Biochem. 48: 901-911.

28. Hill R, Saetnan ER, Scullion J, Gwynn-Jones D, Ostle N, Edwardset A.2016. Temporal and spatial influences incur reconfiguration of Arctic heathland soil bacterial community structure. Environ. Microbiol. 18: 1942-1953.
29. Ji Y, Angel R, Klose M, Claus P, Marotta H, Pinho L, et al. 2016. Structure and function of methanogenicmicrobial communities in sediments of Amazonian lakes with different water types. Environ. Microbiol. 18: 5082-5100.

30. Van Goethem MW, Makhalanyane TP, Valverde A, Cary SC, Cowan DA. 2016. Characterization of bacterial communities in lithobionts and soil niches from Victoria Valley, Antarctica. FEMS Microbiol. Ecol. 92: fiw051.

31. Weise L, Ulrich A, Moreano M, Gessler A, Kayler ZE, Steger K, et al. 2016. Water level changesaffect carbon turnover and microbial community composition in lake sediments. FEMS Microbiol. Ecol. 92: fiw035.

32. Cabezas A, de Araujo JC, Callejas C, Gales, A. Hamelin J, Marone A, et al. 2015. How to use molecular biology tools for the study of the anaerobic digestion process? Rev. Environ. Sci. Bio-Technol. 14: 555-593.

33. Van Dorst J, Bissett A, Palmer AS, Brown M, Snape I, Stark JS, et al. 2014. Community fingerprinting in a sequencing world. FEMS Microbiol. Ecol. 89: 316-330.

34. Sboner A, Mu XJ, Greenbaum D, Auerbach RK, Gerstein MB. 2011. The real cost of sequencing: higher than you think! Genome Biol. 12(8): 125.

35. TalbotG, Topp E, Palin MF, Massé DI. 2008. Evaluation of molecular methods used for establishing the interactions and functions of microorganisms in anaerobic bioreactors. Water Res. 42: 513-537.

36. De Vrieze J, Ijaz UZ, Saunders AM, Theuerl S. 2018. Terminal restriction fragment length polymorphism is an "old school" reliable technique for swift microbial community screening in anaerobic digestion. Sci. Rep. 8: 16818.

37. Bühligen F, Lucas R, Nikolausz M, Kleinsteuber SA.2016. T-RFLP database for the rapid profiling of methanogenic communities in anaerobic digesters. Anaerobe. 39: 114-116.

38. Prakash O, Pandey PK, Kulkarni GJ, Mahale KN, Shouche YS. 2014. Technicalities and glitches of terminal restriction fragment length polymorphism (T-RFLP). Indian J. Microbiol. 54: 255-261.

39. Weissbrodt DG, Shani N, Sinclair L, Lefebvre G,Rossi P, Maillard J, et al. 2012. PyroTRF-ID: a novel bioinformatics methodology for the affiliation of terminalrestriction fragments using $16 \mathrm{~S}$ rRNA gene pyrosequencing data. BMC Microbiol. 12: 1306.

40. VDI. 2006. Fermentation of organic materials - Characterisation of the substrate, sampling, collection of material data, fermentation tests. Verein Deutscher Ingenieure.

41. Schattauer A, Abdoun E, Weiland P, Plöchl M, Heiermann M. 2011. Abundance of trace elements in demonstration biogas plants. Biosyst. Eng. 108: 57-65.

42. Schönberg M, Linke B. 2012. The influence of the temperature regime on the formation of methane in a twophase anaerobic digestion process. Eng. Life Sci. 12: 279-286.

43. Klang J, Theuerl S, Szewzyk U, Huth M, Tölle R, Klocke M. 2015. Dynamic variation of the microbial community structure 
during the long- time mono- fermentation of maize and sugar beet silage. Microb. Biotechnol. 8: 764-775.

44. Dufrêne M, Legendre P. 1997. Species assemblages and indicator species: the need for a flexible asymmetrica approach. Ecol. Monogr. 67: 345-366.

45. McCune B, Mefford MJ. 2011. PC-ORD. Multivariate analysis of ecological data. Version 6.08, Gleneden Beach, Oregon, U.S.A.

46. Clarke KR.1993. Non-parametric multivariate analyses of changes in community structure. Australian J. Ecol. 18: 117143 .

47. Theuerl S, Kohrs F, Benndorf D, Maus I, Wibberg D, Schlüter A, et al. 2015. Community shifts in a well-operating agricultural biogas plant: how process variations are handled by the microbiome, Appl. Microbiol. Biotechnol. 99: 7791-7803.

48. Carballa M, Smits M, Etchebehere C, Boon N, Verstraete W. 2011. Correlations between molecular and operational parameters in continuous lab-scale anaerobic reactors. Appl. Microbiol. Biotechnol. 89: 303-314.

49. Verstraete W, Wittebolle L, Heylen K, Vanparys B, de Vos P, van de Wiele T, et al. 2007. Microbial resource management: the road to go for environmental biotechnology. Eng. Life Sci. 7: 117-126.

50. Niu Q, Takemura Y, Kubota K, Li Y Y. 2015 . Comparing mesophilic and thermophilic anaerobic digestion of chicken manure: microbial community dynamics and process resilience. Waste Manag. 43: 114-122.

51. De Vrieze J, Saunders AM, He Y, Fang J, Nielsen $\mathrm{PH}$, Verstraete W, et al. 2015. Ammonia and temperature determine potential clustering in the anaerobic digestion microbiome. Water Res. 75: 312-323

52. Campanaro S, Treu L, Kougias PG, de Francisci D, Valle G, Angelidaki I. 2016. Metagenomic analysis and functional characterization of the biogas microbiome using high throughput shotgun sequencing and a novel binning strategy. Biotechnol. Biofuels. 9: 26

53. Pap B, Györkei Á, Boboescu IZ, Nagy IK, Bíró T, Kondorosi É, et al. 2015. Temperaturedependent transformation of biogasproducing microbial communities points to the increased importance of hydrogenotrophic methanogenesis under thermophilic operation. Bioresour. Technol. 177: 375-380.

54. Lv Z, Hu M, Harms H, Richnow HH, Liebetrau J, Nikolausz M. 2014. Stable isotope composition of biogas allows early warning of complete process failure as a result of ammonia inhibition in anaerobic digesters. Bioresour. Technol. 167: 251259 .

55. Wang Y, Zhang Y, Wang J, Meng L. 2009. Effects of volatile fatty acid concentrations on methane yield and methanogenic bacteria. Biomass Bioenergy 33: 848-853.
56. Drosg, B. 2013. Process monitoring in biogas plants. In: IEA Bioenergy Task 37 - Energy from Biogas.

57. De Vrieze J, Christiaens MER, Walraedt D, Devooght A, Ijaz UZ, Boon N. 2017. Microbial community redundancy in anaerobic digestion drives process recovery after salinity exposure. Water Res. 111: 109-117.

58. Lu X, Rao S, Shen Z, Lee PKH. 2013. Substrate induced emergence of different active bacterial and archaeal assemblages during biomethane production. Bioresour. Technol. 148: 517-524.

59. Zhang W, Werner JJ, Agler MT, Angenent LT. 2014. Substrate type drives variation in reactor microbiomes of anaerobic digesters. Bioresour. Technol. 151: 397-401.

60. Ziganshina1 EE, Belostotskiy DE, Shushlyaev RV, Miluykov VA, Vankov PY, Ziganshin AM. 2014. Microbial community diversity in anaerobic reactors digesting turkey, chicken, and swine wastes. J. Microbiol. Biotechnol. 24: 1464-1472.

61. Louca S, Polz MF, Mazel F, Albright MBN, Huber JA, O'Connor MI, et al. 2018. Function and functional redundancy in microbial systems. Nat. Ecol. Evol. 2:936-943.

62. Allison SD, Martiny JB. 2008. Resistance, resilience, and redundancy in microbial communities. Proc. Natl. Acad. Sci. USA 105: 11512-11519.

63. Kovács E, Wirth R, Maróti G, Bagi Z, Rákhely G, Kovács KL. 2013. Biogas production from protein-rich biomass: fedbatch anaerobic fermentation of casein and of pig blood and associated changes in microbial community composition, PLoS One 8: e77265.

64. Kovács E, Wirth R, Maróti G, Bagi Z, Nagy K, Minárovits J, et al. 2015. Augmented biogas production from protein-rich substrates and associated metagenomic changes. Bioresour. Technol. 178: 254-261.

65. Westerholm M, Moestedt J, Schnürer A. 2016. Biogas production through syntrophic acetate oxidation and deliberate operating strategies for improved digester performance. Appl. Energy 179: 124-135.

66. Dolfing J. 2014. Thermodynamic constrains of SAO. Appl. Environ. Microbiol. 80: 1539-1541.

67. Amani T, Nosrati M, Sreekrishnan T R. 2010. Anaerobic digestion from the viewpoint of microbiological, chemical, and operational aspects - a review. Environ. Rev. 18: 255-278.

68. Whittle IHF, Walter A, Ebner C, Insam H. 2014. Investigation into the effect of high concentrations of volatile fatty acids in anaerobic digestion on methanogenic communities. Waste Manag. 34: 2080-2089.

69. Murto M, Björnsson L, Mattiasson B. 2004. Impact of food industrial waste on anaerobic co-digestion of sewage sludge and pig manure. J. Environ. Manage. 70: 101-107.

70. Chen Y, Cheng JJ, Creamer KS. 2008. Inhibition of anaerobic digestion process: a review. Bioresour. Technol. 99: 4044-4064. 
4.3 Members of the WWE1 candidate division and the phylum Bacteroidetes as indicators to forecast a subsequent process disturbance

Proceeding of the $3^{\text {rd }}$ International Conference on Biogas Microbiology- ICBM-3

Wageningen, Netherlands 01-03. May 2017 - Oral presentation

Theuerl, S; Alsouleman, K, Klang, J 


\begin{abstract}
In order to achieve a stable, efficient and flexible biogas production microbiologist are faced with the challenge to understand and define the potentials and limits of the complex and highly sensitive ecosystem "biogas plant". Hence, knowledge about the adaptability and resistance of microbial populations to specific ecological conditions are of high importance regarding the development of new control and management strategies.

Within the datasets of three independently conducted projects microbial populations which potentially indicate stable process conditions were identified. Two mesophilic lab-scale experiments investigated the effect of animal manure derived increasing ammonium nitrogen content on the reactor performance with special emphases on the microbiome response. In the third study the microbial community was monitored in a full-scale biogas plant during a change from mesophilic to thermophilic conditions, interrupted by a strong temperature drop due to technical problems. The bacterial and archaeal community was investigated using TRFLP in combination with a cloning/sequencing approach based on 16S rRNA gene analyses.

In all three studies, changing operational parameters led to an inhibition of the process, which was mainly related to an abrupt and distinct change within the archaeal community structure. In contrast the bacterial community showed no specific reaction but a subtle reorganization of the bacterial community occurred over time. Most notable was the decreased abundance, or even disappearance, of specific bacterial TRFs assigned either to the WWE1 candidate division or the phylum Bacteroidetes prior to the change at the archaeal level. These result leads to the assumption that these Bacteria are highly sensitive to changing reactor conditions and might be possible indicatororganisms for a good reactor performance as their disappearance forecasts a subsequent process disturbance.
\end{abstract}




\section{Discussion}

Long-term mesophilic and thermophilic anaerobic digestion experiments were performed to evaluate the amount of poultry manure, specifically how much $\mathrm{NH}_{4}{ }^{+}-\mathrm{N}$ can be tolerated by the AD microbiome in two different temperature ranges and how the microbial community reacts against this operational disturbance (Alsouleman et al., 2016; Alsouleman, 2019). In the following, a comprehensive comparison of the overall performance of the long-term anaerobic digestion experiments in two different temperatures due to the consecutive additive PM levels will be discussed. Special emphasis on the microbial community structure and its dynamic variation during ongoing fermentation will be explained. In addition, the advantage and the potential drawbacks respectively limitation of the main applied key methods are discussed briefly.

\subsection{Methodical aspects}

\subsubsection{Applicability of CSTRs for anaerobic digestion of nitrogen rich manure}

The well-controlled reactors enable to investigate the suitability of the new applied feedstock and also to study comprehensively the involved microbial community which in turn helps in setting up the anaerobic digestion process as efficient as possible (Holm-Nielsen et al., 2009). The continuously respectively completely stirred tank reactor (CSTR) was used in this study due to the simplicity of the process and the reactor operation especially as a process-risk feedstock (manure rich in nitrogen) was applied. Other advantages to use CSTRs are the general low construction and investment costs of this reactor system comparing with other types which are preferable aspects especially for its application in developing countries like Syria.

On the other hand, one main limitation of using this system is the need of the continuous stirring which was hampered due to the continuous increasing in the total solid content arising from the PM addition. A further challenge is the required long hydraulic retention time (HRT) which ranged in this study between 26 and 134 days as a short retention time is likely to cause a washout of the active microbial population (Weiland, 2010; Angelidaki et at., 2011). From the economical point of view, the increased cost arising from the higher energy demand for stirring and suitable dilution to have the favored total solid content to run the CSTR system as efficient as possible 
are other drawbacks when a substrate with high total solid (poultry manure) content is needed to apply.

Nevertheless, from the technical point of view, the findings of this study proved that the lab-scale CSTR was suitable to digest efficiently until the medium PM level (50\% PM $+50 \%$ CS without water addition) in mesophilic condition. While in thermophilic condition the AD of only low PM level (25\% PM $+75 \% \mathrm{CS}$ without water addition) was run efficiently. Even though, different aspects such as the design of digester specific to poultry manure digestion, the impact of separating the anaerobic digestion process of poultry manure, the optimizing of the feedstock feeding system still need to be addressed in order to run the anaerobic digestion process of poultry manure efficiently.

\subsubsection{Applicability of TRFLP analysis for microbial community analysis in poultry manure $A D$}

The TRFLP analysis is considered a rapid, high-throughput, and highly reproducible method in microbial ecology studies. The TRFLP is useful for monitoring the phylogenetic diversity and the dynamic of the involved microbial communities in various environments (Kitts, 2001). However, this technique may underestimate the microbial diversity due to different drawbacks associated with this method itself (Liu et al., 1997). These limitations in application of this technique range from the sampling procedure, via the selection of the primers and restriction enzymes, up to the statistical analyses of the obtained data and linking the microbial community changes to the environmental changes (Osborn et al., 2000; Engebretson and Moyer, 2003; Abdo et al., 2006; Osborne et al., 2006; Schütte et al., 2008; Rademacher et al., 2012).

In this study, the TRFLP analyses were carried out following the optimized protocol proposed by Rademacher et al. (2012). Regarding the DNA extraction, two DNA extractions kits (FastDNA® Spin Kit for Soil, PowerSoil® DNA Isolation Kit), including a beating step were applied. However, an effective DNA extraction in this study was reached by using the FastDNA® Spin Kit for Soil with a mechanical treatment step as recommended also by Bergmann, (2010) and Vanysacker et al., (2010).

The resulted TRFLP profiles (in terms of the number of the detected TRFs and their relative abundance) were comparable with those of other studies on microbial 
communities of the biogas production process (Rademacher et al., 2012; Klang et al., 2015; Theuerl et al., 2015).

To overcome the limitation of the TRFLP analysis arising from the TRFs identification, subsequent 16S rRNA gene sequence libraries were constructed to determine and match the detected TRFs with the respective nucleotide sequences. Nevertheless, there were still reported TRF peaks, which were not represented in the clone libraries. For example no corresponding 16S rRNA gene sequences were identified for the archaeal TRF-174 bp, TRF-627bp and for the bacterial TRF-122bp, TRF-206bp at mesophilic conditions and also for archaeal TRF-68bp, TRF-173bp and for the bacterial TRF-198bp, TRF466bp at thermophilic conditions which indicated putative false/Pseudo-TRFs (Schütte et al., 2008; Rademacher et al., 2012). These Pseudo-TRFs can be produced by PCR and the subsequent restriction enzymes digest. The formation of single strand DNA (ssDNA) sequences during PCR can reproducibly lead to pseudo-TRFs. These ssDNA sequences can form secondary dsDNA structures, which are recognized as target by restriction enzymes in the digestion step leading to false fragments and hence to overestimation of the genetic diversity (Egert \& Friedrich, 2003; 2005). Another main limitation in this study was that, several unrelated organisms can produce the same TRF size. The partial $16 \mathrm{~S}$ rRNA gene sequences do not always allow discrimination between species as one TRF may represent two or more species with identical partial sequence (Dunbar et al., 2000; Kitts, 2001). In another word a single TRF can represent several genera (Brunk et al., 1996; Dunbar et al., 2001; Marsh, 1999). For example, the TRF$107 \mathrm{bp}$ was assigned to two different archaeal orders Methanobacteriales (hydrogenotrophic methanogens) and Methanosarcinales (acetolastic methanogens) (Alsouleman et al., 2016). However, after data analysis, the TRFLP results were sufficient for comparative analyses as they were able to tracking of the microbial community dynamics and follow the main changes in the microbiome structure in response to different PM levels addition.

Due to the high community complexity and broad range of the involved metabolic interactions in anaerobic digestion system (e.g. Nettmann et al., 2010; Wang et al., 2010; Carballa et al., 2011; Regueiro et al., 2012; Fotidis et al., 2014; Cabezas et al., 2015; Theuerl et al., 2015; Toumi et al., 2015), especially in the anaerobic digestion of process-risk feedstocks (nitrogen-rich manure), an expanding knowledge of the microbial community structure and dynamic variations correlated with physicochemical process parameters is of high importance. Therefore, and due to the results of 
this study, the application of the TRFLP technique as pre-screening analysis could be followed by a next generation sequencing technique to have a deeper and more accurate insight of the occurring microbial community in term of structure and functionality. The development of next generation sequencing (NGS) techniques enables us to study the complex microbial community structure from broader and deeper perspectives The application of these high-throughput sequencing technologies to $16 \mathrm{~S}$ rRNA gene increased the resolution of the studying microbial communities in full-scale anaerobic digesters.

Different advantages of NGS over the Sanger sequencing techniques were characterized, which could be summarized as follows: (1) in vitro construction of the sequencing library, (2) in vitro clonal amplification of DNA fragments and (3) the amplified DNA templates are sequenced simultaneously in a massively parallel fashion without the requirement for a physical separation step.

On the other side, the time-consuming and complex nature of these high-throughput techniques is a potential bottleneck for full-scale anaerobic digestion application, The major disadvantage of these techniques are related to (1) the resulted short reads, (2) the relative higher error rate in addition to (3) the complexity and computationally demanding nature of required data analysis.

The first step in these technologies is the PCR of the desired gene, therefore specific primers for this technology are used (Cardenas and Tiedje, 2008; Wang and Qian, 2009). This step is followed by high-throughput sequencing of the resulting amplicons libraries by one of the four available NGS platforms. The choosing of the platforms depends mainly on the need of higher coverage or the need of higher sequences length (Shokralla et al., 2012).

These platform are: Roche 454 Pyrosequencing Genome Sequencer (Roche Diagnostics Corp. Branford, CT, USA), MiSeq and HiSeq 2000 (Illumina Inc. San Diego, CA, USA), AB SOLiD System (Life Technologies Corp. Carlsbad, CA, USA) and Ion Personal Genome Machine (Life Technologies, South San Francisco, CA, USA) (Shokralla et al., 2012).

Each of the previous mentioned platforms has advantages and disadvantages. The major advantages of the 454 Pyrosequencing platforms are the relative long read length obtained and its relatively short run time. This made 454 Pyrosequencing platforms the most commonly used NGS platform for the analysis of environmental DNA for ecological applications. On the other side, the main drawbacks of this platform are the 
homopolymer errors which lead to an overestimation of the number of rare phylotypes and the generated short reads which limited the taxonomic assignment of these sequences to the genus level.

The Ion PGM platforms present cheap alternative platform with relative long reads up to $200 \mathrm{bp}$ but with lower coverage than 454-pyrosequencing.

The main advantage of both Illumina and SOLiD systems compared to the two previous mentioned platform 454 pyrosequencing and Ion PGM is the high output per run (Cao et al., 2017; Levy and Myers, 2016; Cabezas et al., 2015; Buermans and Dunnen, 2014; Scholz et al., 2012)

\subsection{Performance of the anaerobic digestion process during increasing amounts of poultry manure}

\subsubsection{The performance of the control reactor}

Two level of disturbance were distinguished in the study; disturbance on the reactor performance level and disturbance on the microbial level. During the whole experimental period, the control reactor (CR) - which was feed with cattle slurry as sole feedstock (OLR of $3.0 \mathrm{gVS} \mathrm{L}^{-1} \mathrm{~d}^{-1}$ ) - showed no significant changes neither in the produced biogas $\left(\mathrm{R}_{2}=0.24\right.$ and $\left.p<0.001 ; \mathrm{R}_{2}=0.27 ; p<3.7 \times 10^{-25}\right)$ in mesophilic and thermophilic condition respectively, nor in the investigated chemical parameters over the entire experimental period (Alsouleman et al., 2016; Alsouleman, 2019).

The higher biogas production in the thermophilic condition $\left(392 \pm 59 \mathrm{LN} \mathrm{kg} \mathrm{vs}^{-1}\right.$ with $\mathrm{CH}_{4}$ content of $\left.60 \pm 1 \%\right)$ comparing with the mesophilic one $\left(376 \pm 72 \mathrm{LN} \mathrm{kg} \mathrm{vs}^{-1}\right.$ with $\mathrm{CH}_{4}$ content of $62 \pm 2 \%$ ) agreed with the fact that the thermophilic AD has a higher metabolic rate and is hence expected to improve the overall process efficiency (Ahring, 2003; Wilson et al., 2008; Abbassi-Guendouz et al., 2013; Shi et al., 2013).

Several studies have shown that improvements in performance in thermophilic digestion comparing with mesophilic ones are mainly due to an increase in hydrolysis coefficient. (Song et al., 2004: Kim et al., 2006; Ge et al., 2011). The hydrolysis coefficient determines the speed of degradation, rather than to an increase in the fraction of degradable material which could explain the higher biogas yield in thermophilic condition with a lower methane content.

Also, the content of $\mathrm{NH}_{4}{ }^{+}-\mathrm{N}$ and $\mathrm{NH}_{3}$ of the control reactors in both mesophilic and thermophilic conditions were very similar. The ammonium nitrogen $\mathrm{NH}_{4}{ }^{+}-\mathrm{N}$ content 
ranged between $1.8 \pm 0.2 \mathrm{~g} \mathrm{~kg}_{\mathrm{FM}}{ }^{-1}$ in mesophilic condition and $1.9 \pm 0.3 \mathrm{~g} \mathrm{~kg}_{\mathrm{FM}}{ }^{-1}$ in thermophilic condition, while the calculated $\mathrm{NH}_{3}$ value ranged between $0.07 \pm 0.02 \mathrm{~g} \mathrm{~kg}_{\mathrm{FM}}{ }^{-1}$ and $0.08 \pm 0.04 \mathrm{~g} \mathrm{~kg}_{\mathrm{FM}}{ }^{-1}$ respectively during the whole period.

As already known, the $\mathrm{pH}$ values in highly buffered systems like the systems in this study due the high level of alkalinity arising from the degraded proteinaceous wastes can be very stable (Gerardi, 2003). The $\mathrm{pH}$ value in the control reactor at both temperature regimes (mesophilic and thermophilic) varied between 7.3 and 7.8. Therefore, the biogas yield, the methane content in the biogas, and the VFA contents were considered the reliable parameters for process monitoring in terms of process indicators for (in-) stability (Murto et al., 2004; Westerholm et al., 2011). The VFA content was monitored during the whole experimental period. The VFA value in thermophilic control reactor reached to $1.5 \mathrm{~g} \mathrm{~L}^{-1}$ which is higher comparing with its value in mesophilic condition (not exceeding $0.5 \mathrm{~g} \mathrm{~L}^{-1}$ ). The higher VFA content in the thermophilic condition agreed with the fact that the thermophilic AD is characterized with reduced process stability (Gallert et al., 1998; Kim et al., 2006). However, the two previous values of VFA still reflected a stable anaerobic digestion process (Weiland, 2008; Laaber, 2011; Drosg, 2013; LfL, 2013).

\subsubsection{The performance of the experimental reactor at low PM level (25\% PM addition)}

The first experimental phase (EP1) was initiated by applying a low PM level (25\% PM based on VS), the higher temperature led to higher biogas yield of $403 \pm 74 \mathrm{LN} \mathrm{kg} \mathrm{vs}^{-1}$ with $\mathrm{CH}_{4}$ content of $58 \% \pm 1 \%$ in thermophilic AD comparing with $341 \pm 61 \mathrm{LN} \mathrm{kg} \mathrm{vs}^{-1}$ with $\mathrm{CH}_{4}$ content of $62 \% \pm 1 \%$ in mesophilic AD (Ahring, 2003; Wilson et al., 2008; Abbassi-Guendouz et al., 2013; Shi et al., 2013). As expected, the change of feedstock composition resulted in an increase in the $\mathrm{NH}_{4}{ }^{+}-\mathrm{N}$ content from $1.6 \pm 0.1 \mathrm{~g} \mathrm{~kg}_{\mathrm{FM}}{ }^{-1}$ to $3.9 \mathrm{~g} \mathrm{~kg}_{\mathrm{FM}}{ }^{-1}$ (corresponding $\mathrm{NH}_{3}$ content of $0.06 \pm 0.01 \mathrm{~g} \mathrm{~kg}_{\mathrm{FM}}{ }^{-1}$ to $0.3 \mathrm{~g} \mathrm{~kg}_{\mathrm{FM}}{ }^{-1}$ ) in mesophilic AD and from $1.9 \mathrm{~g} \mathrm{~kg}_{\mathrm{FM}}{ }^{-1}$ to $3 \mathrm{~g} \mathrm{~kg}_{\mathrm{FM}}{ }^{-1}$ (corresponding $\mathrm{NH}_{3}$ content of 0.25 $\mathrm{g} \mathrm{kg}_{\mathrm{FM}^{-1}}$ to $0.4 \mathrm{~g} \mathrm{~kg}_{\mathrm{FM}^{-1}}$ ) in thermophilic $\mathrm{AD}$. These values were still lower than the published thresholds for process inhibition at both mesophilic (Schnürer and Nordberg, 2008; Drosg, 2013) and thermophilic conditions (Angelidaki and Ahring, 1993; Niu et al., 2013; Lv et al., 2014).

However, the previous abiotic changes had no significant effect on the overall process performance in this experimental phase in both mesophilic and thermophilic condition 
indicated by an almost stable biogas yield $\left(\mathrm{R}^{2}=0.3 \times 10^{-3} ; \mathrm{p}=0.845\right)\left(\mathrm{R}^{2}=0.31 ; \mathrm{p}=8.8 \mathrm{x}\right.$ $10^{-16}$ ), respectively. Also, the VFA content in first experimental phase in both cases were rather constant.

It could be concluded that, with low PM level, the reactor performance was functionally stable as no significant effects (in terms of disturbance) on the reactor performance in both cases were recorded (Alsouleman et al., 2016; Alsouleman, 2019). The overall reactor performance was efficient and the total biogas yield and methane content in this experimental phase were comparable with those of the control reactors.

So, it is recommended to apply the same mixture on full-scale biogas plants in both cases. The thermophilic anaerobic digestion offers different advantage such as higher metabolic rates (Ahring, 2003; Wilson et al., 2008; Abbassi-Guendouz et al., 2013; Shi et al., 2013) and higher rates of destruction of pathogens due to the higher sanitization effect (Zábranská et al., 2002; Sahlströn, 2003; Bagge et al., 2005; Dang et al., 2013). These aspects are very preferable especially when $\mathrm{AD}$ of animal wastes as treatments technology will be applied. On the other hand, the reduced stability of the thermophilic process compared to the mesophilic process, the higher $\mathrm{CH}_{4}$ content of the biogas in mesophilic condition comparing with thermophilic one in addition to the high energy input for heating process in thermophilic condition (Gallert and Winter, 1997) should be considered in full-scale application.

\subsubsection{The performance of the experimental reactor at medium PM level (50\% PM addition)}

In order to elucidate how much PM-derived $\mathrm{NH}_{4}{ }^{+}-\mathrm{N}$ can be tolerated by a mesophilic and thermophilic anaerobic microbiome, the amount of PM was doubled to $50 \%$ in the second experimental phase (EP2) denominated as medium PM level. The performance of the reactors in both cases as a response to this increasing was absolutely different.

In mesophilic $\mathrm{AD}$, a serious process imbalance occurred shortly after doubling the amount of PM (after 20 days from starting the EP2). The EP2 started with $4.2 \mathrm{~g} \mathrm{~kg}_{\mathrm{FM}}{ }^{-1}$ of $\mathrm{NH}_{4}{ }^{+}-\mathrm{N}$ and a corresponding $\mathrm{NH}_{3}$ content of $0.17 \mathrm{~g} \mathrm{~kg}_{\mathrm{FM}}{ }^{-1}$. The mentioned values are similar to reported inhibition levels of the AD in mesophilic condition, especially an inhibition of the acetoclastic methanogenesis (Schnürer and Nordberg, 2008; Drosg, 2013). This serious disturbance or imbalance in the mesophilic anaerobic digestion process occurred with $\mathrm{NH}_{4}{ }^{+-} \mathrm{N}$ content of $5.9 \mathrm{~g} \mathrm{~kg}_{\mathrm{FM}}{ }^{-1}$ respectively a $\mathrm{NH}_{3}$ content of 
$0.5 \mathrm{~g} \mathrm{~kg}_{\mathrm{FM}^{-1}}$. This disturbance was indicated by a VFA accumulation of almost $10 \mathrm{~g} \mathrm{~L}^{-1}$ in combination with a strong reduction in biogas yield and methane content.

After a certain time with continuous addition of 50\% PM, in this case approximately two weeks, the system started to recover again indicating an adaptation of the microbial community to the given environmental conditions. Despite the continuous increase in the $\mathrm{NH}_{4}{ }^{+-} \mathrm{N}$ content, a decrease in VFA content and subsequently an increase in biogas yield and methane content were observed which rose to similar values as before and almost stabilized until the end of this experimental phase (Alsouleman et al., 2016). These results demonstrated the ability of the mesophilic system to recover again. Hence, it can be assumed, that an adaption or acclimation of the involved microorganism took place. The comparison of the archaeal and bacterial community before and after this disturbance phase revealed fundamental changes which can completely explain the recovery of reactor performance after the disturbance.

While in the thermophilic condition, as was expected the acclimated microbial community to the abiotic parameters in the first experimental phase $\left(\mathrm{NH}_{4}{ }^{+}-\mathrm{N}\right.$ content of $3 \mathrm{~g} \mathrm{~kg}_{\mathrm{FM}}{ }^{-1}$ ) was distinctly negatively influenced by starting the EP2. The irreversible inhibition of the biogas production in this phase started with $\mathrm{NH}_{4}{ }^{+}-\mathrm{N}$ content of 4 $\mathrm{g} \mathrm{kg}_{\mathrm{FM}}{ }^{-1}$ even this value is lower than the previous recorded inhibition values in thermophilic conditions (Angelidaki and Ahring 1993; Niu et al. 2013; Lv et al. 2014). As illustrated previously (Alsouleman, 2019), the reason for the reactor performance deterioration in thermophilic $\mathrm{AD}$ in this experimental phase is not related to just increasing in the $\mathrm{NH}_{4}{ }^{+-} \mathrm{N}$ content but rather to a multiplicity of the prevalent environmental factors, i.e. the increase in the VS content in combination with an increase of the salt content (quantified as by the electrical conductivity) which reached the reported threshold value of $30 \mathrm{mS} \mathrm{cm}^{-1}$ (Chen et al., 2008; De Vrieze et al., 2017). Therefore, the monitoring and controlling of the prevalent operational parameters is very necessary to evaluate accurately the direct effect of the poultry-manure-derived increase in $\mathrm{NH}_{4}{ }^{+}-\mathrm{N}$ and $\mathrm{NH}_{3}$ content on the reactor performance.

The findings in this experimental phase revealed the efficiency of the long term mesophilic anaerobic digestion of the mixture of 50\% PM and 50\% CS (vol/vol based on volatile substances). The acclimated microbial community to the increasing content of $\mathrm{NH}_{4}{ }^{+}-\mathrm{N}$ induced by the medium PM level addition was able to tolerate the $\mathrm{NH}_{4}{ }^{+}-\mathrm{N}$ content as high as $8 \mathrm{~g} \mathrm{~kg}_{\mathrm{FM}^{-1}}$. So that in order to configure the biogas process with the same mixture as efficient as possible on full-scale plants, it has to be used with cautions 
and especially with respect to the demands of the microbiome. In contrast, the thermophilic system was not able to resist the prevalent environmental conditions arising from the 50\% PM addition (vol/vol based on volatile substances) and a complete failure occurred in this phase, even it tried to adapt for a short time which was expressed as called short-termed stable biogas yield phase (Alsouleman, 2019).

\subsubsection{The performance of the experimental reactor at high PM level (75\% PM addition)}

A further increase of PM (high PM level) in mesophilic condition caused a continuous increase in the $\mathrm{NH}_{4}{ }^{+}-\mathrm{N}$ content which reached its highest value of $9.6 \mathrm{~g} \mathrm{kgFM}^{-1}$ at the day 416 and stagnated at this level until the end of EP3. This mentioned value seemed to be not more handled any more by the occurring microbiome and an accumulation of $30.4 \mathrm{~g} \mathrm{~L}^{-1}$ of the VFA content was recorded. Also, the $\mathrm{NH}_{3}$ content showed an unsteady behavior which could be related to a higher buffer capacity within the system. As a consequence, the biogas yield and methane content were negatively influenced resulting in a complete process failure and no recover in the reactor performance was recorded anymore. The fourth (and last) experimental phase (EP4) was started at day 479 by applying $100 \%$ poultry manure. This phase lasted only for 22 days due to the fact that the supplied feedstock could not be any more converted to an efficient amount of methane. At the end of EP4 the system was characterized by a $\mathrm{NH}_{4}{ }^{+}-\mathrm{N}$ content of $11.7 \mathrm{~g} \mathrm{~kg} \mathrm{FM}^{-1}$, a VFA concentration of $44 \mathrm{~g} \mathrm{~L}^{-1}$ and a related $\mathrm{NH}_{3}$ concentration of $0.7 \mathrm{~g} \mathrm{~kg} \mathrm{FM}^{-1}$. Consequently, the reactor feeding was stopped although the prevalent chemical parameters were analyzed for further 33 days whereby no significant changes were recorded.

While in thermophilic condition, after the complete reactor failure and the nonrecovered inhibition in the EP2, no further increase in the PM was applied. Although the reactor feeding was stopped, the prevalent chemical parameters (VFA, conductivity, TS, $\mathrm{NH}_{4}{ }^{+}-\mathrm{N}, \mathrm{pH}, \mathrm{NH}_{3}$ ) were analyzed for further 30 days whereby no significant changes were recorded. 


\subsection{The response of the microbiome to increased amounts of poultry manure}

\subsubsection{Composition of the microbial community in the control reactor}

To figure out and follow the dynamics and response of the microbial community to the disturbances arising from the different added PM levels, the microbial community composition of the control reactor was considered as reference in this study. The control reactor showed a stable $\mathrm{AD}$ process over the entire experimental phase in both mesophilic and thermophilic conditions, although the microbial community structure in mesophilic condition differed evidently from that in thermophilic condition.

The bacterial community structure in mesophilic control reactor were characterized mainly by members from the phylum Bacteroidetes followed by members from the phylum Firmicutes and the WWE1 candidate division (depending on the relative abundance of the particular phylum to the whole bacterial community) while the archaeal community was dominated mainly by members from the genus Methanosaeta. So that, the assumed predominant pathway of methane formation in the mesophilic control reactor was the acetolastic pathway which in turn indicated a good performing reactor system as was previously reported by Regueiro et al. (2012). However, the results also indicated that a certain proportion of the produced biogas yield derived from the hydrogenotrophic pathway due to the presence of members belonging to the genus Methanobrevibacter (order Methanobacteriales) respectively the genus Methanoculleus (order Methanomicrobiales).

In thermophilic $\mathrm{AD}$, the microbial community structure was characterized mainly by members from the phylum Firmicutes Clostridiales, Bacillales, at the bacterial level in combination with archaeal genera Methanosarcina, Methanobrevibacter, Methanothermobacter and Methanoculleus. This microbial structure under thermophilic conditions was in accordance with previous published results and supports the assumption of more or less stable microbial biocenoses and metabolic activity comparing with the mesophilic one. The previous mentioned microbial structure enabled to perform the hydrogenotrophic pathway of methane formation as predominant pathway under thermophilic conditions which is in accordance with previous published results (Rademacher et al., 2012; Niu et al., 2013; De Vrieze et al., 2015; Pap et al., 2015; Campanaro et al., 2016).

To get information about the evenness and organisation of the microbial community, the Pareto-Lorenz evenness curves Fig. 4 and the derived Gini coefficients (Alsouleman et 
al., 2016; Alsouleman, 2019) were defined to facilitate the visualization of the evenness of the microbial communities. The Pareto-Lorenz curve distribution patterns of archaeal and bacterial TRFLP profiles were plotted based on the numbers of TRFs and their relative abundances. While a derived Gini Coefficient was calculated as the normalised area between the given Lorenz curve and the perfect evenness line.

Depending on the Pareto principle, the $20 \%$ of the bacterial TRFs (species) in both, mesophilic and thermophilic conditions, in this experimental phase accounted for approximately $41-43 \%$ of the whole bacterial relative abundance. This in turn reflected a balanced respectively well-established community (Verstraete et al., 2007; Marzorati et al., 2008; Carballa et al., 2011; Theuerl et al., 2015). While the 20\% of the archaeal TRFs corresponded with $69 \%$ of the whole archaeal relative abundance in mesophilic $\mathrm{AD}$ and $47 \%$ in thermophilic AD. This in turn indicated that the thermophilic archaeal community was more even than the archaeal community under the mesophilic condition.

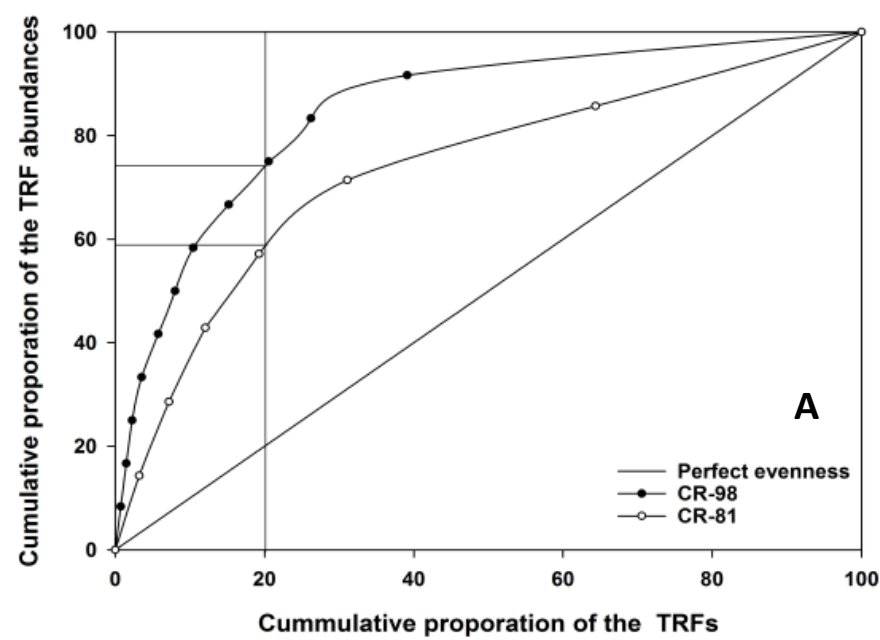




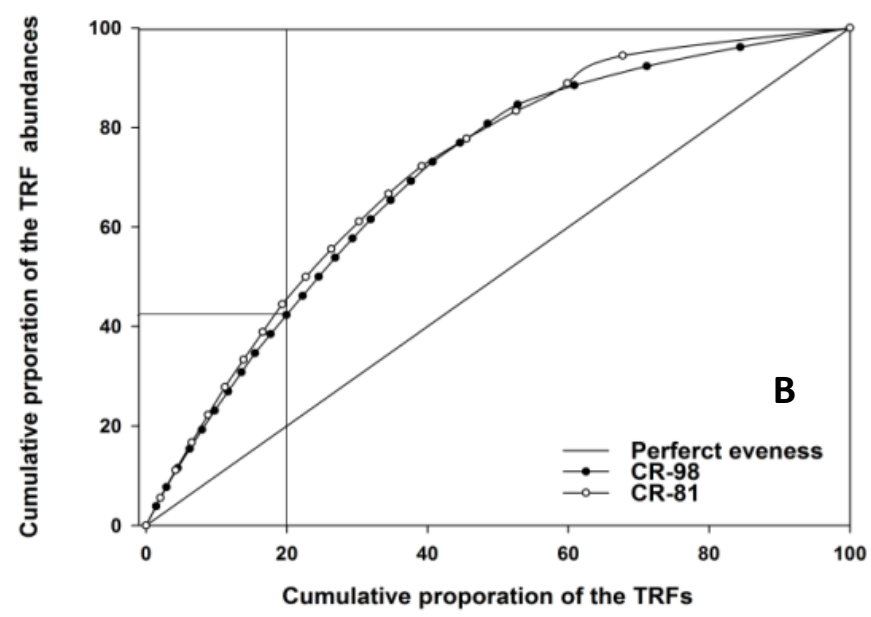

Figure 4: Pareto-Lorenz distribution curves based on 16S rRNA gene T-RFLP patterns of the archaeal (A) and bacterial (B) communities of the control reactor. The curve with filled circles represents the mesophilic condition and with empty circle represents thermophilic condition. The vertical line at the $0.2 x$ axis level is plotted to estimate the Pareto values as indicated by horizontal line. The $45^{\circ}$ diagonal (perfect evenness) represents the perfect evenness of a community.

\subsubsection{Microbial dynamics at low PM level (25\% PM addition)}

It is known from previous studies that the used feedstocks for AD affect the microbial community structure independent from general process conditions (Zhang et al., 2014; De Vrieze et al., 2017). Hence, the microbial community structures in both mesophilic and thermophilic $\mathrm{AD}$ were subjected to alteration by $25 \% \mathrm{PM}$ addition due to changes in the nutrient availability as well as the prevalent abiotic parameters. These changes in the feedstock supply and in the nutrient availability had no significant effects on the reactor performance as was shown previously (Alsouleman et al., 2016: Fig. 1; Alsouleman,2019: Fig. 1).

The results showed that the bacterial community in the first experimental phase was affected clearly in both conditions. The calculated pairwise distance between the bacterial communities of the control reactor and the communities in the first experimental phase showed a change in the bacterial community composition up to $28 \%$ at mesophilic conditions Tab. 2 and up to 17\% at thermophilic conditions (Alsouleman, 2019).

The Shannon and the Richness indices for microbial diversity under thermophilic condition were considerably higher for bacterial than for archaeal communities in both control and experimental reactors in this experimental phase (Alsouleman, 2019). 
Under mesophilic condition, the decreased abundance or even disappearance of some bacterial TRFs assigned either to the WWE1 candidate division or to the phylum Bacteroidetes by the $25 \%$ PM addition, reflected their sensitivity to changing reactor conditions. These bacterial TRFs might be possible indicator-organisms for a good reactor performance as their disappearance forecasts a subsequent process disturbance. At the archaeal level in both mesophilic and thermophilic $\mathrm{AD}$, the dominance of the obligate or facultative acetoclastic methanogens decreased clearly in combination with an increase in the predominance of hydrogenotrophic methanogens as was illustrated previously in detail (Alsouleman et al., 2016; Alsouleman, 2019). These results are in accordance with De Vrieze et al. (2015) and Fotidis et al. (2014) who reported that the obligate or facultative acetoclastic methanogens dominate the archaeal community at medium $\mathrm{NH}_{4}{ }^{+}-\mathrm{N}$, VFA and/or salt concentrations. Furthermore, high concentrations of the mentioned parameters are positively correlated with a predominance of obligate hydrogenotrophic methanogens.

Under thermophilic condition, the clear decrease in the relative abundance of the TRFs assigned to the order Methanoculleus was recorded. These archaeal TRFs could be also potential indicator-organisms for the anaerobic digestion process disturbances.

Hydrogenotrophic methanogens utilize $\left(\mathrm{CO}_{2}\right)$ and molecular hydrogen $\left(\mathrm{H}_{2}\right)$ for methane production. Thus, the acetate produced by fermentative Bacteria has to be converted via the acetate oxidation pathway performed by syntrophic Bacteria (Dolfing, 2014; Westerholm et al., 2016). Thus, it can be assumed in this phase the significant contribution of the syntrophic acetate-oxidizing SAO bacteria. This fact could explain the previous recorded changes within the bacterial community composition of the EP1 and suggested also a strong dependence between the bacteria and archaea members. 
Tab. 2: Similarity matrix in comparison of the bacterial communities over the mesophilic trial period. The calculated pairwise similarity considered both changes in the number and the relative abundance of each detected TRF within and between two samples

\begin{tabular}{|c|c|c|c|c|c|c|c|c|c|c|c|c|c|c|}
\hline \multirow{3}{*}{$\begin{array}{l}\text { AD experimental phases } \\
\text { Sample }\end{array}$} & \multirow{2}{*}{\multicolumn{2}{|c|}{$\begin{array}{l}\text { Experimental phase } 1 \\
\text { (EP1) } \\
25 \% \mathrm{PM}+75 \% \mathrm{CS} \text { a) } \\
(\mathrm{vol} / \mathrm{vol} \mathrm{VS})\end{array}$}} & \multirow{2}{*}{\multicolumn{6}{|c|}{$\begin{array}{c}\text { Experimental phase } 2 \\
\text { (EP2) } \\
50 \% \mathrm{PM}+50 \% \mathrm{CS}(\mathrm{vo} / \mathrm{vol} \mathrm{VS})\end{array}$}} & \multirow{2}{*}{\multicolumn{4}{|c|}{$\begin{array}{c}\text { Experimental phase } 3 \\
\text { (EP3) } \\
75 \% \mathrm{PM}+25 \% \mathrm{CS}(\mathrm{vol} / \mathrm{vol} \mathrm{VS})\end{array}$}} & \multirow{2}{*}{\multicolumn{2}{|c|}{$\begin{array}{l}\text { Experimental phase } 4 \\
\text { (EP4) } \\
100 \% \mathrm{CS}(\mathrm{vol} / \mathrm{vol} \mathrm{VS})\end{array}$}} \\
\hline & & & & & & & & & & & & & & \\
\hline & ER-98 & ER-137 & ER-155 & ER-185 & ER-207 & ER-230 & ER-274 & ER-305 & ER-319 & ER-337 & ER-372 & ER-479 & ER-490 & ER-514 \\
\hline CR-98 & 78 & 72 & 37 & 48 & 31 & 66 & 23 & 59 & 60 & 30 & 46 & 34 & 7 & 10 \\
\hline ER-98 & & 96 & 57 & 75 & 58 & 91 & 41 & 84 & 84 & 49 & 74 & 56 & 19 & 28 \\
\hline ER-137 & & & 76 & 86 & 72 & 89 & 70 & 88 & 87 & 50 & 69 & 55 & 18 & 23 \\
\hline ER-155 & & & & 88 & 80 & 57 & 28 & 69 & 66 & 39 & 37 & 36 & 13 & 9 \\
\hline ER-185 & & & & & 92 & 78 & 42 & 89 & 86 & 54 & 62 & 49 & 20 & 21 \\
\hline ER-207 & & & & & & 68 & 45 & 81 & 78 & 55 & 58 & 46 & 19 & 3 \\
\hline ER-230 & & & & & & & 57 & 91 & 94 & 65 & 79 & 67 & 31 & 30 \\
\hline ER-274 & & & & & & & & 66 & 65 & 89 & 66 & 80 & 66 & 21 \\
\hline ER-305 & & & & & & & & & & & & & & \\
\hline ER-319 & & & & & & & & & 97 & 72 & 79 & 67 & 37 & 32 \\
\hline ER-337 & & & & & & & & & & 74 & 79 & 69 & 39 & 33 \\
\hline ER-372 & & & & & & & & & & & 72 & 75 & 65 & 29 \\
\hline ER-479 & & & & & & & & & & & & 72 & 48 & 40 \\
\hline ER-490 & & & & & & & & & & & & & 75 & 30 \\
\hline ER-514 & & & & & & & & & & & & & & 100 \\
\hline
\end{tabular}

The previously mentioned changes in the microbial community are in agreement with the fact that the stable performance of the anaerobic digestion process indicates usually steady-state production and consumption of metabolites along the phases of this process. In contrast, a population shift at one of these process phases would likely require a concrete change in the remaining populations to maintain the stable state (Fernändenz et al., 1999).

As was known, the organization of the microbial community is the result of the action of the most fitting microorganisms to the prevalent environmental which in turn become dominant within the microbial structure (Marzorati et al., 2008; Wittebolle et al., 2009). Thus, the Lorenz curve is based on the assumption, that the distribution of species within a microbial community relates to the capacity of these species to compensate the disturbances and to conserve functionality even under perturbed conditions. The higher the Gini coefficient, the more uneven is the microbial community (Marzorati et al., 2008; Wittebolle et al., 2009; Theuerl et al., 2015).

As illustrated in Fig. 5 and depending on the Pareto principle, in this experimental phase, $20 \%$ of the bacterial TRFs (assumed indicating species) in both mesophilic and thermophilic bacterial communities accounted for approximately 35 to $45 \%$ of the whole bacterial relative abundance. This in turn means that the most fitting species are dominant and present in high number species. Thus, the well-organized microbial community may explain its ability to deal with the environmental disturbances (new 
feedstock and nutrient availability; low PM level) and save the process functionality as no significant effects on the reactor performance were recorded as was shown previously (Alsouleman et al., 2016: Fig. 1; Alsouleman, 2019: Fig. 1).

As was shown in Fig. 4, the thermophilic archaeal community organization was more even than that in mesophilic condition. This could be due to the predominance of the robust hydrogenotrophic methanogens which are considered the most fitting methanogens to the prevalent environmental condition in EP1 in the thermophilic condition. This archaeal community organization was able to deal with changing of the environmental condition (PM addition) and save its functionality.
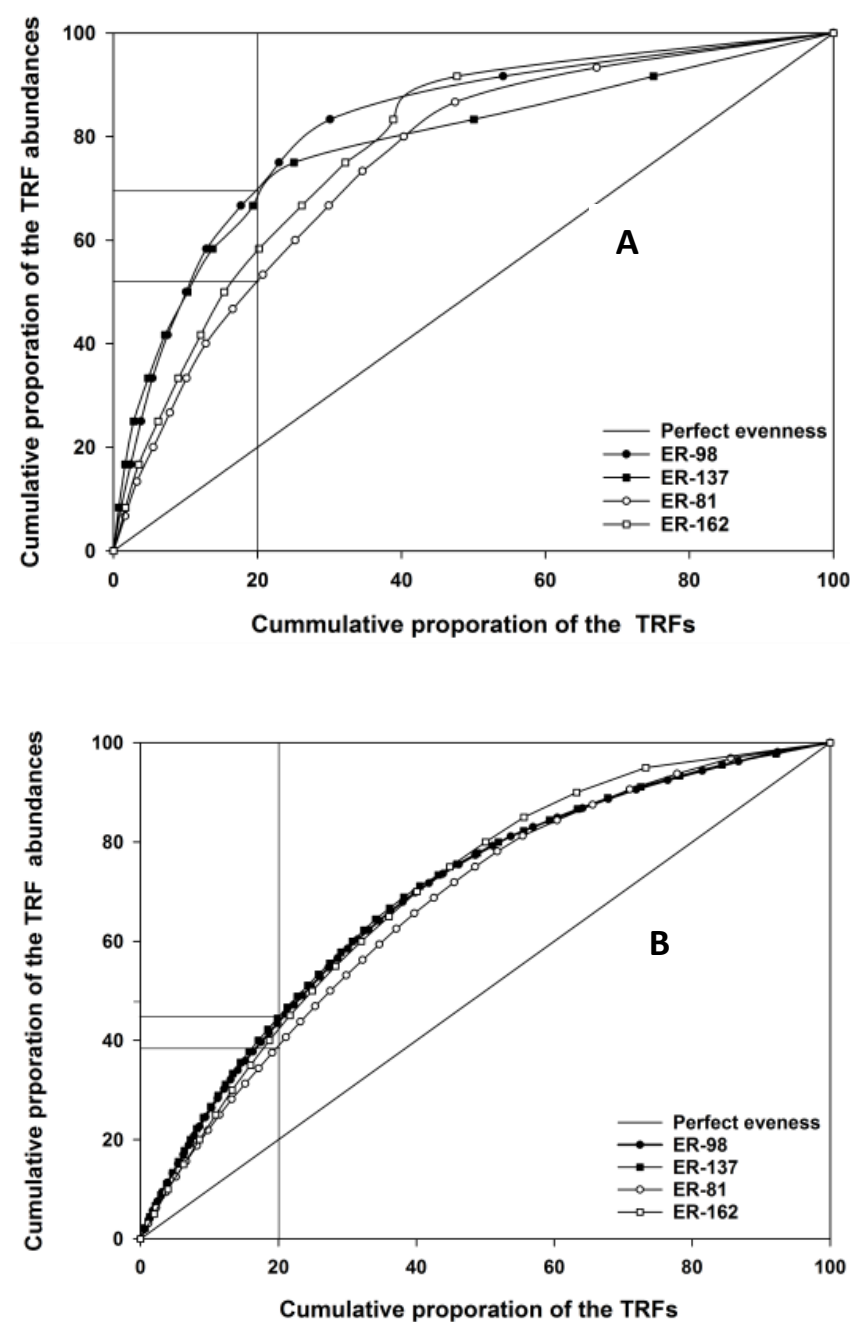

Figure 5: Pareto-Lorenz distribution curves based on 16S rRNA gene T-RFLP patterns of the archaeal (A) and bacterial (B) communities in the first experimental phase. The curve with filled circles represents the mesophilic condition and with empty circle represents thermophilic condition. The vertical line at the $0.2 x$ axis level is plotted to estimate the Pareto values as indicated by horizontal line. The $45^{\circ}$ diagonal (perfect evenness) represents the perfect evenness of a community. 


\subsubsection{Microbial dynamics at medium PM level (50\% PM addition)}

In the second experimental phase with continuous addition of medium PM level, the TRFLP and the consequent identification of representatives for most abundant taxa, showed a significant difference in the microbial community structure in mesophilic and thermophilic conditions comparing with that under low PM level.

In the mesophilic $\mathrm{AD}$ experiment, at the beginning of the second experimental phase, an increase in the relative abundance of members from the order Bacteroidetes - which are reported as acid producers (Hahnke et al., 2016) - was recoded as a response to the change in the feedstock supply. These finding were supported by the applied indicator species analysis (ISA) as the highest significant indicator values for the TRFs related to this family (IV $\geq 70$ with $p \leq 0.05$ ) were recorded at the beginning of EP2 Tab. 3. Thus, this increased abundance may explain the subsequent VFA accumulation as several members from the order Bacteroidales have been reported as acid producers with acetic acid and propionic acid as main end products (Chen \& Dong, 2005; Grabowski et al., 2005). Moreover, at the archaeal level, the Bacteroidales-dominated AD microbiomes were also dominated by the archaeal family Methanosaetaceae (De Vrieze et al., 2015; Alsouleman et al., 2016). This family is well-known to be significantly negative correlated with both increasing the VFA and $\mathrm{NH}_{4}{ }^{+}-\mathrm{N}$ content. Afterwards, a reorganisation of the bacterial community occurred as the Bacteroidetes-dominated microbiome was gradually replaced by members of the order Clostridiales (phylum Firmicutes). At this point it is questionable whether the VFAs produced by Bacteriodales led to self-inhibition or whether the increasing $\mathrm{NH}_{4}{ }^{+}-\mathrm{N}$ content suppressed their growth.

In addition to that, the continuous increasing in the $\mathrm{NH}_{4}{ }^{+}-\mathrm{N}$ content arising from the continuous addition of 50\% PM may explain the subsequent VFA accumulation and as a consequence led to a replacement of the acetoclastic pathway of methane formation by hydrogenotrophic pathway on the archaeal level. The new microbial community structure is in accordance with the results of De Vrieze et al. (2015) and Fotidis et al. (2014). The subsequent change in the archaeal community structure would be likely a response to the change at the bacterial level which in turn formed a new microbial community able to maintain stable reactor performance. Fernandenz et al. (1999) proved also that the flexible community structure of their reactor characterising by 
sequential replacement of microbiome's members led also to a stable reactor performance.

It could be assumed here, that the multiple populations in the mesophilic anaerobic digestion permit the replacement of negatively impacted population (Bacteroidales, acetoclastic pathway) by others (Clostridiales, hydrogenotrophic pathway) which were able to maintain the stability of the reactor performance.

The Gini Coefficient values derived from the Pareto-Lorenz patterns were between 0.37 and 0.45 for the bacterial communities and between 0.44 and 0.66 for the archaeal ones. These values indicated also well-established communities with intermediate evenness. This microbial community consisted not only of the generalists (such as TRF-152, TRF181 in the bacterial community) that are mostly defined by their predominant occurrence but also specialists (such as TRF-65, TRF-169 in the bacterial community) which are able to compensate the environmental disturbances.

Concluding the addition of medium level of PM in mesophilic condition resulted in a new microbial community structure (Clostridiales-Methanobacteriaceae-dominated microbiome) which was functional redundant compared with the former one as the overall process rates were similar after the disturbance phase. It could be assumed that the microbial community in this experimental phase was extremely dynamic community due to its ability to maintain a functionality stable reactor performance. Here, the anaerobic microbial community enabled to adapt to changing environmental conditions by a natural-regulated and highly efficient microbial diversity management system. 
Tab. 3: Indicator species analysis (ISA) for the given process conditions in the first two mesophilic experimental phases (EP 1 and EP 2) as the results revealed the most important shifts in the microbiome. Given are the values for the nitrogen as well the acid related parameter (left side) in combination with the detected indicator TRFs and their phylogenetic assignment (right side). ISA produces indicator values (IV ranging from 0 to 100 , absent to exclusively present) for each TRF in defined groups of a given environment. Only IV with $\mathrm{p}>0.05$ is shown

\begin{tabular}{|c|c|c|c|c|c|c|c|c|c|c|c|c|c|c|c|c|c|c|c|c|c|c|c|}
\hline \multirow{3}{*}{$\begin{array}{l}\begin{array}{c}\text { Experimental } \\
\text { phase }\end{array} \\
\text { phe }\end{array}$} & \multirow{3}{*}{$\begin{array}{c}\text { Sample } \\
\text { name }\end{array}$} & \multirow{3}{*}{$\mathrm{NH}_{4}{ }^{+}-\mathrm{N}$} & \multirow{3}{*}{$\mathrm{NH}_{3}$} & \multicolumn{6}{|c|}{ Corresponding environmental categories } & \multirow[b]{2}{*}{ iVA } & \multirow[b]{2}{*}{ CA } & \multicolumn{11}{|c|}{ Indicator species analyses with $p<0.05$} & \multirow{2}{*}{$\begin{array}{l}\text { Phyogenetic assignment of the detected TRFs } \\
\text { [sorted by phylum,order, family] }\end{array}$} \\
\hline & & & & VFA & AA & $\begin{array}{l}\text { PA } \\
{[g \mathrm{~kg}}\end{array}$ & $\begin{array}{l}\mathrm{nBA} \\
\left.=\mathrm{M}^{-1}\right]\end{array}$ & iBA & nVA & & & $\begin{array}{l}\text { TRF } \\
\text { [bp] }\end{array}$ & $\mathrm{IV} \mathrm{N}_{4}{ }^{+}-\mathrm{N}$ & $\mathrm{IV} \mathrm{NH}_{3}$ & IV VFA & IV AA & IV PA & IV nBA & IV iBA & IV nVA & IV iva & IV CA & \\
\hline & & & & & & & & & & & & 83 & 47 & 35 & 35 & 46 & 40 & 70 & 75 & 56 & 70 & 56 & Actinobacteria, Actinomycetales, Sanguibacteraceae \\
\hline \multirow[t]{2}{*}{ EP 1} & ER-day98 & 3,6 & 175 & 0,1 & 0,1 & 0,00 & 0,00 & 0,00 & 0,00 & 0,00 & 0,00 & & & & & & & & & & & & \\
\hline & & & & & & & & & & & & 92 & 43 & 31 & 31 & 41 & 37 & 66 & 58 & ns & 66 & ns & Bacteroidetes, Bacteroidales, Porphyromonadaceae \\
\hline \multirow[t]{2}{*}{ EP 1} & ER-day 137 & 3,5 & 145 & 0,1 & 0,1 & 0,02 & 0,00 & 0,00 & 0,00 & 0,00 & 0,00 & & & & & & & & & & & & \\
\hline & & & & & & & & & & & & 93 & 43 & 29 & 29 & 38 & 39 & 76 & 61 & 61 & 76 & 61 & Bacteroidetes, Bacteroidales, Porphyromonadaceae \\
\hline \multirow[t]{3}{*}{ EP 2} & ER-day155 & 3,9 & 177 & 0,1 & 0,1 & 0,00 & 0,00 & 0,00 & 0,00 & 0,00 & 0,00 & & & & & & & & & & & & \\
\hline & & & & & & & & & & & & 112 & 37 & 71 & 71 & 71 & 31 & ns & 35 & ns & ns & ns & unknown Bacteria \\
\hline & & & & & & & & & & & & 186 & 44 & 28 & 28 & 37 & 38 & 62 & 55 & 71 & 62 & 71 & Bacteroidetes, Bacteroidales \\
\hline EP2 2 & ER-day185 & 5,0 & 297 & 4,1 & 3,7 & 0,41 & 0,02 & 0,04 & 0,00 & 0,04 & 0,00 & 180 & 60 & 100 & 100 & 100 & 100 & 50 & 100 & ns & 50 & ns & unknown Bacteria \\
\hline \multirow{4}{*}{ EP 2} & & & & & & & & & & & & 65 & 66 & 27 & 27 & 27 & 27 & ns & ns & 71 & ns & 71 & Firmicutes, Clostridiales \\
\hline & ER-day207 & 5,5 & 310 & 8,8 & 7,5 & 0,96 & 0,22 & 0,30 & 0,02 & 0,28 & 0,02 & 143 & ns & 37 & 37 & 41 & 40 & 57 & 51 & 80 & 57 & 80 & Firmicutes, Clostridiales, Peptococcaceae \\
\hline & & & & & & & & & & & & 239 & 72 & 51 & 51 & 51 & 51 & 52 & 68 & 88 & 52 & 88 & unknown Bacteria \\
\hline & & & & & & & & & & & & 544 & ns & 36 & 36 & 40 & 40 & 52 & 46 & 80 & 52 & 80 & unknown Bacteria \\
\hline \multirow{2}{*}{ EP 2} & ER-day230 & 5,8 & 499 & 2,1 & 1,9 & 0,18 & 0,02 & 0,02 & 0,00 & 0,04 & 0,00 & 100 & 33 & 100 & 100 & 100 & 100 & 50 & 50 & ns & 50 & ns & Bacteroidetes, Bacteroidales \\
\hline & $\begin{array}{l}\text { ER-day230 } \\
\text { ER-day274 }\end{array}$ & $\begin{array}{l}5,8 \\
5,9\end{array}$ & $\begin{array}{l}499 \\
533\end{array}$ & $\begin{array}{l}2,1 \\
2.0\end{array}$ & $\begin{array}{l}1,9 \\
1,7\end{array}$ & $\begin{array}{l}0,18 \\
0,29\end{array}$ & $\begin{array}{l}0,02 \\
0,03\end{array}$ & $\begin{array}{l}0,02 \\
0,02\end{array}$ & $\begin{array}{l}0,00 \\
0,00\end{array}$ & $\begin{array}{l}0,04 \\
0,02\end{array}$ & 0,000 & 97 & 67 & 50 & 50 & 50 & 50 & 67 & 100 & ns & 67 & ns & Bacteroidetes, Bacteroidales \\
\hline \multirow{3}{*}{ EP 2} & & & & & & & & & & & & 216 & 33 & 100 & 100 & 100 & 100 & 100 & 50 & ns & 100 & ns & \multirow{3}{*}{$\begin{array}{c}\text { Firmicutes } \\
\text { Firmicutes, Clostridiales, Lachnospiraceae } \\
\text { unknown Bacteria }\end{array}$} \\
\hline & ER-day274 & 5,9 & 533 & 2,0 & 1,7 & 0,29 & 0,03 & 0,02 & 0,00 & 0,02 & 0,00 & 296 & 33 & 100 & 100 & 100 & 100 & 100 & 50 & ns & 100 & ns & \\
\hline & & & & & & & & & & & & 481 & ns & 70 & 70 & 76 & 70 & 79 & 37 & ns & 79 & ns & \\
\hline
\end{tabular}

$\mathrm{EP}=$ experimental phase, $\mathrm{ER}=$ experimental reactor, $\mathrm{NH} 4+-\mathrm{N}=$ ammonium nitrogen, $\mathrm{NH} 3=$ free ammonia nitrogen, $\mathrm{VFA}=$ volatile fatty acids, $\mathrm{AA}=$ acetic acid, $\mathrm{PA}=$ propionic acid, $\mathrm{nBA}=\mathrm{n}$-tutyric acid, $\mathrm{iBA}=$ Iso-butyric acid, $\mathrm{nVA}=\mathrm{n}$-vareic acid, $\mathrm{iVA}=$ Iso-valeric acid, $\mathrm{CA}=$ capronic acid, $\mathrm{TRF}=$ terminal restriction fragment, $\mathrm{bp}=$ base pair, $\mathrm{IV}=$ indicator value 
While in thermophilic condition, the anaerobic microbiome adapted to thermophilic condition is much more sensitive for process disturbances arising from 50\% PM which resulted in a complete process failure.

The Shannon's and Richness indices for the bacterial and archaeal communities were lower in this experimental phase comparing with those of control reactor and of the first experimental phase.

The Shannon's index of the sample ER-250 for the bacterial and archaeal communities under thermophilic condition reflected the lowest diversity of the microbial community during the entire experimental phase (Alsouleman, 2019).

The NMS analysis revealed that, a multiplicity of the prevalent environmental factors arising from medium PM level addition affected negatively the both archaeal and bacterial microbial community which caused later deterioration in thermophilic reactor performance.

The general trend of the archaeal community structure was towards the obligate hydrogenotrophic pathway. A clear increase in the relative abundance of TRF-336 assigned to the genus Methanobrevibacter was recorded and formed $68 \%$ of the entire archaeal community structure. Whereby a clear decrease in the relative abundance of TRF-627 assigned to the genus Methanosarcina completely. (Alsouleman, 2019).

This obligate hydrogenotrophic methanogens is well known to be the more stable/robust metabolic pathway considering the risk of ammonia toxicity (Chen et al., 2008; Demirel and Scherer, 2008; Fotidis et al., 2014). During the last years a lot is known about the inhibition thresholds of the $\mathrm{NH}_{4}{ }^{+}-\mathrm{N}$ respectively the $\mathrm{NH}_{3}$ concentration, especially for the obligate and facultative acetolastic methanogens (e.g. De Vrieze et al., 2012; Niu et al., 2013; Niu et al., 2014) but on the other hand less information are available about the threshold values of the $\mathrm{NH}_{4}{ }^{+}-\mathrm{N}$ respectively the $\mathrm{NH}_{3}$ concentration for the obligate hydrogenotrophic methanogens in thermophilic condition. So that and regarding the presented results, a threshold could be proposed at $\geq 4 \mathrm{~g} \mathrm{~kg}_{\mathrm{FM}}{ }^{-1}$ for $\mathrm{NH}_{4}{ }^{+} \mathrm{N}$ corresponding to $\geq 0.5 \mathrm{~g} \mathrm{~kg}_{\mathrm{FM}}^{-1}$ for $\mathrm{NH}_{3}$ at $55^{\circ} \mathrm{C}$ (Alsouleman, 2019).

The NMS results showed that the multiplicity of the prevalent environmental factors arising from the 50\% addition of PM caused inhibition of methanogenic activity which in turn forced the bacterial community to restructure (inhibition of the acid converting bacteria). A clear decrease in the relative abundance of TRF-94 assigned to the genus 
Bacillales, and in the relative abundance of TRF-75 and TRF-216 assigned to the genus Lactobacillales (Alsouleman, 2019).

This suggested a strong dependence between Bacteria and Archaea members in the microbial community. It could be concluded here that the acclimated thermophilic microbial community failed to tolerate a medium PM level and a complete deterioration in the process occurred. Even though during the inhibition period, the microbial community was only able to compensate the prevalent operational parameter arising from medium PM level addition for a short time (second phase showing short-termed stable biogas yield) (Alsouleman, 2019).

Even the Pareto-Lorenz curves Fig. 6 and the derived Gini coefficient values in this experimental phase (Alsouleman, 2019) reflected a well-balanced community composition which is assumed to be robust against the prevalent environmental factors but as mentioned previously the acclimated thermophilic microbial community failed to tolerate the multiplicity prevalent environmental factors arising from a medium PM level.
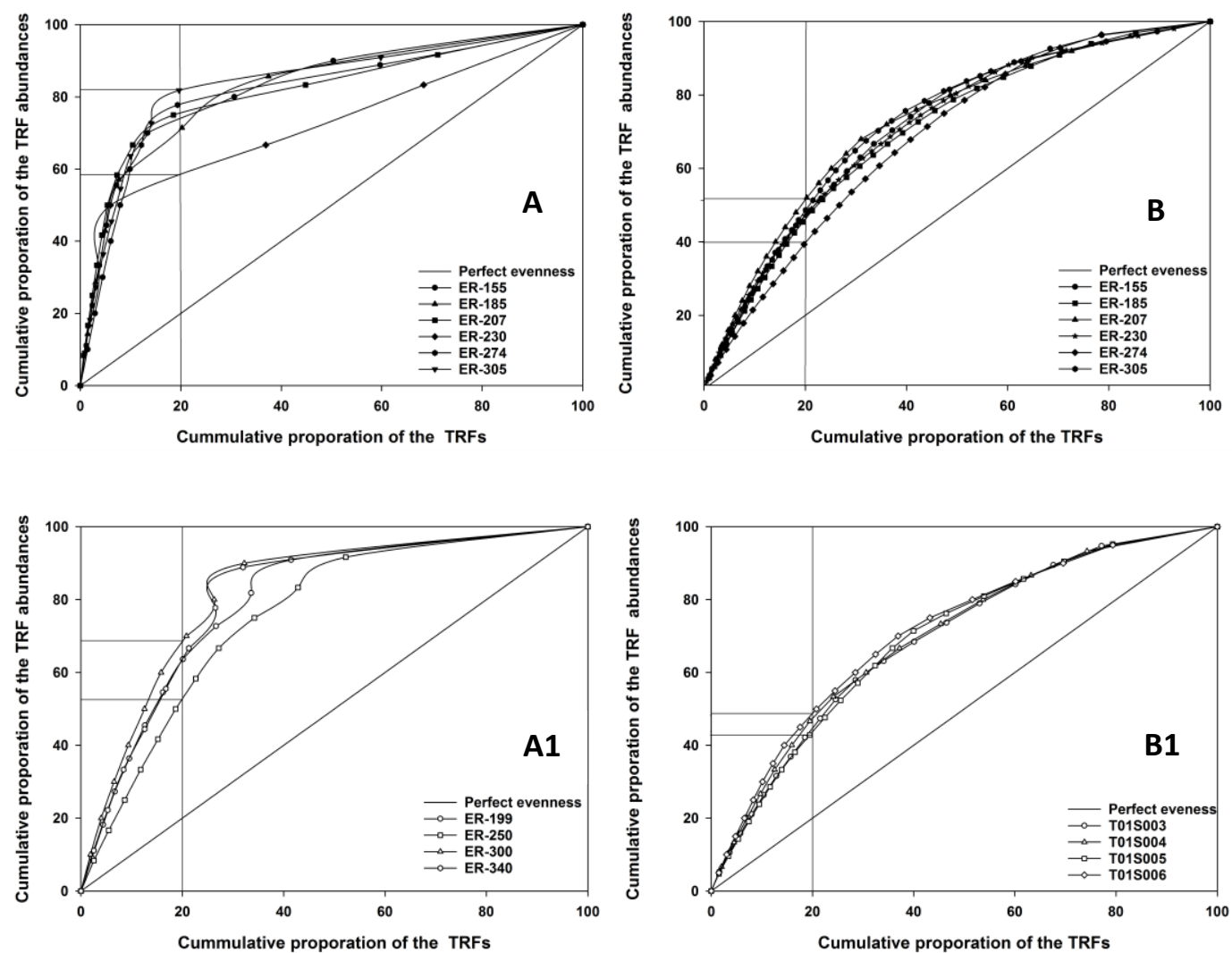
Figure 6: Pareto-Lorenz distribution curves based on 16S rRNA gene T-RFLP patterns of the bacterial communities in mesophilic condition (B); the archaeal communities in mesophilic condition (A); the bacterial communities in thermophilic condition (B1); the archaeal communities in mesophilic condition (A1) in the second experimental phase. The curve with filled circles represents the mesophilic condition and with empty circle represents thermophilic condition. The vertical line at the $0.2 x$ axis level is plotted to estimate the Pareto values as indicated by horizontal line. The $45^{\circ}$ diagonal (perfect evenness) represents the perfect evenness of a community.

\subsubsection{Microbial dynamics at high PM level (75\% PM addition)}

A further increase of PM (75\% in EP3, respectively 100\% in EP4) was not able to be tolerating anymore and a complete failure in the mesophilic reactor performance occurred.

According to the ongoing increase of the $\mathrm{NH}_{4}{ }^{+}-\mathrm{N}$ content during EP3, the trend of EP3 microbial community was moving on towards a Clostridiales-Methanobacteriaceaedominated microbiome. Depending on the serious decrease in the biogas yield and methane content in this experimental phase, it could be assumed that the methanogenic activity was inhibited. A clear decrease in the relative abundance of the order Methanobacteriales (symbolized by TRF-107) and the genus Methanoculleus (symbolized by TRF-429bp) were recorded. Hence, it could be concluded that this inhibition of the methanogenic activity led to an inhibition in the activity of the acid converting bacteria which grows in syntrophic association with methanogens.

In this phase, the hydrolytic and acidogenic bacterial community members of the microbiome still converted the supplied feedstock/substrates into acids as identified by the continuous increase in the VFA content but the successive steps of conversion were completely inhibited. The occurring microbial community in this experimental phase could not compensate the induced process disturbance (the methanogenic activity was seriously inhibited), and a complete process failure occurred as a significant decrease in the biogas yield and methane content was recorded (Alsouleman et al., 2016).

In thermophilic condition, no more microbiological samples were analysed in this phase as a complete reactor failure was already detected from the previous phase. 


\section{Conclusions and Outlook}

The findings of this study contribute to the basic understanding of the response of the microbial community in terms of restructuring and reorganization under increasing PM levels.

The results of this study proved that the CSTR was suitable to digest efficiently until the medium PM level on the lab-scale. However, further improvement of the reactor system is required to run the anaerobic digestion process of nitrogen rich substrate on full-scale efficiently; such as optimizing the mixing mechanism and separate the anaerobic digestion process of nitrogen-rich substance into two phases.

The finding of the microbial community analysis proved the validity of the TRFLP technique as pre-screening analysis which enables to follow the main microbial community dynamics due to the different added PM levels. More investigations are required to study deeply the structure and functionality of the involved microbial community as complex interacting microbial network.

The application of the next generation sequencing techniques could be applied in future to determine the different functional redundant microbial assemblage which can ensure a stable or resilient reactor performance.

With low and medium PM amounts, the acclimated occurring microbial community was able to adapt (in terms of restructuring and reorganization) to the new environmental conditions arising from changes in the feedstock supply and in the nutrient availability in mesophilic condition. The functional redundancy was the major microbial strategy in mesophilic condition ensuring an ongoing and stable biogas production as the compositional shifts did not affect significantly the reactor performance.

Hence it could be concluded, that under mesophilic condition the anaerobic digestion of low (25\%PM+75\% CS) and medium (50\% PM+50\% CS) PM levels (vol/vol based on volatile substances) could be applied efficiently on a full scale. Thereafter with increasing the PM amount, the microbial shifts under loss of functionality are likely to occur. 
In contrast, under thermophilic condition, the acclimated occurring microbial community was able to adapt only to the low PM level. The multiplicity of prevalent operational factors arising from the application of medium level of PM was the reason for the reactor performance deterioration. Thus, the succession of the microbial community structure was unsuited to overcome the process disturbance. Therefore, deep investigations of the interaction or synergy effects of different operational factors on the microbial community are required. It could be concluded here that, the anaerobic digestion of low PM level could be applied without disturbances on a full scale, but with increasing the PM amount an irreversible inhibition are likely to take place.

Regarding the presented results, the threshold values of the $\mathrm{NH}_{4}{ }^{+}-\mathrm{N}$ respectively the $\mathrm{NH}_{3}$ concentration for the obligate hydrogenotrophic methanogens in thermophilic condition could be proposed at $\geq 4 \mathrm{~g} \mathrm{~kg}_{\mathrm{FM}}{ }^{-1}$ for $\mathrm{NH}_{4}{ }^{+}-\mathrm{N}$ corresponding to $\geq 0.5 \mathrm{~g} \mathrm{~kg}_{\mathrm{FM}}{ }^{-1}$ for $\mathrm{NH}_{3}$ at $55^{\circ} \mathrm{C}$.

Also, the medium community organisation values (Gini coefficients) found in this study reflected a well-established microbial community in mesophilic with low and medium PM level and with low PM level in thermophilic condition. These microbial communities were robust and able to compensate the applied environmental disturbances and maintain the stability of the reactor performance.

These parameters were not be able to reflect the accurate and actual state of the microbial community in the thermophilic condition with medium PM level. Therefore, further research is required to optimize and determine the optimal value of these parameters independent of the applied molecular techniques.

Hence, in future the comprehensive identifying of the biogas process-relevant microorganisms especially operated with process-risk feedstocks like nitrogen-rich substances could be used as validation standards or as indicators for process emerging disturbances. Also, the co-occurrence network analyses, which provide a comprehensive picture of the interactions within the microbial community in a specific condition , explain how the disturbances (different added PM levels) affects firstly this interactions which in turn alter the function of the ecosystem (anaerobic digestion performance) and also give the opportunity to define the keystone species (a species who has a large impact and a great role in relation to its relative abundance in a specific ecosystem), should be applied to achieve highly efficient anaerobic digestion process . 
Hence, the results of this study present a basis for more researches on the applicability of use nitrogen-rich manure for anaerobic digestion as alternative treatment technology for animal waste management on full-scale biogas reactor and as a bioenergy resource. 


\section{References}

Abbassi-Guendouz, A., Brockmann, D., Trably, E., Dumas, C., Delgenès, J.P., STEYER, J.P. \& EsCUDIÉ, R. (2012): Total solids content drives high solid anaerobic digestion via mass transfer limitation. Bioresour Technol, 111, 55-61.

Abdo, Z., Schüette, U.M.E., Bent, S.J., Williams, C. J., Forney, L. J. \& Joyce, P. (2006): Statistical methods for characterizing diversity of microbial communities by analysis of terminal restriction fragment length polymorphisms of 16S rRNA genes. Environ Microbiol, 8, 929-938.

Abouelenien, F., Namba, Y., Kosseva, M.R., Nishio, N. \& NaKashimada, Y. (2014): Enhancement of methane production from co-digestion of chicken manure with agricultural wastes. Bioresour Technol, 159, 80-7.

AHN, J. \& FORSTER, C. (2002): The effect of temperature variations on the performance of mesophilic and thermophilic anaerobic filters treating a simulated papermill wastewater. Process Biochemistry, 37, 589-594.

Ahring, B. K. (2003): Perspectives for anaerobic digestion, Adv Biochem Eng Biotechnol, 81, 1-30.

Akyol, C., Turker, G., Ince, O., Ertekin, E., Üstüner, O. \& Ince, B. (2016): Performance and microbial community variations in thermophilic anaerobic digesters treating OTC medicated cow manure under different operational conditions. Bioresour Technol, 205, 191-198.

AlEXANDRATOS, N.\& BRUINSMA, J. (2012): World agriculture towards 2030/2050: the 2012 revision. ESA Working paper, FAO, No. 12-03.

Allison, S.D. \& MARTiny, J.B. (2008): Resistance, resilience, and redundancy in microbial communities. Proc. Natl. Acad. Sci, 105, 11512-11519.

Alsouleman, K., Linke, B., Klang, J., Klocke, M., Krakat, N. \& Theuerl, S. (2016): Reorganisation of a mesophilic biogas microbiome as response to a stepwise increase of ammonium nitrogen induced by poultry manure supply, Bioresource Technol, 208, 200-204.

Amani, A., Nosrati, M. \& Sreekrishnan, T.R. (2010): Anaerobic digestion from the viewpoint of microbiological, chemical, and operational aspects - a review. Environmental Reviews, 18, 255-278.

Amann, R. I., Ludwig, W. \& SchleIFER, K.H. (1995): Phylogenetic identification and in situ detection of individual microbial cells without cultivation. Microbiol Rev. 59, 143-169.

ANGELIDAKI, I. \& AHRING, B.K. (1993): Thermophilic anaerobic digestion of livestock waste: the effect of ammonia, Appl. Biochem. Biotechnol, 38, 560-564.

ANGElidAKI, I., EllegaARD, L. (2003): Codigestion of manure and organic wastes in centralized biogas plants. Appl. Biochem. Biotechnol. 109, 95-105.

Angelidaki, I., Karakashev, D., Batstone, D.J., Plugge, C. M. \& Stams, A.J.M. (2011): Biomethanation and Its Potential. Methods in enzymology, 494, 327-351. 
Angenent, L.T., Karim, K., Al-Dahhan, M.H. \& Domiguez-Espinosa, R. (2004): Production of bioenergy and biochemicals from industrial and agricultural wastewater. Trends Biotechnol, 22, 477-485.

Angenent, L.T., SUnG, S.W. \& RASKIn, L. (2002): Methanogenic population dynamics during start-up of a full-scale anaerobic sequencing batch reactor treating swine waste. Water Res, 36, 4648-4654.

Anozie, AN., LAyokun, SK., \& OKeKe, C. U. (2005): An Evaluation of a Batch PilotScale Digester for Gas Production from Agricultural. Energy Sources, 27, 1301-1311.

Arthurson, V. (2009): Closing the Global Energy and Nutrient Cycles through Application of Biogas Residue to Agricultural Land - Potential Benefits and Drawbacks. Energies, 2, 226-242

AtUANYA, E.I. \& AigBIRIOR, M. (2002): Mesophilic biomethanation and treatment of poultry waste-water using pilot scale UASB reactor. Environ Monit Assess, 77, 139147.

Bagge, E., SAhlström, L. \& Albihn, A. (2005): The effect of hygienic treatment on the microbial flora of biowaste at biogas plants. Water Res, 39, 4879-4886.

Bayrakdar, A. ,Molaey, R., SÜrmeli, Ö., SAhinkay, E. \& ÇAlli, B. (2017): Biogas production from chicken manure: Co-digestion with spent poppy straw. Elsevier International Biodeterioration \& Biodegradation, 119, 205-210.

Bekkering, J., Broekhuis, A.A. \& van Gernert, W.J.T., (2010): Optimisation of a green gas supply chain - a review. Bioresource Technology, 101, 450-456.

Berghuis, B.A., Yu, F.B., Schulz, F. Blainey, P.C., Woyke, T. \& QuAKe S.R. (2019): Hydrogenotrophic methanogenesis in archaeal phylum Verstraetearchaeota reveals the shared ancestry of all methanogens. PNAS, 116, 5037-5044.

Bergmann, I. (2012): Characterization of methanogenic Archaea communities in biogas reactors by quantitative PCR. Dissertation Technische Universität, Berlin.

BMU Public Relations Division (2018): Climate Action in Figures Facts, Trends and Incentives for German Climate Policy 2018 edition. Federal Ministry for the Environment, Nature Conservation and Nuclear Safety. Berlin, Germany.

BMU, (2009): Renewable energy sources in figures - national and international development (2009a) Federal Ministry for the Environment, Nature Conservation and Nuclear Safety. Berlin, Germany.

Borrel, G., AdAM, P.S. \& Gribaldo, S. (2016): Methanogenesis and the WoodLjungdahl pathway: an ancient, versatile and fragile association. Genome Biol. Evol, 8, 1706-1711.

Bouse, K.J., Scroccaro, D., Sima, J., Weissenbacher, N. \& Fuchs, W. (2016): Influence of the gas composition on the efficiency of ammonia stripping of biogas digestate. Bioresource Technol, 203, 259- 66.

Bruckner T., Bashmakov, I. A., Mulugetta, Y., Chum, H., DE la Vega Navarro, A., Edmonds, J., FaAiu, A., Fungtammasan, B., Garg, A., Hertwich, E., Honnery, D., Infield, D.,Kainuma, M.,Khennas, S., Kim, S., Nimir, H. B., Riahi, K., STRACHAN, 
N, Wiser, R., Zhang, X., Asayama, Y., Baiocchi, G., Cherubini, F., Czajkowska, A., Darghouth, N., Dooley, J., Gibon, T., Gujba, H., Hoen, B., De Jager, D., Jewell, J., Kadner, S., Kim, S., Larsen, P., Michaelowa, A., Mills, A., Morita, K., Neuhoff, K., Macaspac Hernandez, A., Rogner, H., Salvatore, J., Schlömer, S., Seyboth, K., von Stechow, C. \& Upadhyay, J. (2014): Chapter 7: Energy Systems, in: Climate Change 2014: Mitigation of Climate Change. Contribution of Working Group III to the Fifth Assessment Report of the Intergovernmental Panel on Climate Change (IPCC), Cambridge University Press, Cambridge, United Kingdom and New York, NY, USA.

Brugger, S.D., Frei, L., Frey, P.M., Aebi, S., Mühlemann, K. \& Hilty, M. (2012): 16S rRNA Terminal Restriction Fragment Length Polymorphis for the Characterization of the Nasopharyngeal Microbiota. PLoS ONE 7, e52241.

BUERMANS , H.P.J., DEN DUNNEN, J.T. (2014): Next generation sequencing technology: Advances and applications. Biochimica et Biophysica Acta 1842, 1932-1941.

BujoczeK, G., Oleszkiewicz, J., Sparling, R. \& Cenkowski, S. (2000): High Solid Anaerobic Digestion of Chicken Manure. Journal of Agricultural Engineering Research, 76, 51-60.

Cabezas, A., Calabria de Araujo, J., Callejas, C., Galès, A., Hamelin, J., Marone, A., Sousa, D. Z., Trably, E. \& Etchebehere, C. (2015): How to use molecular biology tools for the study of the anaerobic digestion process? Rev. Environ. Sci. Bio-Technol, 14, 555-593.

Callaghan, F. J., Wase, D. A. J., Thayanithy, K., \& Forster, C. F. (2002): Continuous co-digestion of cattle slurry with fruit and vegetable wastes and chicken manure. Biomass and Bioenergy, 22, 71-77.

Campanaro, S., Treu, L., Kougias, P.G., De Francisci, D, Valle, G. \& Angelidaki, I. (2016): Metagenomic analysis and functional characterization of the biogas microbiome using high throughput shotgun sequencing and a novel binning strategy. Biotechnol Biofuels, 9, 1-17.

CaO,Y.,FAnning, S.,Proos, S., Jordan, K., \& Srikumar, S. (2017): A review on the applications of next generation sequencing technologies as applied to food-related microbiome studies. Front. Microbiol. 8:1829.

Carballa, M., Smits, M., Etchebehere, C., Boon, N. \& Verstraete, W. (2011): Correlations between molecular and operational parameters in continuous lab-scale anaerobic reactors, Appl Microbiol Biotechnol 89, 303-314.

Carlini, M., Castellucci, S. \& Moneti, M. (2015): Biogas production from poultry manure and cheese whey wastewater under mesophilic conditions in batch reactor. Energy Procedia, 82, 811-818.

Chamy, R., León, C., Vivanco, E., Poirrier, P. \& Ramos, C. (2011): Anaerobic monodigestion of poultry manure: Determination of operational parameters for CSTR. Water Science \& Technology 65, 53-59.

Chen, Y., Cheng, J.J. \& CReAmer, K.S. (2008): Inhibition of anaerobic digestion process: A review. Bioresource Technol, 99, 4044-4064. 
CONRAD, R. \& WETTER, B. (1990): Influence of temperature on energetics of hydrogen metabolism in homoacetogenic methanogenic, and other anaerobic bacteria. Arch. Microbiol. 155, 94-98.

Country Report Syria, (2009): Provision of Technical Support/Services for an Economical, Technological and Environmental Impact Assessment of National Regulations and Incentives for Renewable Energy and Energy Efficiency. http://www.rcreee.org/sites/default/files/rcreee_rs_countryreport_syria_en_2009.pdf

(Last access 20.04.2019)

Cuetos, M. J., Martinez, E. J., Moreno, R., Gonzalez, R., Otero, M. \& Gomez, X. (2017): Enhancing anaerobic digestion of poultry blood using activated carbon. J Adv Res, 8, 297-307.

Dagnall, S., HiLl, J., \& PegG, D. (2000): Resource mapping and analysis of farm livestock manures assessing the opportunities for biomass $t$-energy schemes, Bioresour.Technol, 71, 225-234.

DALKILIC K. \& UGURLU, A. (2015): Biogas production from chicken manure at different organic loading rates in a mesophilic-thermopilic two stage anaerobic system. Journal of Bioscience and Bioengineering, 120, 315-322.

DÄMmgENA, U., \& WeBBB, J. (2006): The development of the EMEP/CORINAIR Guidebook with respect to the emissions of different nitrogen and carbon species from animal production. Agriculture, Ecosystems \& Environment, 112, 241-248.

De Baere, L.A., Devocht, M., van Assche, P. \& Verstraete, W. (1984): Influence of high $\mathrm{NaCl}$ and $\mathrm{NH} 4 \mathrm{Cl}$ salt levels on methanogenic associations. Water Res, 18, 543548.

De Vrieze, J., Christiaens, M.E.R., Walraedt, D., Devooght, A., Ijaz, U.Z. \& Boon, N. (2017): Microbial community redundancy in anaerobic digestion drives process recovery after salinity exposure. Water Research, 11, 109-117.

De VRIEZE, J., IJAZ, UZ., SAUnders, AM. \& TheuerL, S. (2018): Terminal restriction fragment length polymorphism is an "old school" reliable technique for swift microbial community screening in anaerobic digestion. Scientific RePOrTS, 8, 16818. DOI:10.1038/s41598-018-34921-7

De Vrieze, J., Saunders, A.M., He, Y., Fang, J., Nielsen, P.H., Verstraete, W. \& Boon, N. (2015): Ammonia and temperature determine potential clustering in the anaerobic digestion microbiome. Water Res, 75, 312-323.

DEMIREL, B. \& Scherer, P. (2008): The roles of acetotrophic and hydrogenotrophic methanogens during anaerobic conversion of biomass to methane: a review. Rev Environ Sci Biotechnol, 7, 173-190.

DrosG, B. (2013): Process monitoring in biogas plants. Technical Brochure, IEA Bioenergy Task 37 - Energy from Biogas.

Dunbar, J., Ticknor, L.O., Kuske, C.R. (2000): Assessment of microbial diversity in four southwestern United States soils by 16S rRNA gene terminal restriction fragment analysis. Appl Environ Microbiol, 66, 2943-2950

Egert, M., \& FrIEDrich, M. W. (2003). Formation of Pseudo-Terminal Restriction Fragments, a PCR-Related Bias Affecting Terminal Restriction Fragment Length 
Polymorphism Analysis of Microbial Community Structure. Applied and Environmental Microbiology, 69, 2555-2562.

EgerT, M., \& FrIEDRICH, M. W. (2005). Post-amplification Klenow fragment treatment alleviates PCR bias caused by partially single-stranded amplicons. Journal of Microbiological Methods, 61, 69-75.

ENGEBRETSON, J. J. \& MOYER, C. L. (2003): Fidelity of select restriction endonucleases in determining microbial diversity by terminal-restriction fragment length polymorphism. Appl Environ Microbiol, 69, 4823-4829.

ENWALL, K. \& HALlin, S. (2009): Comparison of T-RFLP and DGGE techniques to assess denitrifier community composition in soil. Lett Appl Microbiol, 48, 145-148.

Evans, P.N., PARKs, D.H., Chadwick, G.L., Robbins, S.J., OrPhan, V.J., Golding, S. D. \& Tyson, GW. (2015): Methane metabolism in the archaeal phylum Bathyarchaeota revealed by genome-centric metagenomics. Science, 350, 434-438.

FAO, FAO Animal Production and health division, Poultry sector country review. Food and Agriculture organization of the united nations. (2007), Re-edited October 2008.

Feng, X. M., Karlsson, A., Svensson, B. H. \& Bertilsson, S. (2010): Impact of trace element addition on biogas production from food industrial waste - linking process to microbial communities. FEMS Microbiol Ecol, 74, 226-240.

Fernandez A., Huang S.Y., Seston S., Xing J., Hickey R., Criddle C. \& Tiedje J. (1999): How stable is stable? Function versus community composition. Appl Environ Microbiol, 65, 3697-3704.

Field, J.A., Caldwell, J.S., Jeyanayagam, S., Reneau JR., R.B., Kroontje, W. \& Collins, E.R. (1984): Fertilizer recovery from anaerobic digesters. Trans. ASAE, 27, 1871-1876.

FNR ed. - Fachagentur Nachwachsende Rohstoffe e.V. (2008): Biogas: an introduction. pp. 1-83. Gülzow-Prüzen, Germany: FNR.

FNR ed. - Fachagentur Nachwachsende Rohstoffe e.V. (2019) Bioenergy in Germany facts and figures. pp. 1-50. Gülzow-Prüzen, Germany: FNR.

Fotidis, I. A., KARAKASHEV, D. \& ANGELIDAKI, I. (2013): Bioaugmentation with an acetate-oxidising consortium as a tool to tackle ammonia inhibition of anaerobic digestion. Bioresour Technol, 146, 57-62.

Fotidis, I., KARAKASHEV, D. \& ANGELIDAKI. I. (2014): The dominant acetate degradation pathway/ methanogenic composition in full-scale anaerobic digesters operating under different ammonia levels. Int J Environ Sci Technol, 11, 2087-2094.

FOURNIER, G.P. \& GOGARTEN, J.P. (2008): Evolution of acetoclastic methanogenesis in Methanosarcina via horizontal gene transfer from cellulolytic Clostridia. J. Bacteriol, 190, 1124-1127. 
Gagen, E. J., Huber, H., Meador, T., Hinrichs, K. U. \& Thomm, M. (2013): Novel cultivation-based approach to understanding the miscellaneous crenarchaeotic group (MCG) Archaea from sedimentary ecosystems. Appl. Environ. Microbiol, 79, 64006406.

GAllert, C., BAuer, S. \& Winter, J. (1998): Effect of ammonia on the anaerobic degradation of protein by a mesophilic and thermophilic biowaste population. Applied Microbiology and Biotechnology, 50, 495-501.

Ge, H., Jensen, P.D. \& Batstone, D.J. (2011): Temperature phased anaerobic digestion increases apparent hydrolysis rate for waste activated sludge. Water Res, 4, 1597-1606.

Gentile, M.E., Jessup, C.M., Nyman, J.L. \& CRiddle, C.S. (2007): Correlation of functional instability and community dynamics in denitrifying dispersed-growth reactors. Appl Environ Microbiol, 73, 680-690.

GERARDI, M.H. (2003): The microbiology of the anaerobic digestion. John Wiley \& Sons, Inc., Hoboken, New Jersey.

Godon, J.J., Zumstein, E., Dabert, P., Habouzit, F. \& Moletta, R. (1997): Molecular microbial diversity of an anaerobic digester as determined by small-subunit rDNA sequence analysis. Appl. Environ. Microbiol, 63, 2802-2813.

Gribaldo, S. \& BrochiER-ARMANET, C. (2006): The origin and evolution of Archaea: a state of the art. Philosophical Transactions of the Royal Society: Biological Sciences, 361, 1007-1022.

Hahnke, S., Langer, T., Koeck, DE. \& Klocke, M. (2016): Description of Proteiniphilum saccharofermentans sp. nov., Petrimonas mucosa sp. nov. and Fermentimonas caenicola gen. nov., sp. nov., isolated from mesophilic laboratory-scale biogas reactors, and emended description of the genus Proteiniphilum. International Journal of Systematic and Evolutionary Microbiology, 66, 1466-1475.

Hansen, K.H., Angelidaki, I. \& Ahring, B.K. (1998): Anaerobic digestion of swine manure: Inhibition by Ammonia. Water Research, 32, 5-12.

He, Y., Li, M., Perumal. V., Feng, X., Fang, J. \& Xie, J. (2016): Genomic and enzymatic evidence for acetogenesis among multiple lineages of the archaeal phylum Bathyarchaeota widespread in marine sediments. Nat Microbiol. 1, 16035.

Henderson, R. M., Reinert, S. A., Dekhtyar, P., Migdal, A. (2018): Climate change in 2018: implication for business. Harvard Business scholl, 9, 317-332.

Henrichs, D.M., Poggi-Varaldo, H.M. \& OleszKiewicz, J.A. (1990): Effects of ammonia on anaerobic digestion of simple organic substrates. J Environ Eng, 116, 698710 . 
Ho, D. P., Jensen, P. D., Damien J. Batstone, J. J. (2013): Methanosarcinaceae and Acetate-Oxidizing Pathways Dominate in High-Rate Thermophilic Anaerobic Digestion of Waste-Activated Sludge. Appl. Environ. Microbiol, 79, 6491-6500.

IEA Bioenergy Countries' Report - Update 2018. Bioenergy policies and status of implementation, IEA Bioenergy. 1-11.

IEA-International Energy Agency- Global Energy \& CO2 Status Report: The latest trends in energy and emissions in 2018. https://www.iea.org/geco/emissions. (Last access 15.05.2019)

IRENA- international renewable energy agency- RENEWABLE ENERGY COUNTRY PROFILES, Middle East- November 2012 edition- www.irena.org.

Jetten, M.S., Strous, M., VAn de Pas-Schoonen, K.T., Schalk, J., VAn Dongen, U.G., VAn de GraAf, A.A., Logemann, S., MuYzer, G., van LoOSDrecht, M.C. \& KUENEN, J.G. (1999): The anaerobic oxidation of ammonium. FEMS Microbiol Rev, 22, 421-437.

JongBloed, A.W. \& LenIS, N.P. (1998): Environmental Concerns About Animal Manure. Journal of Animal Science, 76, 2641-8.

KADAM P.C. \& BOONE, D.R. (1996): Influence of pH on ammonia accumulation and toxicity in halophilic, methylotrophic methanogens. Appl Environ Microbiol, 62, 486492.

Kalyuzhnyi, S., Estradade los Santos, L., Martinez, J. R. (1998): Anaerobic treatment of raw and preclarified potato-maize wastewater in a UASB reactor. Bioresource Technology, 66, 195-199.

Kelleher, B.P., Leahy, J.J., Henihan, A.M., O’Dwyer, T.F., Sutton, D. \& LeAHy, M.J. (2002): Advances in poultry litter disposal technology- a review. Bioresour.Technol, 83, 27-36.

KIM, J.K., OH, B.R., ChUN, Y.N. \& KIM S.W. (2006): Effects of temperature and hydraulic retention time on anaerobic digestion of food waste. J. Biosci. Bioeng, 102, 328-332.

KIM, M., MORRISON, M., \& YU, Z. (2011): Evaluation of different partial 16S rRNA gene sequence regions for phylogenetic analysis of microbiomes. J Microbiol Methods, 84, 81-87.

Kirchmann, H.; \& WiTter, E. (1992): Composition of fresh, aerobic and anaerobic farm animal dungs. Bioresour. Technol, 40, 137-142.

KITTS, C.L. (2001): Terminal restriction fragment patterns: a tool for comparing microbial communities and assessing community dynamics. Curr Issues Intest Microbiol, 2, 17-25.

Klang, J., Theuerl, S., SzewzyK, U., Huth, M., Tölle, R. \& Klocke, M. (2015): Dynamic variation of the microbial community structure during the long time mono fermentation of maize and sugar beet silage. Microbial Biotechnology, 8,764-775. 
KLEEREBEZEM R. \& VAN LOOSDRECHT M.C.M. (2007): Mixed culture biotechnology for bioenergy production. Curr Opin Biotechnol, 18, 207-212.

Kroeker, E.J., Schulte, D.D., Sparling, A.B. \& Lapp, H.M. (1979): Anaerobic treatment process stability. J. Water Pollut. Control Fed, 51, 718-727.

Krylova, N.I., Khabiboulline, R.E., Naumova R.P. \& Nagel M.A. (1997): The Influence of Ammonium and Methods for Removal during the Anaerobic Treatment of Poultry Manure. J. Chem. Tech. Biotechnol, 70, 99-105.

Kubo, K., Lloyd, G., Biddle, J.B., Amann, R., Teske, A. \& Knittel, K. (2012): Archaea of the Miscellaneous Crenarchaeotal Group are abundant, diverse and widespread in marine sediments. ISME J, 6, 1949-1965.

LAABER, M. (2011): Gütesiegel Biogas - Evaluierung der technischen, ökologischen und sozioökonomischen Rahmenbedingungen für eine Ökostromproduktion aus Biogas. Dissertation, at the University of Natural Resources and Life Sciences, Vienna.

Lang, K., Schuldes, J., Klingl, A., Poehlein, A., Daniel, R. \& Brune, A. (2015): New mode of energy metabolism in the seventh order of methanogens as revealed by comparative genome analysis of 'Candidatus Methanoplasma termitum'. Appl. Environ. Microbiol, 81, 1338-1352.

LARSEN, K.E. (1986): Fertilizer value of anaerobic treated cattle and pig slurry to barley and beet. In: Efficient land use of sludge and manure. Efficient land use of sludge and manure / edited by Kofoed, A. D.; Williams, J. H.; L`Hermite, P., Eds.; Elsevier Applied Science Publishers: London, U.K., 56-60.

LAtiFI, P., KARRABI, M. \& DANESh, S. (2019): Anaerobic co-digestion of poultry slaughterhouse wastes with sewage sludge in batch-mode bioreactors (effect of inoculum-substrate ratio and total solids). Renewable and sustainable energy reviews, 107, 288-296.

LaZar, C.S., Biddle, J.F., Meador, T.B., Blair, N., Hinrichs, K.U. \& Teske A.P. (2014): Environmental controls on intragroup diversity of the uncultured benthic Archaea of the miscellaneous Crenarchaeotal group lineage naturally enriched in anoxic sediments of the White Oak River estuary (North Carolina, USA) Environ. Microbiol, 17, 2228-2238.

Le Quéré, C., Andrew, R. M., Friedlingstein, P., Sitch, S., Hauck, J., Pongratz, J., Pickers, P. A., Korsbakken, J. I., Peters, G. P., Canadell, J. G., Arneth, A., Arora, V. K., Barbero, L., Bastos, A., Bopp, L., Chevallier, F., Chini, L. P., Ciais, P., Doney, S. C., Gkritzalis, T., Goll, D. S., Harris, I., Haverd, V., HofFman, F. M., Hoppema, M., Houghton, R. A., Hurtt, G., Ilyina, T., Jain, A. K., Johannessen, T., Jones, C. D., Kato, E., Keeling, R. F., GoldewiJk, K. K., Landschützer, P., Lefèvre, N., Lienert, S., LiU, Z., LombardozZi, D., MetZl, N., MunRo, D. R., NABel, J. E. M. S., Nakaoka, S.-I., Neill, C., Olsen, A., Ono, T., Patra, P., Peregon, A., Peters, W., Peylin, P., Pfeil, B., Pierrot, D., Poulter, B., Rehder, G., ResPlandy, L., Robertson, E., Rocher, M., Rödenbeck, C., Schuster, U., Schwinger, J., Séférian, R., SkJelvan, I., Steinhoff, T., Sutton, A., Tans, P. P., Tian, H., TILbroOK, B., Tubiello, F. N., VAN DER LAAN-LuiJKX, I. T., VAN DER WERF, G. R., Viovy, N., Walker, A. P., Wiltshire, A. J., Wright, R., Zaehle, S., \& Zheng, B. (2018): Global Carbon Budget, Earth Syst. Sci. Data, 10, 2141-2194, https://doi.org/10.5194/essd-10-2141-2018. 
LeE, S.H., Kang, H.J., LeE, Y.H., Lee, T.J., HaN, K., ChOI, Y. \& PARK, H. (2012): Monitoring bacterial community structure and variability in time scale in full-scale anaerobic digesters. J Environ Monit, 14, 1893-1905.

LEVY, S E., MYERS, R M. (2016): Advancements in next-generation sequencing. Annu. Rev. Genom. Hum. Genet. 17, 95-115.

LfL - Bayerische Landesanstalt fur Landwirtschaft (2013). Arbeitsschwerpunkt "Regenerative Energien" - Methodik der Datenerfassung und Bewertung. (http://www.lfl.bayern.de/arbeitsschwerpunkte/as_biogas/15736.

Li, C., Strömberg, S., LiU, G., ACHU Nges, I. \& LiU, J. (2017): Assessment of regional biomass as co-substrate in the anaerobic digestion of chicken manure: Impact of codigestion with chicken processing waste, seagrass and Miscanthus. Biochemical Engineering Journal, 118, 1-10.

Li, R., Duan, N., Zhang, Y., LiU, Z., Li, B. \& Zhang, D. (2017): Anaerobic codigestion of chicken manure and microalgae Chlorella sp.: methane potential, microbial diversity and synergistic impact evaluation. J. Waste Manag, 6, 120-127.

Li, T., MAZEAs, L., SGHIR, A., Lebion, G. \& Bouchez, T. (2009): Insights into networks of functional microbes catalysing methanization of cellulose under mesophilic conditions. Environ Microbiol, 11, 889-904.

LI, Y., Zhang, Y., Sun, Y., Wu, S., Kong, X. \& YuAn, Z. (2017): The performance efficiency of bioaugmentation to prevent anaerobic digestion failure from ammonia and propionate inhibition. Bioresour Technol, 231, 94-100.

Lin, L., YuAn, S., Chen, J., Xu, Z., \& Lu, X. (2009). Removal of ammonia nitrogen in wastewater by microwave radiation. Journal of Hazardous Materials, 161, 1063-1068.

LiU, W.T., MARsh, T.L., Cheng, H. \& Forney, L.J. (1997): Characterization of microbial diversity by determining terminal restriction fragment length polymorphisms of genes encoding 16S rRNA. Appl. Environ. Microbiol, 63, 4516-4522.

LiU, Y. \& WhiTMAN, W.B. (2008): Metabolic, phylogenetic, and ecological diversity of the methanogenic Archaea, Ann. N. Y. Acad. Sci, 1125, 171-189.

Lukow, T., Dunfield, PF. \& LIESACK, W. (2000): Use of the T-RFLP technique to assess spatial and temporal changes in the bacterial community structure within an agricultural soil planted with transgenic and non-transgenic potato plants. FEMS Microbiol Ecol, 32, 241-247.

Lv, Z., Hu, M., Harms, H., Richnow, H., Liebetrau, J. \& Nikolausz, M (2014): Stable isotope composition of biogas allows early warning of complete process failure as a result of ammonia inhibition in anaerobic digesters. Bioresource Technology, 167, 251-259.

Magrí, A., BÉline, F. \& DABert, P. (2013): Feasibility and interest of the anammox process as treatment alternative for anaerobic digester supernatants in manure processing- an overview. J Environ Manag, 131, 170-84.

MALIN, C. \& ILLMER, P. (2007): Ability of DNA content and DGGE analysis to reflect the performance condition of an anaerobic biowaste fermenter. Microbiological Research, 163, 503-511. 
Manual for the EEA greenhouse gas data viewer, version 10.2, (2016). European environment Agency, EEA.

MARSH, T.L. (1999): Terminal restriction fragment length polymorphism (T-RFLP): an emerging method for characterizing diversity among homologous populations of amplification products. Curr Opin Microbiol, 2, 323-327.

Martinot, E., Chaurey, A., \& Lew, D. (2002): Renewable energy markets in developing countries. Annu Rev Energy Environ 27, 309-48.

Maus, I., Rumming, M., Bergmann, I., Heeg, K., Pohl, M., Nettmann, E., Jaenicke, S., Blom, J., PÜHler, A., Schlüter, A., Sczyrba, A. \& Klocke M. (2018): Characterization of Bathyarchaeota genomes assembled from metagenomes of biofilms residing in mesophilic and thermophilic biogas reactors. Biotechnol Biofuels, 11, 167.

Marzorati, M., Wittebolle, L., Boon, N., Daffonchio, D., \& Verstraete, W. (2008). How to get more out of molecular fingerprints: practical tools for microbial ecology. Environmental Microbiology, 10, 1571-1581.

Mcinerney, M. J, Struchtemeyer, C.G., Sieber, J., Mouttaki, H., Stams, A.J.M., Schink, B. RholinM L. \& Gunsalus, R.P. (2008): Physiology, ecology, phylogeny, and genomics of microorganisms capable of syntrophic metabolism. Ann NY Acad Sci, 1125, 58-72.

Marquer, P., Rabade, T. \& Forti, R. (2015) : Meat production statistics, Eurostat Statistics $\quad$ Explained: https://ec.europa.eu/eurostat/statisticsexplained/pdfscache/28947.pdf (last access 20.02.2019)

Meng, J., Xu, J., QIn, D., He, Y., Xiao X. \& Wang F. (2014): Genetic and functional properties of uncultivated MCG Archaea assessed by metagenome and gene expression analyses. The ISME Journal, 8, 650-659.

Milán, Z., Sánchez, E., Weiland, P., Borja, R., Martin, A. \& Ilangovan, K. (2001): Influence of different natural zeolite concentrations on the anaerobic digestion of piggery waste. Bioresource. Technol, 80, 37-43.

Moeller, H.B., Sommer, S.G. \& Ahring, B.K. (2004): Methane productivity of manure, straw and solid fractions of manure, Biomass Bioenergy, 26, 485-495.

Möller, K., Stinner, W., Deuker, A. \& Leithold, G. (2008): Effects of different manuring systems with and without biogas digestion on nitrogen cycle and crop yield in mixed organic dairy farming systems. Nutr. Cycl. Agroecosyst, 82, 209-232.

Mumme, J., Srocke, F., HeEg, K. \& Werner, M. (2014): Use of biochars in anaerobic digestion. Bioresour Technol, 164, 189-97.

Murto, M., BJÖRnsson, L. \& MAtTiAsson, B. (2004): Impact of food industrial waste on anaerobic co-digestion of sewage sludge and pig manure. 2004. Journal of Environmental Management, 70, 101-107.

NAsir, I., Mohd GHazI, T., OMAR, R. (2012): Anaerobic digestion technology in livestock manure treatment for biogas production. A review. Eng. Life Sci, 12, 258269. 
NELLES, M., SCHÜCH, A., \& MORSCHECK, G. (2011): Biogenious WASTE TO Energy - Challenges and SOlutions. Journal of Sustainable EnERgy \& ENVIRONMENT, SPECIAL ISSUE 57- 61.

Nettmann, E., Bergmann, I., Pramschüfer, S., Mundt, K., Plogsties, V., Herrmannm, C. \& Klocke, M. (2010): Polyphasic analyses of methanogenic archaeal communities in agricultural biogas plants. Appl Environ Microbiol, 76, 2540-2548.

NI, S-Q. \& ZHANG, J. (2013): Anaerobic ammonium oxidation: from laboratory to fullscale application. BioMed Research International, , Article ID 469360, 10 pages.

Niu, Q., Kubota, K., QiaO, W., Jing, Z., Zhang, Y., \& LI, Y.Y. (2015): Effect of ammonia inhibition on microbial community dynamic and process functional resilience in mesophilic methane fermentation of chicken manure. Chem Technol Biotechnol, 90, 2161-2169.

NIU, Q., QIAO, W., QIANG, H. \& LI, Y.Y. (2013): Microbial community shifts and biogas conversion computation during steady, inhibited and recovered stages of thermophilic methane fermentation on chicken manure with a wide variation of ammonia. Bioresour Technol, 146, 223-233.

NiU, Q., QIaOM W., QIANG, H., HoJo, T. \& LI, Y.Y. (2013): Mesophilic methane fermentation of chicken manure at a wide range of ammonia concentration: stability, inhibition and recovery. Bioresource Technology, 137, 358-367.

OsBorn, A.M., MoORE, ERB. \& Timmis, K.N. (2000): An evaluation of terminalrestriction fragment length polymorphism (T-RFLP) analysis for the study of microbial community structure and dynamics. Environ Microbiol, 2, 39-50.

Osborne, CA., REEs, GN., BERnSteIn, Y. \& JANSSEN P.H. (2006): New threshold and confidence estimates for terminal restriction fragment length polymorphism analysis of complex bacterial communities. Appl Environ Microbiol, 72, 1270-1278.

Pap, B., Györkei, Á., Boboescu, I. Z., Nagy, I. K., Bíró, T., Kondorosi, E. \& MARótI, G. (2015): Temperature-dependent transformation of biogas-producing microbial communities points to the increased importance of hydrogenotrophic methanogenesis under thermophilic operation. Bioresour Technol, 177, 375-380.

Plaixats, J., Barcelo, J. \& Garcia-Moreno, J. (1988): Characterization of the effluent residue from anaerobic digestion of pig excreta for its utilization as fertilizer. Agrochemica, 32, 236-239.

Pycke, B., Etchebehere, C., Van de Caveye, P., Negroni, A., Verstraete, W. \& BoON, N. (2011): A timecourse analysis of four full-scale anaerobic digesters in relation to the dynamics of change of their microbial communities. Water Sci Technol, 63, 769775 .

Rademacher, A., Nolte. C., Schönberg. M. \& Klocke. M. (2012): Temperature increases from 55 to $75^{\circ} \mathrm{C}$ in a two-phase biogas reactor result in fundamental alterations within the bacterial and archaeal community structure, Appl Microbiol Biotechnol, 96, 565-576.

RAdEMACHer, A., ZAKRZEwski, M., SCHLÜTER, A., SchÖNBERG, M., SzCZEPANOWSKi, R., Goesmann, A., PüHLer, A. \& Klocke, M. (2012): Characterization of microbial 
biofilms in a thermophilic biogas system by high-throughput metagenome sequencing. FEMS Microbiol Ecol, 79, 785-799.

RADEMACHER, A. (2013): Microbiology of phase separated reactor systems for biomethanation at high temperatures $\left(55-75^{\circ} \mathrm{C}\right)$. Dissertation, Technische Universität Berlin.

Rajagopal, R., Massé, D. I., Singh, G. (2013) : A critical review on inhibition of anaerobic digestion process by excess ammonia. Bioresource Technol, 143, 632-641.

Ramaswamy, J., \& Vemareddy, P.S. (2015): Production of biogas using small-scale plug flow reactor and sizing calculation for biodegradable solid waste. Wind, Water, and Solar, 2, https://link.springer.com/article/10.1186/s40807-015-0006-0

RCREEE, (2019): The Regional Center for Renewable Energy and Energy Efficiency. http://www.rcreee.org/content/syria (Last access 20.04.2019).

Regueiro, L., Spirito, C.M., Usack, J.G., Hospodsky, D., Werner, J.J. \& ANGenent, L.T. (2015): Comparing the inhibitory thresholds of dairy manure co-digesters after prolonged acclimation periods: Part 2-correlations between microbiomes and environment. Water Research, 87, 458-466.

Regueiro, L., Veiga, P., Figueroa, M., Alonso-Gutierrez, J., Stams, AJM., Lema, J. M.\& CARBALlA M. (2012): Relationship between microbial activity and microbial community structure in six full-scale anaerobic digesters. Microbiol Res, 167, $581-$ 589.

REN21, Renewables 2015 Global Status Report. Renewable Energy Policy Network for the 21st Century. Paris. France. ISBN 978-3-9815934-6-4. http://www.ren21.net/wpcontent/uploads/2015/07/REN12-GSR2015_Onlinebook_low1.pdf (last access 15.02.2019)

Romero-GüIza, M.S., Astals, S., Chimenos J.M., Martínez, M. \& MatA-Alvarez, J. (2014): Improving anaerobic digestion of pig manure by adding in the same reactor a stabilizing agent formulated with low-grade magnesium oxide. Biomass- Bioenergy, 67, 243-51.

SAHLSTRÖM, L. (2003): A review of survival of pathogenic Bacteria in organic waste used in biogas plants Bioresource Technol, 87, 61-66.

SAKAR, S., YeTILMEZSOY, K. \& KocAK, E. (2009): Anaerobic digestion technology in poultry and livestock waste treatment - a literature review. Waste Management \& Research, 27, 3-18.

SCARlat, N., DAllemand, J.F.\& FAHL, F. (2018): Biogas: Developments and perspectives in Europe. Renewable Energy, 129, 457-472.

Scarlat, N., Dallemand, J.F., Monforti-Ferrario, F., Banja, M. \& Motola, V. (2015): Renewable energy policy framework and bioenergy contribution in the European Union: an overview from national renewable energy action plans and progress reports, Renew. Sustain. Energy Rev, 51, 969-985.

Schattauer, A., Abdoun, E., Weiland, P., Plöchl, M., \& Heiermann, M. (2011): Abundance of trace elements in demonstration biogas plants. Biosystems Engineering, 108, 57-65. 
SchefTElowitz, M. \& ThräN, D. (2016): Unlocking the Energy Potential of ManureAn Assessment of the Biogas Production Potential at the Farm Level in Germany. Agriculture 6, 20, doi:10.3390/agriculture6020020

SCHINK, B. (1997): Energetics of syntrophic cooperation in methanogenic degradation. Microbiol. Molec. Biol. Rev, 61, 262-280.

Scholz, M.B., Lo, C-C.\& ChAIN, P.SG. (2012): Next generation sequencing and bioinformatic bottlenecks: the current state of metagenomic data analysis. Current Opinion in Biotechnology, 23, 9-15

SCHNÜRER, A. \& NoRDBERG, A. (2008): Ammonia, a selective agent for methane production by syntrophic acetate oxidation at mesophilic temperature. Water Sci. Technol, 57, 735-740.

Schütte, UME., Abdo, Z., Bent, S.J., Shyu, C., Williams, C.J., Pierson, J.D. \& FORNEY, L.J. (2008): Advances in the use of terminal restriction fragment length polymorphism (T-RFLP) analysis of $16 \mathrm{~S}$ rRNA genes to characterize microbial communities. Appl Microbiol Biotechnol, 80, 365-380.

Sekiguchi, Y., Kamagata, Y., Syutsubo, K., Ohashi, A., Harada, H. \& NaKamura, K. (1998): Phylogenetic diversity of mesophilic and thermophilic granular sludges determined by 16S rRNA gene analysis. Microbiology, 144, 2655-2665.

Shah, A., Lamers, M. \& Streck, T. (2016): $\mathrm{N}_{2} \mathrm{O}$ and $\mathrm{CO}_{2}$ emissions from South German arable soil after am amendment of manures and composts. Environmental Earth Sciences. 75, 427.

Shi, J., WAng, Z., Stiverson, JA., Yu, Z. \& Li, Y. (2013: Reactor performance and microbial community dynamics during solid-state anaerobic digestion of corn stover at mesophilic and thermophilic conditions. Bioresour. Technol, 136, 574-581.

Singh, K., LeE, K., Worley, J., Risse, L.M. \& DAS, K.C. (2012): Anaerobic digestion of poultry litter: A REVIEW. Applied Engineering in Agriculture, 26, 677-688.

SiRIWONGRUNGSON, V., ZENG, RJ. \& ANGELIDAKI, I. (2007): Homoacetogenesis as the alternative pathway for $\mathrm{H} 2$ sink during thermophilic anaerobic degradation of butyrate under suppressed methanogenesis. Water Res, 41, 4204-4210.

Smith P., Bustamante, M., Ahammad, H., Clark, H., Dong, H., E.A. Elsiddig, Haberl, H., Harper, R., House, J., Jafari, M., MASera, O., MbOW, C. Ravindranath, N.H., Rice, C.W., Robledo Abad, C., Romanovskaya, A., SPERling, F. \& TubIEllo, F. (2014): Agriculture, Forestry and Other Land Use (AFOLU). In: Climate Change 2014: Mitigation of Climate Change. Contribution of Working Group III to the Fifth Assessment Report of the Intergovernmental Panel on Climate Change [Edenhofer, O., R. Pichs-Madruga, Y. Sokona, E. Farahani, S. Kadner, K. Seyboth, A. Adler, I. Baum, S. Brunner, P. Eickemeier, B. Kriemann, J. Savolainen, S. Schlömer, C. von Stechow, T. Zwickel and J.C. Minx (eds.)]. Cambridge University Press, Cambridge, United Kingdom and New York, NY, USA.

SoNG, Y.C., KWON, S.J. \& WoO J.H. (2004): Mesophilic and thermophilic temperature co-phase anaerobic digestion compared with single-stage mesophilic- and thermophilic digestion of sewage sludge. Water Res, 38, 1653-1662. 
SprotT, G.D., ShAw, K.M. \& JARrell, K.F. (1984): Ammonia/potassium exchange in methanogenic Bacteria. J Biol Chem, 259,12602-12608.

STEWART, E.J. (2012): Growing Unculturable Bacteria. J Bacteriol, 194, 4151-4160.

Su, C., LeI, L., Duan, Y., Zhang, K.Q. \& YAng, J (2012): Culture-independent methods for studying environmental microorganisms: methods, application, and perspective. Appl Microbiol Biotechnol, 93, 993-1003.

Sundberg, C., Al-Soud, WA., Larsson, M., Alm, E., Yekta S.S., Svensson, B.H., SøRENSEN, S.J. \& KARLSSON, A. (2013): 454 pyrosequencing analyses of bacterial and archaeal richness in 21 full-scale biogas digesters. FEMS Microbiol Ecol, 85, 612-626.

SunG, S. \& LIU, T. (2003): Ammonia inhibition on thermophilic anaerobic digestion. Chemosphere, 53, 43-52.

Szarka, N., Scholwin, F. \& Trommler, M. (2013): A novel role for bioenergy: a flexible, demand-oriented power supply. Energy, 61, 18-26.

Tada, C., Yang, Y., Hanaoka, T., Sonoda, A., OoI, K. \& Sawayama, S. (2005): Effect of natural zeolite on methane production for anaerobic digestion of ammonium rich organic sludge. Bioresour. Technol, 96, 459-464.

Talbot, G., TopP, E., Palin, MF. \& Massé, D.I. (2008): Evaluation of molecular methods used for establishing the interactions and functions of microorganisms in anaerobic bioreactors. Water Res, 42, 513-537.

Thauer, RK., Kaster, AK., Goenrich, M., Schick, M. Hiromoto, T. \& Shima, S. (2010): Hydrogenases from methanogenic Archaea, nickel, a novel cofactor and H2 storage. Ann. Rev. Biochem, 79, 507-536.

Thauer, RK., Kaster, AK., Seedorf, H., Buckel, W. \& Hedderich, R. (2008): Methanogenic Archaea: ecologically relevant differences in energy conservation. Nat. Rev. Microbiol, 6, 579-591.

Theuerl, S., Kohrs, F., Benndorf, D., Maus, I, Wibberg, D., Schlüter, A., Kausmann, R., Heiermann, M., Rapp, E., Reichl, U. \& Klocke, M. (2015): Community shifts in a well-operating agricultural biogas plant: how process variations are handled by the microbiome, Appl Microbiol Biotechnol, 99, 7791-7803.

Theuerl, S., Klang, J. \& Prochnow, A. (2019): Process Disturbances in Agricultural Biogas Production- Causes, Mechanisms and Effects on the Biogas Microbiome: A Review. Energies, 12, 365.

Thompson, E., WAnG, Q. \& LI, M. (2013): Anaerobic digester systems (ADS) for multiple dairy farms: a GIS analysis for optimal site selection, Energy Pol, 61, 114-124.

Toumi, J., Miladi, B., Farhat, A., Nouira, S., Hamdi, M., Gtari, M. \& Bouallagui, H. (2015): Microbial ecology overview during anaerobic codigestion of dairy wastewater and cattle manure and use in agriculture of obtained bio-fertilisers. Bioresource Technology, 198, 141-149.

UBA, Umweltbundesamt, German Environment Agency. (2013): Berichterstattung unter der Klimarahmenkonvention der Vereinten Nationen und dem Kyoto-Protokoll 
2013. Nationaler Inventarbericht zum Deutschen Treibhausgasinventar, 1990-2011 Umweltbundesamt, Dessau-Roßlau, Germany.

UsACK, J.G. \& ANGENENT, L.T. (2015): Comparing the inhibitory thresholds of dairy manure co-digesters after prolonged acclimation periods: Part 1 e Performance and operating limits. Water Research, 87, 446-457.

Van Dorst, J. Bissett, A., Palmer, AS., Brown, M., Snape, J. Stark, JS., RAymond, B., McKinlay, J., Ji, M., Winsley, T. \& Ferrari, B.C. (2014): Community fingerprinting in a sequencing world. FEMS Microbiol. Ecol, 89, 316-330.

Vanwonterghem, I., Evans, PN., Donovan, HP., Jensen, PD., Woodcroft, BJ., Hugenholtz P. \& Tyson, G.W. (2016): Methylotrophic methanogenesis discovered in the archaeal phylum Verstraetearchaeota. Nature Microbilogy, 1, 16170.

Vanwonterghem, I., Jensen, PD., Ho, DP., Batstone, DJ., \& Tyson, G.W. (2014): Linking microbial community structure, interactions and functions in anaerobic digesters using new molecular techniques. Current Opinion in Biotechnology, 24, 5564 .

Verstraete, W., Wittebolle, L., Heylen, K., Vanparys, B., de Vos, P., Van de WiEle, T., BoON, N. (2007). Microbial resource management: the road to go for environmental biotechnology. Eng Life Sci, 7, 117-126.

VE` TROVSKY, T\& BALDRIAN, P. (2013): The Variability of the 16S rRNA Gene in Bacterial Genomes and Its Consequences for Bacterial Community Analyses. PLoSONE, 8, e57923.

Wagner, M., Amann, R., Lemmer, H. \& SchleIFer, K.H. (1993): Prob ing activated sludge with oligonucleotides specific for Proteobacteria - Inadequacy of culturedependent methods for describing microbial community structure. Appl Environ Microbiol, 59, 1520-1525.

Walker, LM., IYer, K., HeAven, S. \& BAnKs, C. J. (2011): Ammonia removal in anaerobic digestion by biogas stripping: An evaluation of process alternatives using a first order rate model based on experimental findings. Chemical Engineering Journal, 178, 138-145.

Wang, H., Vuorela, M., Keränen, AL., Lehtinen, TM., Lensu, A., Lehtomäki A. \& Rintala, J. (2010): Development of microbial populations in the anaerobic hydrolysis of grass silage for methane production. FEMS Microbiol Ecol, 72, 496-506.

Wang, Q., Garrity, GM., TIEDJE, JM., \& Cole, J.R. (2007): Naive Bayesian classifier for rapid assignment of rRNA sequences into the new bacterial taxonomy. Appl Environ Microbiol, 73, 5261-5267.

WeBb, R. \& HAWKES, F.R. (1985): The anaerobic digestion of poultry manure: Variation of gas yield with influent concentration and ammonium-nitrogen levels. Agricultural Wastes, 14, 135-156

WeIland, P. (2008): Wichtige Messdaten für den Prozessablauf und Stand der Technik in der Praxis. In: Fachagentur Nachwachsende Rohstoffe e.V. - FNR (eds.), Gulzower Fachgesprache, Band 27, Messen, Steuern, Regeln bei der Biogaserzeugung, 17-31. 
WeILAND, P. (2010): Biogas production: current state and perspectives. Applied Microbiology and Biotechnology 85, 849-860.

Weise, L., Ulrich, A., Moreano, M., Gessler, A., KaYler, ZE., Steger, K., Zeller, B., RUDOLPH, K., KnezeviC-Jaric, J. \& PREMKe, K. (2016): Water level changes affect carbon turnover and microbial community composition in lake sediments. FEMS Microbiology Ecology, 92, 2016, fiw035.

Weissbrodt， DG., Shani， N., Sinclair, L., Lefebvre， G., Rossi, P., Maillard, J., Rougemont, J. \& Holliger C. (2012): Pyro TRF-ID: a novel bioinformatics methodology for the affiliation of terminal-restriction fragments using 16S rRNA gene pyrosequencing data. BMC Microbiol, 12, 306.

Werner, J.J., Knights, D., Garcia, M.L., Scalfone, NB., Smith, S., Yarasheski, K., Cummings TA., BeERS, AR., KNIGHT, R. \& ANGENENT L.T. (2011): Bacterial community structures are unique and resilient in fullscale bioenergy systems. PNAS, 108, 4158-4163.

Westerholm, M., Dolfing, J., Sherry, A., Gray ND., Head, IM. \& SchnÜrer, A. (2011): Quantification of syntrophic acetate-oxidizingmicrobial communities in biogas processes. Environmental Microbiology Reports, 3, 500-505.

Westerholm, M., Moestedt, J. \& Schnürer, A. (2016): Biogas production through syntrophic acetate oxidation and deliberate operating strategies for improved digester performance. Appl Energ, 179, 124-135.

Wilson, CA., Murthy, SM., Fang, Y. \& NovaK, J.T. (2008): The effect of temperature on the performance and stability of thermophilic anaerobic digestion, Water Sci Technol. 57, 297-304

Witzig, M., DA Silva, A. C., Green-Engert, R., Hoelzle, K., Zeller, E., Seifert, J., HoElzLe, L. E. \& RodeHhutsCoRD, M. (2015): Spatial Variation of the Gut Microbiota in Broiler Chickens as Affected by Dietary Available Phosphorus and Assessed by T-RFLP Analysis and 454 Pyrosequencing. PLOS ONE, 10 (11).

Wittebolle, L., Vervaeren, H., Verstraete, W., \& Boon, N. (2007). Quantifying Community Dynamics of Nitrifiers in Functionally Stable Reactors. Applied and Environmental Microbiology, 74, 286-293.

WRI, World Resource Institute. (2012): Climate Analysis Indicators Tool (CAIT) (version 9.0); World Resources Institute, Washington, DC, USA.

https://sites.google.com/site/climateanalysisindicatorstool/cait-international-8-0 (last access 20.03.2019)

YENIGÜN, O. \& DEMIREL, B. (2013): Ammonia inhibition in anaerobic digestion: a review. Process Biochem, 48, 901-911.

ZÁbranská, J., Dohanyos, M., Dohanyos, M., Jenicek, P., ZaplatílKová, P. \& KUTIL, J. (2002): The contribution of thermophilic anaerobic digestion to the stable operation of wastewater sludge treatment. Water Science \& Technology, 46, 447-53

ZAHAN, Z. \& OTHMAN, M.Z. (2019): Effect of pre-treatment on sequential anaerobic codigestion of chicken litter with agricultural and food wastes under semi-solid conditions and comparison with wet anaerobic digestion. Bioresource technology, 281, 286-295. 
ZakrZewski, M., Goesmann, A., Jaenicke, S., JÜnemann, S., EIKMEYer, F., Szczepanowski, R., AbuAl-Soud W., Sørensen, S., Pühler, A. \& Schlüter, A. (2012): Profiling of the metabolically active community from a production-scale biogas plant by means of high-throughput metatranscriptome sequencing. J Biotechnol, 158, 248-58.

Zarraonaindia, I., SMith DP. \& Gilbert J.A. (2013): Beyond the genome: community-level analysis of the microbial world. Biol Philos, 28, 261-282.

Zhang, W., Werner, JJ., Agler, MT. \& Angenent, L.T. (2014): Substrate type drives variation in reactor microbiomes of anaerobic digesters Bioresource Technol, 151, 397 401.

Zhang, Y., Cañas, EMZ., Zhu, Z., Linville, JL., Chen,S. \& He, Q. (2011): Robustness of archaeal populations in anaerobic co- digestion of dairy and poultry wastes. Bioresource Technology,102, 779-785.

Ziganshin, AM., Schmidt, T., Scholwin, F., Il'inskaya, ON., Harms, H. \& KLEINSTEUBER, S. (2011): Bacteria and Archaea involved in anaerobic digestion of distiller's grains with solubles. Appl Microbiol Biotechnol, 89, 2039-2050. 


\section{E C L A R A T I O N S}

1. I, hereby, declare that this Ph.D. dissertation has not been presented to any other examining body either in its present or a similar form. Furthermore, I also affirm that I have not applied for a Ph.D. at any other higher school of education.

Göttingen,

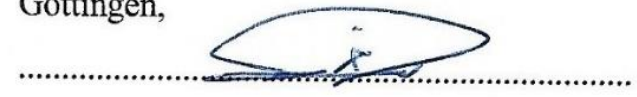

KHULUD ALSOULEMAN

2. I, hereby, solemnly declare that this dissertation was undertaken independently and without any unauthorised aid.

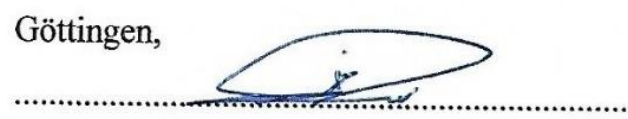

KHULUD ALSOULEMAN 


\section{Appendix}

A1: The relative distribution of the detected bacterial and archaeal terminal restrictions fragments (TRFs) in mesophilic experiment highlighted by colors according to an increasing abundance and their phylogenetic assignment

\begin{tabular}{|c|c|c|c|c|c|c|c|c|c|c|c|c|c|c|c|c|c|}
\hline \multirow[t]{5}{*}{ Domain } & \multirow[t]{5}{*}{ TRF [bp] } & \multicolumn{15}{|c|}{ Sampling points \& experimental phases } & \multirow{5}{*}{ Phyogenetic assignment of the detected TRFS } \\
\hline & & \multirow{4}{*}{$\begin{array}{l}\text { starter community } \\
\qquad \begin{array}{l}G_{B}=0.41 \\
G_{A}=0.69\end{array}\end{array}$} & \multicolumn{2}{|c|}{ EP1 } & \multicolumn{6}{|c|}{ EP2 } & \multicolumn{4}{|c|}{ EP3 } & \multicolumn{2}{|c|}{ EP4 } & \\
\hline & & & ER-98 & ER-137 & ER-155 & ER-185 & ER-207 & ER-230 & 0 ER-274 & ER-305 & ER-319 & ER-337 & ER-372 & ER-479 & ER-490 & ER-514 & \\
\hline & & & $\begin{array}{l}G_{\mathrm{g}}= \\
0.39\end{array}$ & $\begin{array}{l}G_{B}= \\
0.40\end{array}$ & $\begin{array}{l}G_{8}= \\
0.44\end{array}$ & $\begin{array}{l}G_{B}= \\
0.41\end{array}$ & $G_{B}=0.45$ & $\begin{array}{ll}5 & G_{B}= \\
0.43\end{array}$ & $\mathrm{G}_{\mathrm{B}}=0.37$ & $G_{B}=0.45$ & $G_{B}=0.44$ & $\begin{array}{c}G_{B}= \\
0.44\end{array}$ & $G_{B}=0.33$ & $\begin{array}{c}G_{B}= \\
0.39 \\
0.39\end{array}$ & $\begin{array}{l}G_{8}= \\
0.39\end{array}$ & $\begin{array}{l}G_{B}= \\
0.38\end{array}$ & \\
\hline & & & & & & $\partial_{A}=0.64$ & $4 G_{A}=0.63$ & & $44 G_{A}=0.64$ & $G_{A}=0.68$ & $G_{A}=0.62$ & $2 G_{A}=0.60$ & $0 G_{A}=0.49 C$ & $9 G_{A}=0.61$ & $G_{A}=0.56 C$ & & \\
\hline \multirow[t]{27}{*}{ Bacteria } & 65 & 0 & 0 & 0 & 0 & 4 & 8 & 7 & 8 & 5 & 9 & 12 & 5 & 5 & 5 & 0 & \multirow{27}{*}{ 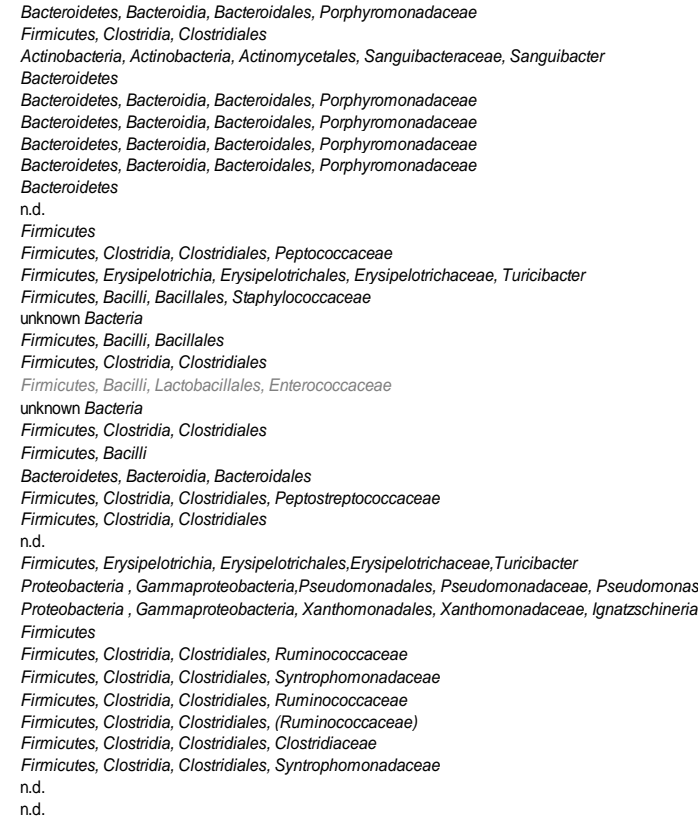 } \\
\hline & 83 & 3 & 3 & 4 & 4 & 0 & 0 & 0 & 0 & 0 & 0 & 4 & 0 & 0 & 0 & 0 & \\
\hline & 86 & 3 & 0 & & 0 & 0 & 0 & 0 & 0 & 0 & 0 & 0 & 0 & 0 & 0 & 0 & \\
\hline & 93 & 3 & 4 & $\frac{13}{4}$ & $\frac{2 l}{4}$ & $\frac{11}{3}$ & $\frac{18}{0}$ & $\begin{array}{l}7 \\
0\end{array}$ & $\begin{array}{l}0 \\
0\end{array}$ & ${ }_{0}^{9}$ & ${ }_{0}^{9}$ & ${ }_{0}^{3}$ & $\begin{array}{l}0 \\
0\end{array}$ & 2 & $\begin{array}{l}0 \\
0\end{array}$ & $\begin{array}{l}0 \\
0\end{array}$ & \\
\hline & 97 & 3 & 0 & & 3 & 0 & 0 & 5 & 6 & 4 & 5 & 3 & 0 & 8 & 11 & 0 & \\
\hline & 100 & 0 & 0 & 0 & 0 & 0 & 0 & 7 & 7 & 3 & 3 & 4 & 0 & 5 & 0 & 0 & \\
\hline & $\begin{array}{l}108 \\
112\end{array}$ & $\begin{array}{l}2 \\
0\end{array}$ & $\begin{array}{l}0 \\
0\end{array}$ & $\begin{array}{l}0 \\
0 \\
0\end{array}$ & $\begin{array}{l}0 \\
4\end{array}$ & $\begin{array}{l}0 \\
3\end{array}$ & $\begin{array}{l}0 \\
0 \\
0\end{array}$ & 0 & 0 & 0 & 0 & 0 & $\begin{array}{l}0 \\
0\end{array}$ & $\begin{array}{l}0 \\
0\end{array}$ & $\begin{array}{l}0 \\
0\end{array}$ & $\begin{array}{l}0 \\
0\end{array}$ & \\
\hline & $\begin{array}{l}112 \\
132\end{array}$ & $\begin{array}{l}0 \\
0\end{array}$ & $\begin{array}{l}0 \\
0\end{array}$ & $\begin{array}{l}0 \\
0\end{array}$ & $\begin{array}{l}4 \\
0\end{array}$ & $\begin{array}{l}3 \\
0\end{array}$ & $\begin{array}{l}0 \\
0\end{array}$ & $\begin{array}{l}0 \\
2\end{array}$ & $\begin{array}{l}0 \\
0\end{array}$ & $\begin{array}{l}0 \\
0\end{array}$ & $\begin{array}{l}0 \\
0\end{array}$ & $\begin{array}{l}0 \\
0\end{array}$ & $\begin{array}{l}0 \\
0\end{array}$ & $\begin{array}{l}0 \\
0\end{array}$ & $\begin{array}{l}0 \\
0\end{array}$ & $\begin{array}{l}0 \\
0\end{array}$ & \\
\hline & 143 & 0 & 2 & 0 & & 3 & 2 & 3 & 0 & 0 & 0 & 0 & 0 & 0 & 2 & 0 & \\
\hline & $\begin{array}{l}152 \\
155\end{array}$ & $\begin{array}{l}5 \\
0\end{array}$ & $\begin{array}{l}4 \\
0\end{array}$ & $\begin{array}{l}4 \\
0\end{array}$ & $\begin{array}{l}3 \\
0\end{array}$ & 3 & 6 & 5 & 3 & 5 & 5 & 5 & $\begin{array}{l}0 \\
0\end{array}$ & 0 & 0 & $\begin{array}{l}0 \\
7\end{array}$ & \\
\hline & $\begin{array}{l}155 \\
161\end{array}$ & 10 & 6 & 3 & $\begin{array}{l}0 \\
0\end{array}$ & $\begin{array}{l}0 \\
0\end{array}$ & $\begin{array}{l}0 \\
0\end{array}$ & $\begin{array}{l}0 \\
0\end{array}$ & $\begin{array}{l}0 \\
0\end{array}$ & 0 & $\begin{array}{l}0 \\
0\end{array}$ & 0 & $\begin{array}{l}0 \\
0\end{array}$ & $\begin{array}{l}0 \\
0\end{array}$ & $\begin{array}{l}2 \\
0\end{array}$ & 0 & \\
\hline & 166 & 0 & 0 & 0 & 0 & 0 & 0 & 0 & 0 & 0 & 0 & 2 & 0 & 0 & & 4 & \\
\hline & 169 & 0 & 4 & 4 & 7 & 6 & 7 & 7 & 21 & 10 & 9 & 23 & 11 & 16 & 17 & 5 & \\
\hline & 180 & 0 & 0 & 0 & 0 & 3 & 0 & 0 & 0 & 0 & 0 & 0 & 0 & 0 & 0 & 0 & \\
\hline & 181 & 3 & 5 & 6 & 7 & 9 & 12 & 7 & 3 & 10 & 9 & 7 & 3 & 0 & 2 & 3 & \\
\hline & 186 & 10 & 8 & 8 & 10 & 5 & 0 & 0 & 0 & 4 & 2 & 0 & 0 & 0 & 0 & 0 & \\
\hline & 192 & 8 & $\begin{array}{l}0 \\
0 \\
0\end{array}$ & 0 & & $\begin{array}{l}0 \\
0\end{array}$ & $\begin{array}{l}0 \\
0\end{array}$ & $\begin{array}{l}3 \\
0\end{array}$ & $\begin{array}{l}0 \\
0\end{array}$ & $\begin{array}{l}0 \\
0\end{array}$ & $\begin{array}{l}0 \\
0\end{array}$ & $\begin{array}{l}0 \\
0\end{array}$ & $\begin{array}{l}0 \\
0\end{array}$ & 0 & 0 & 0 & \\
\hline & $\begin{array}{l}194 \\
206\end{array}$ & 2 & 2 & 0 & $\begin{array}{l}0 \\
0\end{array}$ & $\begin{array}{l}0 \\
0\end{array}$ & $\begin{array}{l}0 \\
0\end{array}$ & 2 & 3 & 0 & 0 & 0 & 2 & $\begin{array}{l}0 \\
0\end{array}$ & 0 & 0 & \\
\hline & & & & & & & & & & & & & & & & & \\
\hline & 213 & 0 & 3 & 2 & 0 & 0 & 0 & 0 & 0 & 2 & 2 & 0 & 2 & 0 & 2 & 9 & \\
\hline & 217 & 2 & 3 & 3 & 0 & 0 & 0 & 0 & 6 & 3 & 2 & 3 & 0 & 2 & 0 & 0 & \\
\hline & 222 & 0 & 4 & 5 & 4 & 5 & 9 & 2 & 4 & 6 & 0 & 0 & 7 & 4 & 0 & 0 & \\
\hline & 225 & 0 & 0 & 0 & 0 & 0 & 0 & 0 & 0 & 0 & 0 & 6 & 6 & 0 & 2 & 0 & \\
\hline & 228 & 4 & & & & 0 & 0 & 0 & 2 & 0 & & & 2 & 5 & 6 & 0 & \\
\hline & 233 & $\begin{array}{l}0 \\
0\end{array}$ & $\begin{array}{l}0 \\
0 \\
0\end{array}$ & 0 & $\begin{array}{l}0 \\
0\end{array}$ & $\begin{array}{l}0 \\
0\end{array}$ & $\begin{array}{l}0 \\
0\end{array}$ & $\begin{array}{l}0 \\
0\end{array}$ & 0 & $\begin{array}{l}0 \\
0\end{array}$ & 0 & 0 & $\begin{array}{l}0 \\
0\end{array}$ & $\begin{array}{l}0 \\
0\end{array}$ & 0 & $\begin{array}{l}2 \\
5\end{array}$ & \\
\hline & $\begin{array}{l}250 \\
239\end{array}$ & 0 & 0 & 0 & 0 & 0 & 3 & 0 & 3 & 0 & 0 & 0 & 3 & 0 & 0 & 0 & \\
\hline & 241 & & & & & & & & & & & & & & & & \\
\hline
\end{tabular}




\section{A1 (continue)}

\begin{tabular}{|c|c|c|c|c|c|c|c|c|c|c|c|c|c|c|c|c|c|}
\hline \multirow[t]{5}{*}{ Domain } & \multirow[t]{5}{*}{ TRF [bp] } & \multicolumn{15}{|c|}{ Sampling points \& experimental phases } & \multirow{5}{*}{ Phyogenetic assignment of the detected TRFs } \\
\hline & & \multirow{4}{*}{$\begin{array}{l}\text { starter community } \\
\qquad G_{B}=0.41 \\
G_{A}=0.69\end{array}$} & \multicolumn{2}{|c|}{ EP1 } & \multicolumn{6}{|c|}{ EP2 } & \multicolumn{4}{|c|}{ EP3 } & \multicolumn{2}{|c|}{ EP4 } & \\
\hline & & & $\overline{E R-98}$ & ER-137 & ER-155 & ER-185 & ER-207 & ER-230 & $\begin{array}{ll}0 & \text { ER-274 } \\
\end{array}$ & ER-305 & $\begin{array}{l}E R-319 \\
\end{array}$ & ER-337 & ER-372 & ER-479 & $\overline{E R-490}$ & $\overline{E R-514}$ & \\
\hline & & & $G_{B}=$ & $G_{B}=$ & $G_{B}=$ & $G_{B}=$ & $G_{B}=0.45$ & $G_{B}=$ & $G_{B}=0.37$ & $G_{B}=0.45$ & $G_{B}=0.44$ & $G_{B}=$ & $G_{B}=0.33$ & $G_{B}=$ & $G_{B}=$ & $G_{B}=$ & \\
\hline & & & $G_{A}=0.64 C$ & $\begin{array}{c}0.40 \\
G_{A}=0.57\end{array}$ & $G_{A}=0.65$ & $G_{A}=0.64$ & $4 G_{A}=0.63$ & $\begin{array}{ll}0.43 \\
B\end{array}$ & $44 G_{A}=0.64$ & $G_{A}=0.68$ & $G_{A}=0.62$ & $G_{A}=0.64$ & $0 G_{A}=0.49$ & $9 G_{A}=0.61$ & $G_{A}=0.56$ & 0.38 & \\
\hline \multirow[t]{23}{*}{ Bacteria } & 290 & 0 & 0 & 0 & 0 & 0 & 0 & 0 & 0 & 0 & 0 & 0 & 0 & 0 & 3 & 0 & \multirow{23}{*}{ 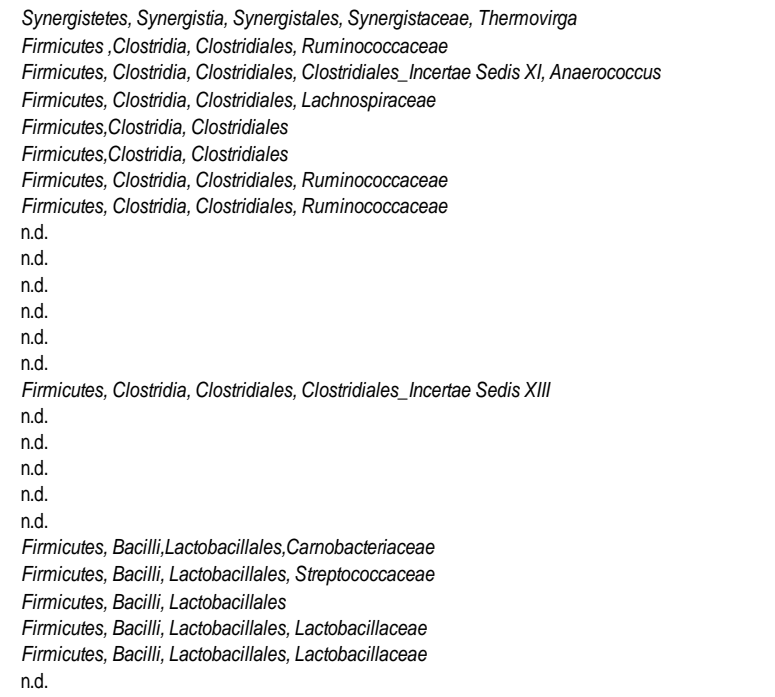 } \\
\hline & 296 & 0 & 0 & 0 & 0 & 0 & 0 & 0 & 2 & 0 & 0 & 4 & 4 & 3 & 4 & 0 & \\
\hline & 297 & 0 & 0 & 0 & 0 & 0 & 0 & 0 & 0 & 0 & 0 & 0 & 0 & 5 & 8 & 0 & \\
\hline & 298 & 0 & 0 & 0 & 3 & 3 & 3 & 3 & 6 & 5 & 5 & 8 & 6 & 4 & 8 & 13 & \\
\hline & 300 & 0 & 0 & 0 & 0 & 0 & 0 & 0 & 0 & 0 & 0 & 0 & 0 & 7 & 0 & 0 & \\
\hline & 317 & 0 & 0 & 0 & 0 & 0 & 0 & 0 & 0 & 0 & 0 & 0 & 4 & 4 & 9 & 9 & \\
\hline & 368 & 0 & 0 & 0 & 0 & 0 & 0 & 0 & 0 & 0 & 0 & 0 & 0 & 0 & 0 & 2 & \\
\hline & 373 & 0 & 2 & 3 & 0 & 0 & 0 & 0 & 0 & 0 & 0 & 0 & 0 & 0 & 0 & 0 & \\
\hline & 378 & 0 & 0 & 0 & 0 & 0 & 0 & 0 & 0 & 0 & 0 & 0 & 2 & 0 & 0 & 3 & \\
\hline & 393 & 0 & 0 & 0 & 0 & 0 & 2 & 0 & 0 & 0 & 0 & 0 & 0 & 0 & 0 & 0 & \\
\hline & 453 & 0 & 0 & 0 & 2 & 0 & 2 & 0 & 2 & 0 & 0 & 0 & 0 & 0 & 0 & 0 & \\
\hline & $\begin{array}{l}400 \\
481\end{array}$ & 0 & 0 & 0 & 0 & 0 & 0 & 0 & 2 & 0 & 0 & 0 & 0 & 0 & 0 & 0 & \\
\hline & 487 & 0 & 0 & 0 & 0 & 0 & 0 & 0 & 2 & 0 & 0 & 0 & 3 & 0 & 0 & 0 & \\
\hline & 489 & 0 & 0 & 0 & 0 & 0 & 0 & 0 & 0 & 0 & 0 & 0 & 0 & 0 & 2 & 9 & \\
\hline & 491 & 0 & 0 & 0 & 0 & 0 & 0 & 0 & 0 & 0 & 0 & 0 & 0 & 2 & 2 & 0 & \\
\hline & 537 & 0 & 0 & 0 & 0 & 0 & 0 & 0 & 0 & 0 & 0 & 0 & 3 & 0 & 0 & 0 & \\
\hline & 543 & 0 & 0 & 0 & 0 & 2 & 0 & 0 & 0 & 0 & 0 & 0 & 0 & 3 & 4 & 9 & \\
\hline & 544 & 0 & 2 & 2 & 3 & 5 & 7 & 0 & 0 & 0 & 2 & 0 & 4 & 3 & 0 & 0 & \\
\hline & 553 & 0 & 0 & 0 & 0 & 0 & 0 & 0 & 2 & 0 & 2 & 0 & 2 & 3 & 0 & 0 & \\
\hline & 558 & 0 & 0 & 0 & 0 & 0 & 0 & 0 & 0 & 0 & 0 & 0 & 4 & 2 & 4 & 4 & \\
\hline & 564 & 0 & 0 & 0 & 2 & 6 & 5 & 0 & 3 & 8 & 6 & 0 & 3 & 0 & 0 & 0 & \\
\hline & 566 & 0 & 0 & 0 & 0 & 0 & 0 & 0 & 0 & 0 & 0 & 0 & 0 & 2 & 0 & 3 & \\
\hline & 571 & 0 & 0 & 0 & 0 & 0 & 0 & 0 & 0 & 0 & 0 & 0 & 0 & 0 & 0 & 3 & \\
\hline \multirow[t]{10}{*}{ Archaea } & $\begin{array}{l}74 \\
83\end{array}$ & 5 & 4 & 3 & 3 & 3 & 0 & 0 & 0 & 0 & 0 & 0 & 0 & 0 & 0 & 0 & \multirow{10}{*}{ 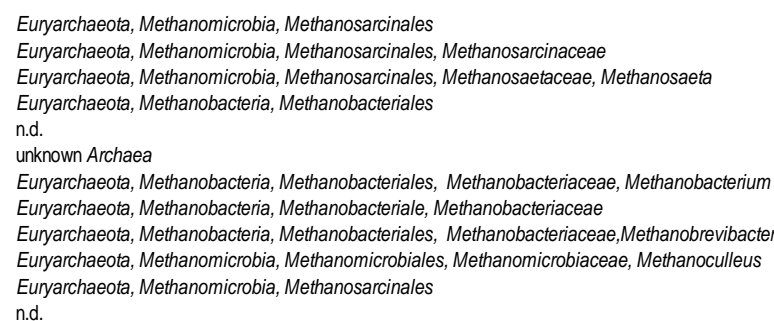 } \\
\hline & 107 & 63 & 49 & 25 & 49 & 63 & 26 & 31 & 6 & 6 & 5 & 3 & 0 & 0 & 0 & 0 & \\
\hline & 174 & 0 & 0 & 0 & 0 & 0 & 0 & 0 & 0 & 0 & 0 & 0 & 0 & 5 & 3 & 3 & \\
\hline & 318 & 0 & 0 & 2 & 0 & 0 & 3 & 0 & 0 & 0 & 2 & 0 & 2 & 3 & 25 & 9 & \\
\hline & 319 & 0 & 0 & 0 & 0 & 0 & 0 & 0 & 0 & 0 & 0 & 0 & 0 & 8 & 0 & 0 & \\
\hline & 340 & 19 & 34 & 56 & 37 & 30 & 63 & 63 & 81 & 81 & 74 & 83 & 90 & 84 & 70 & 88 & \\
\hline & 346 & 0 & 0 & 0 & 0 & 0 & 0 & 0 & 3 & 0 & 0 & 0 & 0 & 0 & 0 & 0 & \\
\hline & 429 & 7 & 5 & 6 & 3 & 0 & 0 & 3 & 7 & 6 & 10 & 10 & 6 & 0 & 0 & 0 & \\
\hline & 470 & 0 & 2 & 3 & 0 & 0 & 0 & 0 & 0 & 0 & 3 & 1 & 0 & 0 & 0 & 0 & \\
\hline & 627 & 0 & 0 & 0 & 0 & 0 & 0 & 0 & 0 & 0 & 0 & 0 & 0 & 0 & 0 & 0 & \\
\hline
\end{tabular}


A 2: Indicator species analysis (ISA) for the given process conditions in the two thermophilic experimental phases (EP 1 and EP 2). Given are the values for the nitrogen as well the acid related parameter (left side) in combination with the detected indicator TRFs and their phylogenetic assignment (right side). ISA produces indicator values (IV ranging from 0 to 100, absent to exclusively present) for each TRF in defined groups of a given environment. Only IV with $\mathrm{p}>0.05$ is shown

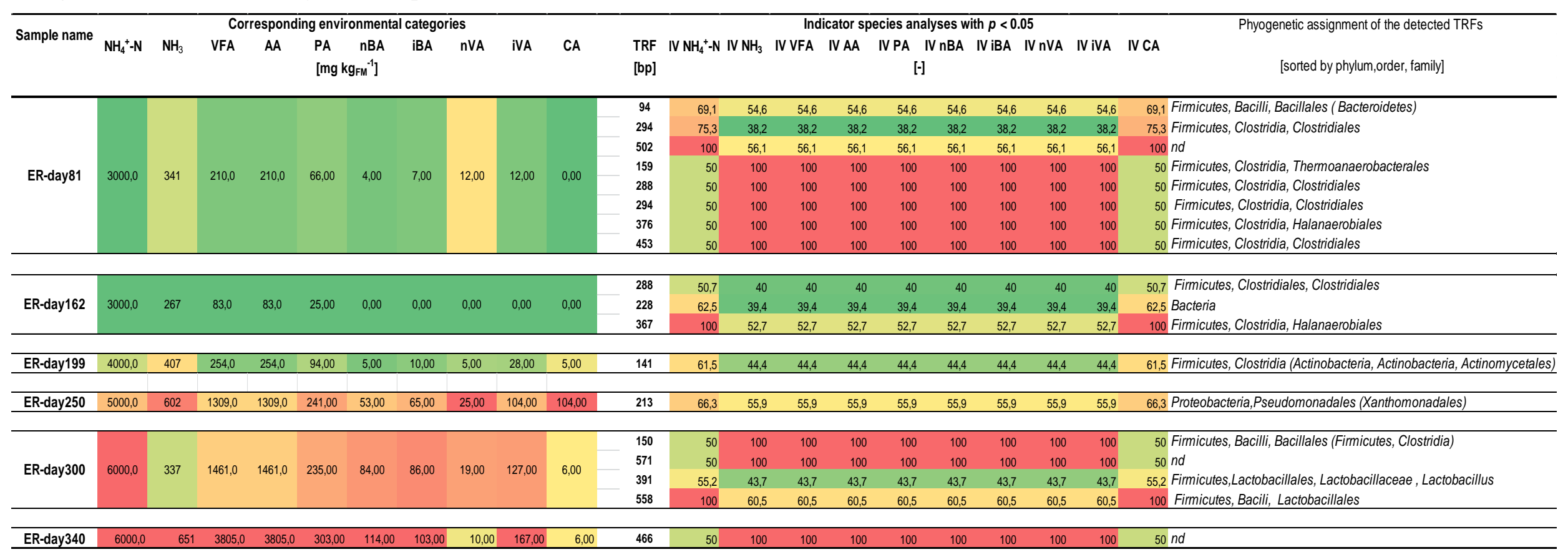

